\title{
Use of zeolites for greener and more para-selective electrophilic aromatic substitution reactions
}

\author{
Keith Smith* and Gamal A. El-Hiti*i \\ School of Chemistry, Cardiff University, Main Building, Park Place, Cardiff, UK \\ CF10 3AT.E-mail: smithk13@cardiff.ac.uk, el-hitiga@cardiff.ac.uk; Fax: +44 \\ (0)2920870600; Tel: +44 (0)2920870600
}

Electrophilic aromatic substitution is one of the most important reactions in synthetic organic chemistry. Such reactions are used for the synthesis of important intermediates that can be used as precursors for the production of pharmaceutical, agrochemical and industrial products. However, many commercial processes to produce such materials still rely on technology that was developed many years ago. Such processes commonly lead to mixtures of regioisomers and in recent years several new approaches have been developed to gain control over the regiochemistry of the reactions. Zeolites can act as heterogeneous catalysts, support reagents, entrain by-products, enhance product para-selectivities via shape-selectivity and avoid aqueous work-ups. For example, zeolites can have advantages in para-regioselective nitration, halogenation, alkylation, acylation and methanesulfonylation reactions under modest conditions. Moreover, usually they can be easily removed from reaction mixtures by simple filtration and regenerated by heating and can then be reused several times to give almost the same yield and selectivity as fresh samples. This review surveys the use of zeolites as para-selective catalysts for a whole range of aromatic substitution reactions, based largely on our own work in the area, but set in the wider context of other related work.

\section{Introduction: assessment of "green-ness" of chemical processes}

It is widely recognised that there is a growing need for more environmentally friendly processes in the chemical industry. Obviously, the production of chemicals needs to be profitable, but recently the costs associated with the treatment of chemical waste have been increasing. Therefore, even from an economic perspective it is very important that chemical processes are designed to minimize the waste produced. In the case of pharmaceuticals it is especially important that such processes be 
considered from the start as early registration of synthetic routes militates against later adoption of superior 'green' synthetic approaches.

The trend towards what has become known as 'green chemistry' or 'sustainable technology' is therefore growing. Green chemistry is a shift from traditional concepts of process efficiency, which generally concentrate on molar yields of chemical products, to ones that take into account elimination of waste at source and avoidance of use of toxic materials. ${ }^{1-11}$ The underlying ideas behind 'green' chemistry have been put forward by Anastas and Warner ${ }^{1,2}$ and are encompassed in twelve principles, but green chemistry can be expressed simply as chemistry that utilizes renewable raw materials, eliminates waste and avoids use of toxic and/or hazardous reagents and solvents in the production of chemicals. ${ }^{12}$

While it may be easy to accept the principles of green chemistry, it is more difficult to assess how "green" any particular chemical process might be. One relevant approach involves consideration of an environmental impact factor (E-factor), defined as the mass ratio of waste to desirable product resulting from a particular manufacturing process. ${ }^{13-20}$ The E-Factor for a particular product can be calculated from the number of tons of raw materials purchased and the number of tons of products sold, with water generally not included in the E-factor calculation. The ideal E-factor is zero and in the oil industry E-factors are very low. However, E-factors increase dramatically on going from bulk chemicals to pharmaceuticals. ${ }^{17}$

Atom efficiency is another useful concept for the evaluation of the waste quantities that would be generated by alternative synthetic routes to a specific product. ${ }^{18,19}$ Dividing the relative molecular mass of the desired product by the sum total of the relative molecular masses of all substances produced in the stoichiometric equation(s) for the reaction(s) involved gives rise to the atom efficiency.

In order to evaluate the full environmental impact of alternative routes, however, it is also necessary to take into consideration the nature and quantities of all reagents, solvents and energy used and the nature of the waste produced in the course of the reactions. In order to take account of these factors, another concept is that of an environmental quotient (EQ), for which the E-factor (E) is multiplied by an arbitrarily assigned unfriendliness quotient (Q), which depends on the toxicity and ease of recyclability of the material generated as waste.

Clearly, assessing the "green-ness" of any chemical process is not a very precise science, but use of concepts such as those described above can help provide 
some guidance. In general, modern methods for production of chemicals should ideally be atom efficient, be safe, have only one step with no solvent, generate minimal waste, have minimal energy requirements, be based on renewable resources, and be environmentally benign. Such 'green' synthetic routes might involve use of recyclable catalysts, recyclable and more benign solvents, and/or alternative energy sources. Advances have been made in all of these areas. However, commercial synthetic routes are introduced at an early stage of the product development cycle, so that many will not yet have benefited from the new ideas. In this review we hope to demonstrate how ideas of green chemistry have influenced some of our own work.

\section{Electrophilic aromatic substitution and the role of catalysts}

The synthesis of valuable industrial, pharmaceutical, agrochemical and fine chemicals frequently involves electrophilic aromatic substitution reactions. Indeed, substituted aromatic compounds represent useful intermediates in many synthetic processes. For example, aromatic nitro compounds are versatile chemical feedstocks for a wide range of industrial products, including pharmaceuticals, agrochemicals, dyestuffs and explosives. Halogenated aromatic compounds have numerous applications as fine chemicals and for synthesis of pesticides and pharmaceuticals and are also useful precursors of organometallic compounds. Regioselective dialkylation of naphthalene is of great interest as 2,6-dialkylnaphthalenes can be oxidised to naphthalene-2,6dicarboxylic acid, used to prepare the commercially valuable poly(ethylene naphthalenedicarboxylate), which is increasingly finding use in films, liquid crystal polymers, packaging, coatings and adhesives. Similarly, acetylation of aromatic compounds is an important tool for the synthesis of aromatic ketones, some of which are useful intermediates for other valuable industrial and pharmaceutical compounds, while some sulfones have applications in agrochemicals, polymers and other industrial fields. Despite the importance of such compounds, their commercial syntheses commonly suffer serious disadvantages, including some or all of the following: large quantities of mineral or Lewis acids as activators, which on work-up are hydrolysed with generation of large quantities of corrosive and toxic waste byproducts; the use of stoichiometric quantities of reagents that produce metal salts as waste; poor yields; or production of mixtures of regioisomers with low selectivity. ${ }^{20-28}$ Major efforts are therefore being made to develop cleaner and environmentally friendlier processes. ${ }^{29-43}$ 
The presence of a solid acid catalyst, particularly a zeolite, in a liquid phase reaction can enhance reaction rate, support reagents, entrain by-products and enhance product selectivities. ${ }^{29-43}$ Regioselectivity of substitution is often fundamental to achieving a greener aromatic substitution process. Clearly, E-factors are higher when production of the desired regioisomer is lower, but often there are few features to help control regioselectivity. Having the catalytic sites located within the rigid pores of a zeolite's inorganic matrix imposes additional constraints on reacting partners, favouring production of one regioisomer, usually the most linear one (e.g. the paraisomer), over other possible ones (e.g. ortho-). For this reason, much of our work in this area has involved the use of zeolites.

\section{Solid acid catalysts and zeolite structures}

A range of common solid catalysts including zeolites, ${ }^{42-44}$ acidic clays, ${ }^{45}$ organic ionexchange resins, ${ }^{46,47}$ supported heteropoly acids $^{48}$ and others ${ }^{49}$ are used in electrophilic aromatic substitution reactions. The term zeolite was first used by the Swedish mineralogist A. F. Cronstedt in $1756 .{ }^{50}$ Zeolites are crystalline, highly ordered, microporous aluminosilicates with intracrystalline channels and cages of molecular dimensions. The elementary building units of zeolites are $\left[\mathrm{SiO}_{4}\right]^{4-}$ and $\left[\mathrm{AlO}_{4}\right]^{5-}$ tetrahedra that are linked together through oxygen bridges. The tetrahedra share corners to form ordered three-dimensional macrostructures. The negatively charged framework structures may contain linked cages, cavities or channels, resulting in zeolites having high surface areas $\left(500-700 \mathrm{~m}^{2} / \mathrm{g}\right)$, most of which is internal. The cavities may be of the right size to allow small molecules to enter, which allows chemical reactions to take place within them, and this can provide selectivity.

The diameter of the pore entrance plays an important role in the ability of a zeolite to contribute to a chemical reaction. Zeolites are classified according to their pore sizes as small, medium and large pore zeolites. For example, zeolite A (Linde Type A; Fig. 1), a small pore zeolite, has an approximate empirical formula such as $\mathrm{Na}_{12}\left[\mathrm{Al}_{12} \mathrm{Si}_{12} \mathrm{O}_{48}\right] .27 \mathrm{H}_{2} \mathrm{O}$, with a ring aperture having 8 tetrahedral atoms ( $\mathrm{Si}$ or $\mathrm{Al}$ ) in the ring, leading to a pore diameter of around 4.1 $\AA$. Zeolite $\mathrm{A}$ is used for water softening by ion-exchange and for drying solvents, since only small molecules such as $\mathrm{H}_{2} \mathrm{O}$ can enter its pores. Three charge-balancing cations $\left(\mathrm{K}^{+}, \mathrm{Na}^{+}\right.$and $\left.\mathrm{Ca}^{2+}\right)$ are commonly associated with this type of zeolite. Zeolite $\mathrm{K}^{+} \mathrm{A}$ is referred to as $3 \mathrm{~A}$ 
molecular sieve, having a pore diameter of around $3 \AA$. Zeolites $\mathrm{Na}^{+} \mathrm{A}$ and $\mathrm{Ca}^{2+} \mathrm{A}$ are known as $4 \mathrm{~A}$ and $5 \mathrm{~A}$ molecular sieves, respectively, because of their pore diameters.

Zeolite ZSM-5 (Zeolite Socony Mobil-number 5; Fig 1) ${ }^{51}$ is an example of a medium pore zeolite and is also known as a MFI type zeolite. It has an empirical formula such as $\mathrm{Na}_{n}\left[\mathrm{Si}_{26-\mathrm{n}} \mathrm{Al}_{\mathrm{n}} \mathrm{O}_{192}\right] .16 \mathrm{H}_{2} \mathrm{O}$, where $\mathrm{n} \leq 8,{ }^{38}$ and has 10 tetrahedral atoms in its apertures, leading to oval pores. Its three dimensional structure clearly indicates that the zeolite crystal contains two types of channels, straight channels (5.3 x $5.6 \AA$ ) and sinusoidal channels (5.1 x $5.5 \AA$ ). The sinusoidal channels are located in planes normal to the axes of the straight channels.

Zeolites $\mathrm{X}$ and $\mathrm{Y}$ are known as synthetic faujasites (FAU; Fig. 1) ${ }^{51}$ and are large pore zeolites with 12 tetrahedral atoms in their apertures and the same threedimensional pore structures. The entry ports are about $7 \AA$ in diameter but channels run in three perpendicular dimensions and intersect to form large, spherical internal cavities called $\alpha$-cages (or supercages) about $13 \AA$ in diameter. The main difference between zeolites $\mathrm{X}$ and $\mathrm{Y}$ is the silicon to aluminium ( $\mathrm{Si} / \mathrm{Al}$ ) ratio. Zeolite $\mathrm{X}$ has a low silicon content with a $\mathrm{Si} / \mathrm{Al}$ ratio in the range of 1.0-1.5, whereas the $\mathrm{Si} / \mathrm{Al}$ ratio in zeolite $\mathrm{Y}$ is always above 1.5. The naturally occurring zeolite, faujasite, has a Si/Al ratio of $c a$. 2.2. Zeolite $\mathrm{X}$ contains a higher density of acidic sites than that zeolite $\mathrm{Y}$ as a result of its high aluminium content, but the acid strength of an individual site is lower in zeolite X. Both zeolites can be exchanged with various cations.

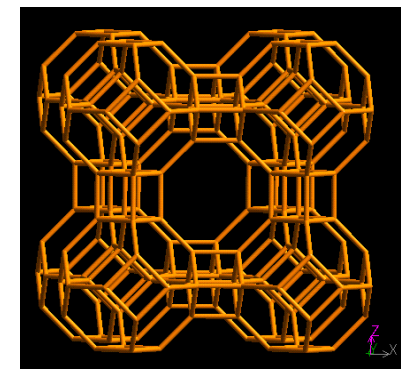

Zeolite A

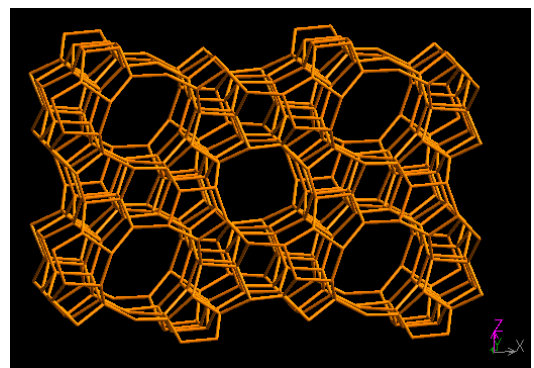

Zeolite ZSM-5

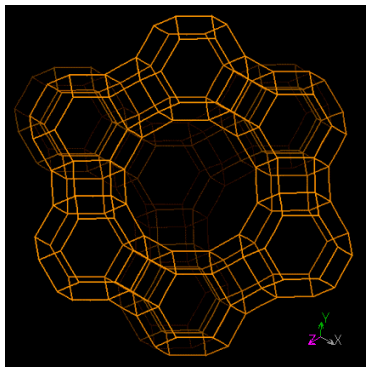

Zeolites $\mathrm{X}$ and $\mathrm{Y}$

Fig. 1 Structures of zeolites A, ZSM-5, X and $\mathrm{Y}^{51}$

The mordenite structure has channels with 8 and 12 tetrahedral atoms in their apertures (Fig. 2). ${ }^{51}$ It also has a relatively high content of silica. In contrast to zeolites $\mathrm{X}$ and $\mathrm{Y}$, mordenite contains a one-dimensional system of channels; the smaller channels cannot accommodate most organic molecules, but the larger ones can. 
Zeolite $\beta$ (Fig. 2$)^{51}$ has a large pore size and complex structure. It has a three dimensional pore network with intersecting channels having 12 tetrahedral atom apertures, giving rise to large internal cavities similar to those in zeolites $\mathrm{X}$ and $\mathrm{Y}$. There are two types of linear channels with pore diameters of $7.0 \times 6.4 \AA$ and $5.5 \times$ $5.5 \AA$, present in a 2:1 ratio. The third channel is tortuous. Zeolite $\beta$ has a relatively high $\mathrm{Si} / \mathrm{Al}$ ratio of about 13 , although it can be varied. It is made up of three polymorphic structures, polymorphs A, B and C (Fig. 3), ${ }^{52}$ that differ in the way that the cages are stacked with respect to each other. Polymorph $\mathrm{C}$ contains only one repeating unit (i.e. AAAA...) and is present in small amounts as it is unstable. Polymorph A has two repeating units (ABAB...) and $\mathrm{B}$ has three (ABCABC...).

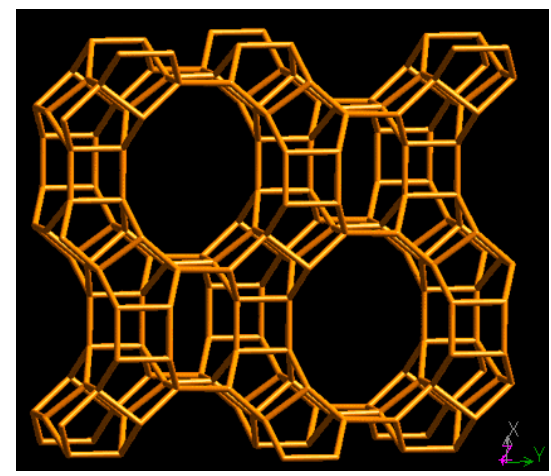

Mordenite

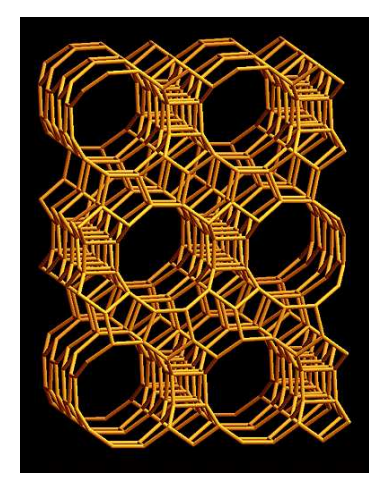

Zeolite $\beta$

Fig. 2 Structure of mordenite and zeolite $\beta^{51}$

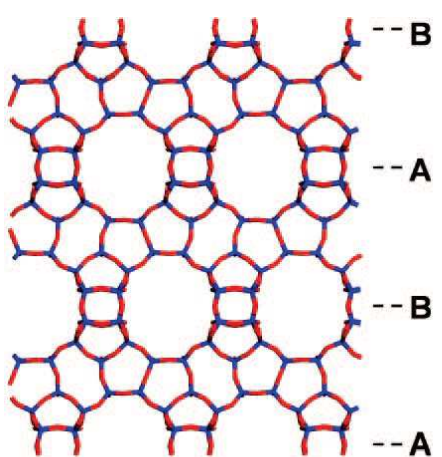

(a)

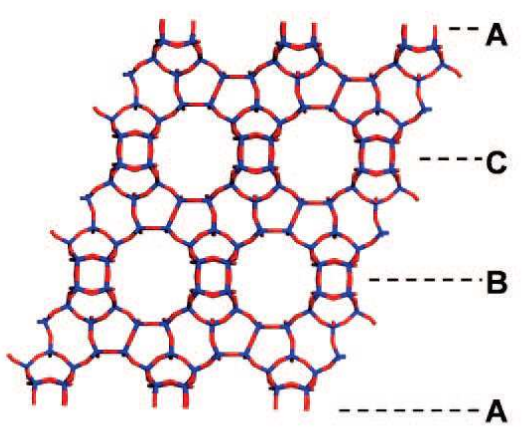

(b)

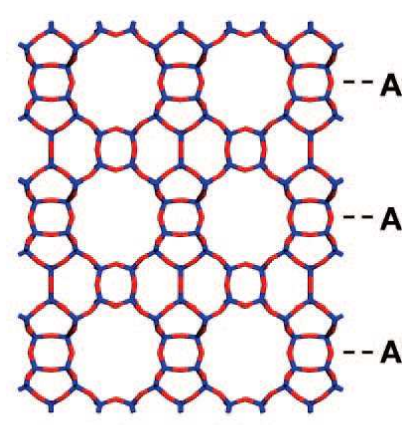

(c)

Polymorph A (ABAB...)

Polymorph B (ABCABC...)

Fig. 3 Framework structures of polymorphs $A, B$ and $C$ of zeolite $\beta^{52}$

Table 1 summarizes the pore dimensions for the zeolites discussed above. There are many other types, but these are the ones in most common commercial use. 
Table 1 Aperture sizes (number of tetrahedral atoms, $\mathrm{T}$ ) and approximate pore dimensions for some common zeolites

\begin{tabular}{lllll}
\hline Zeolite & Zeolite type & Aperture (no. T) & Pore diameter $(\AA)$ & Dimensionality \\
\hline A & Small pore & 8 & 4.1 & 3 \\
ZSM-5 & Medium pore & 10 & $5.3 \times 5.6 \& 5.1 \times 5.5$ & 3 \\
X and Y & Large pore & 12 & 7.4 & 3 \\
Mordenite & Large pore & 12 & $6.5 \times 7.0$ & 1 \\
Beta & Large pore & 12 & $5.7 \times 7.5$ & 3 \\
\hline
\end{tabular}

Zeolites are widely used in chemical reactions as solid acidic catalysts. Active Brønsted sites in zeolites can be increased by converting the sodium form to its protonated form. Typically, treatment of $\mathrm{Na}^{+}$-zeolite with an aqueous ammonium salt is used to give the corresponding $\mathrm{NH}_{4}{ }^{+}$-zeolite, which loses $\mathrm{NH}_{3}$ on heating to produce the corresponding $\mathrm{H}^{+}$-zeolite. ${ }^{53}$ Heating a zeolite at high temperature (more than $400{ }^{\circ} \mathrm{C}$ ) in air for several hours (known as calcination) can remove water from the zeolite. Brønsted acid sites in zeolites are also converted into Lewis acid centres as a result of dehydration that takes place at high temperature.

The selectivity observed in reactions catalysed by zeolites depends largely on the size and shape of the pore networks. This property can be useful for separating specific isomers from a reaction mixture or can help in directing reactions towards a desired product. The shape selectivity observed for zeolite catalysis has been classified into three different types. 1) Reactant shape selectivity - when only reagents with the appropriate dimensions can enter the zeolite pores and react. 2) Product selectivity - when only products with the appropriate dimensions will diffuse out of the pores. 3) Transition state shape selectivity - when the dimensions and shapes of the transition states within the pores of the zeolite affect the ease of formation of specific products within the pores.

We and others have been investigating the use of recoverable and regenerable zeolites for development of cleaner and more para-regioselective aromatic substitution reactions. Some of our progress in the area is reported in this review, but is set in the wider context of other related work.

\section{Regioselective nitration of simple aromatic compounds}

Nitration of aromatic compounds is one of the most important and widely studied chemical reactions. ${ }^{28,54}$ Traditionally, nitration has been performed with a mixture of 
nitric and sulfuric acids. However, this method is often highly unselective for nitration of substituted aromatic compounds and disposal of the spent acid reagents represents a serious environmental issue. ${ }^{55-58}$ In order to address these problems several alternative nitration methods have been developed. The use of solid catalysts is potentially attractive because of the ease of recovery and reuse of the catalyst, with the added possibility that the solid might enhance the selectivity, particularly if it is a zeolite. Therefore, regioselective nitration of simple aromatics over zeolite catalysts has been the subject of much study, and it has become clear that the selectivity of the reaction depends on the nature of both the catalyst and the nitrating agent.

It is useful to consider the role a zeolite might play in the reaction. In a traditional 'mixed acid' nitration, the nitric acid is the source of the nitro group that becomes incorporated into the aromatic product, but without the sulfuric acid the reaction is slow and low-yielding. The sulfuric acid provides a level of acidity that encourages formation of the active nitrating species, nitronium ion (Scheme 1, step 1), and a means of deactivating the water produced alongside the nitronium ion, again perhaps involving protonation (Scheme 1; e.g. step 2 or 3). If a zeolite were to replace sulfuric acid directly in the reaction, it would need to fulfil both of these roles.

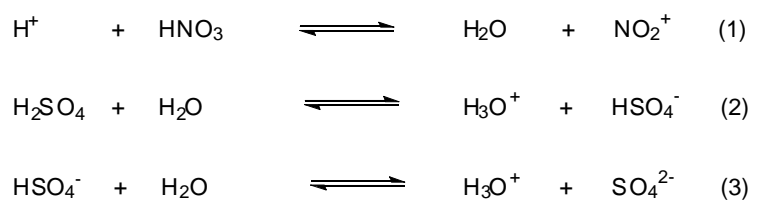

Scheme 1 Formation of nitronium ion from mixed acids

Zeolites can indeed offer sites as acidic as those present in concentrated sulfuric acid, though only in zeolites with relatively high Si:Al ratios. Proton forms of such zeolites can arbitrarily be represented by a formula for an aluminosilicate with a 20:1 Si:Al ratio, $\mathrm{H}\left(\mathrm{SiO}_{2}\right)_{20}\left(\mathrm{AlO}_{2}\right)$, which has a relative mass of over 1000 Daltons. If it were assumed that a convenient reaction profile for a 'mixed acid' reaction would be achieved using two moles of sulfuric acid (one to effect step 1 and one to effect step 2; Scheme 1), then the quantity of sulfuric acid needed for a reaction of one mole of aromatic substrate (92 $\mathrm{g}$ in the case of toluene as substrate) would approach $200 \mathrm{~g}$. For the arbitrary zeolite to be able to replace sulfuric acid directly, over $2000 \mathrm{~g}$ would be required. Not only would such a quantity be inconvenient and highly expensive for 
nitration of, say, toluene (92 g) with nitric acid (63 g), but the substrate and reagent would be completely absorbed into the pores to leave a dry material. It would be very difficult to ensure that all of the substrate molecules would find all of the reagent molecules, since diffusion through the pores might be limited under such circumstances. Therefore, for zeolites to be useful in nitration reactions, they cannot take on the role of water-remover and their role as proton donor must be catalytic.

At the outset of our own research in this area the aim was to find an alternative to nitric acid as the source of the nitro group. If a zeolite were to have any beneficial effect, it would need to catalyse the reaction, so it should be capable of protonation to give nitronium ion, and the by-product should be less prone to quenching the nitration reaction than the water produced in the case of nitric acid.

\subsection{Attempts at para-selective nitration of phenol}

The traditional method of phenol nitration involves the use of a mixture of nitric and sulfuric acids to produce nitrophenols in which the paralortho ratio increases from around $c a$. 0.48 to around 1.1 as the concentration of sulfuric acid increases. ${ }^{59}$ However, the disadvantages associated with this process have stimulated efforts to develop cleaner and more environmentally benign processes.

Several solid catalytic systems have been developed for the nitration of phenol to nitrophenols. The most popular reagents have been nitric acid and acetyl nitrate and solids used include silica gel, ${ }^{60}$ metal salt modified clays, ${ }^{61,62}$ mixed metal oxides, ${ }^{63}$ a variety of strongly acidic solids (e.g. heteropolyacids, ${ }^{64,65}$ sulfated MCM-41, ${ }^{66}$ silica impregnated with sulfuric acid ${ }^{67}$ or a hydrogen sulfate salt, ${ }^{68}$ sulfated titania ${ }^{69,70}$ and sulfated mixed metal oxides. ${ }^{71}$ With the highly acidic solids ortho-nitrophenol generally predominates to a much greater extent than with a mixture of sulfuric and nitric acids, regardless of the structure of the solid. By contrast, different degrees of para-selectivity have been reported with some of the less acidic solids. However, such observations are difficult to interpret since nitric acid is capable of nitrating phenol (albeit in a rather messy fashion) without catalysis by added agents and because the mechanism of nitration is complicated, ${ }^{54,72}$ potentially involving some or all of the following: direct nitration of the ring; addition to Wheland intermediates; elimination of nitrous acid from such adducts; nitrosation by nitrous acid produced; intermediacy of phenyl nitrate; cyclohexadienone intermediates; rearrangements; and oxidation. 
Nitration of phenol (1; Scheme 2) has been reported over various types of zeolites, including non-acidic or weakly acidic ion-exchanged zeolites. ${ }^{73-75}$ For example, nitration of phenol (1; Scheme 2) using dilute nitric acid in a solvent at room temperature over proton forms of various types of zeolites produces mixtures of nitrophenols $\mathbf{2}$ and $\mathbf{3}$ in which the ortho-isomer is predominant (Table 2). ${ }^{73}$

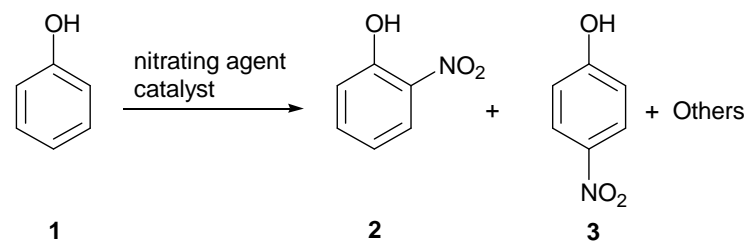

Scheme 2 Nitration of phenol (1) using a nitrating reagent over a zeolite

Table 2 Nitration of phenol (1) according to Scheme 2 using dil. $\mathrm{HNO}_{3}$ over zeolites in a solvent ${ }^{a}$

\begin{tabular}{lllll}
\hline \multirow{2}{*}{ Catalyst } & Solvent & \multicolumn{2}{l}{ Yield $(\%)^{b}$} & Benzoquinone \\
\cline { 3 - 5 } & & $\mathbf{2}$ & $\mathbf{3}$ & 5 \\
\hline $\mathrm{HZSM}-5$ & $\mathrm{CCl}_{4}$ & 33 & 22 & 6 \\
$\mathrm{HY}$ & $\mathrm{CCl}_{4}$ & 36 & 18 & 3 \\
$\mathrm{H} \beta$ & $\mathrm{CCl}_{4}$ & 84 & 10 & 7 \\
$\mathrm{H} \beta$ & $\mathrm{MeOH}_{\mathrm{H} \beta}$ & 5 & - & 3 \\
$\mathrm{H} \beta$ & $\mathrm{Et}_{2} \mathrm{O}$ & 44 & 42 & 6 \\
$\mathrm{H} \beta$ & $2-\mathrm{Butanone}$ & 51 & 19 & 9 \\
$\mathrm{H} \beta$ & $\mathrm{H}_{2} \mathrm{O}$ & 37 & 17 & 6
\end{tabular}

${ }^{a}$ An equimolar mixture of $\mathbf{1}$ and $\mathrm{HNO}_{3}(30 \%)$ in the presence of a catalyst (50\%; $\mathrm{w} / \mathrm{w}$ ) and a solvent was stirred at room temperature for $2 \mathrm{~h} .{ }^{73 b}$ Numbers expressed as percentages have been rounded to the whole number.

It is clear from Table 2 that zeolite $\mathrm{H} \beta$ was the most active catalyst among the zeolites tried. Also, the para/ortho ratios were dependent on the solvent used. The para/ortho ratio was highest (0.97) when diethyl ether was employed as the solvent and lowest (0.11) when $\mathrm{CCl}_{4}$ was the solvent. ${ }^{73} \mathrm{~A}$ significant quantity of benzoquinone (3-9\% yield) was also obtained as a side-product due to oxidation of phenol. This by-product was the major product identified (7\%) when methanol was the solvent and a minor by-product (3\%) when diethyl ether or $\mathrm{CCl}_{4}$ was the solvent. Clearly, 2-nitrophenol (2) was the major product in most cases, despite the fact that 
zeolites are normally associated with increased para-selectivity in electrophilic substitution reactions of aromatic compounds.

Phenol has also been nitrated using fuming nitric acid over various cation-exchanged faujasite zeolites in hexane, at both low loading of phenol ( $0.07 \mathrm{~g}$ of $\mathbf{1}$ to $0.50 \mathrm{~g}$ of zeolite) and at higher loading ( $0.8 \mathrm{~g}$ of $\mathbf{1}$ to $0.5 \mathrm{~g}$ of zeolite). ${ }^{74}$ Most of the reactions gave substantial quantities of 2,4,6-trinitrophenol and other unidentified by-products and a predominance of $\mathbf{2}$ over $\mathbf{3}$, but in one case (use of CsY at a low loading of phenol) the major product formed, in $58 \%$ yield, was $\mathbf{3}$, and the $\mathbf{3 / 2}$ ratio was $c a$. 4.7. The reason for the para-selectivity with CsY could be attributed to the large size of the Cs cation, which reduces the cage size and hinders formation of $\mathbf{2}$, and the very low loading, which encourages most of the reaction to occur within the pores. The result demonstrates the possibility of controlling regioselectivity through shape-selectivity, but it is not a practical approach for para-nitration of phenol.

Our own approach involved investigation of nitration of phenol using iso-propyl nitrate as reagent, chosen because of its lack of reactivity in the absence of a catalyst, which would ensure that the zeolite had to be involved in catalysing the reaction. Our initial attempt, over zeolite $\mathrm{H} \beta(\mathrm{Si} / \mathrm{Al}=12.5)$ in 1,2-dichloroethane (DCE) under reflux for $48 \mathrm{~h}$, gave nitrophenols 2 and $\mathbf{3}$ with a $\mathbf{3 / 2}$ ratio of 1.0 in a combined yield of $60 \%{ }^{75}$ iso-Propoxybenzene ( $i$-PB, $2 \%$ yield) was obtained as the only side product. ${ }^{75}$ The low overall recovery of products arose because material (mainly phenol) was lost from the reaction mixture by evaporation during the long reaction period. By carrying out the reaction in an autoclave under otherwise identical conditions, the nitrophenols $\mathbf{2}$ and $\mathbf{3}$ were obtained in 94\% yield, but still with a 3/2 ratio of 1.0 , along with $4 \%$ of iso-propoxybenzene. For simplicity while investigating other parameters normal reflux conditions were used; material losses could be controlled later under autoclave conditions if a useful process should be discovered.

The effect of the solid catalyst in the reaction was tested with a number of different acidic zeolites. ${ }^{75}$ The results,recorded in Table 3 , showed that all types of zeolites tried catalysed the reaction. The reaction was complete only when the large pore zeolite $\mathrm{H} \beta(\mathrm{Si} / \mathrm{Al}=12.5)$ was used as the catalyst. Other $\mathrm{H} \beta$ catalysts with higher $\mathrm{Si} / \mathrm{Al}$ ratios gave nitrophenols $\mathbf{2}$ and $\mathbf{3}$ in comparable or lower yields and with lower $\mathbf{3 / 2}$ ratios, along with unreacted phenol, suggesting that their more highly acidic sites favour ortho-product formation, but that the availability of fewer acidic sites causes 
slowing of the reaction. Zeolite $\mathrm{HY}$ behaved in a manner comparable to $\mathrm{H} \beta$ ( $\mathrm{Si} / \mathrm{Al}=$ 300), while H-mordenite, a large pore zeolite with a more restrictive channel structure, gave an even higher predominance of $\mathbf{2}$ over 3. HZSM-5, a medium pore zeolite, resulted in $\mathbf{2 / 3}$ ratios similar to those with $\mathrm{H} \beta$, but in more modest yields. ${ }^{75}$

Table 3 Nitration of phenol (1) according to Scheme 2 using iso-propyl nitrate over various zeolites ${ }^{a}$

\begin{tabular}{|c|c|c|c|c|}
\hline \multirow{2}{*}{ Catalyst (Si/Al) } & \multicolumn{4}{|c|}{ Yields (\%) } \\
\hline & 1 & 2 & 3 & $i$-PB \\
\hline No catalyst & 56 & - & - & - \\
\hline $\mathrm{H} \beta(12.5)$ & - & 30 & 30 & 2 \\
\hline $\mathrm{H} \beta(150)$ & 21 & 40 & 22 & 5 \\
\hline $\mathrm{H} \beta(300)$ & 23 & 34 & 16 & 4 \\
\hline HY (5.1) & 21 & 33 & 19 & 3 \\
\hline HY (30) & 23 & 34 & 18 & 5 \\
\hline H-Mordenite (20) & 64 & 20 & 8 & 1 \\
\hline H-Mordenite (90) & 29 & 40 & 13 & 1 \\
\hline HZSM-5 (30) & 31 & 28 & 27 & - \\
\hline HZMS-5 (50) & 47 & 19 & 15 & - \\
\hline
\end{tabular}

${ }^{a}$ A mixture of zeolite $(2 \mathrm{~g})$, phenol $(\mathbf{1} ; 0.90 \mathrm{~g}, 9.5 \mathrm{mmol})$ and iso-propyl nitrate (2.00 $\mathrm{g}, 19.0 \mathrm{mmol})$ in DCE $(50 \mathrm{ml})$ was refluxed for $48 \mathrm{~h}^{75}$

The amount of catalyst affected the reaction rate but did not substantially affect the selectivity. Similarly, the rate increased as more reagent was used, resulting in a trend to higher product yields and higher recorded mass balances (because phenol is removed more quickly by reaction). ${ }^{75}$ However, there was again little effect on product proportions and at the highest reagent concentration a small amount of 2,4-dinitrophenol was also produced. Consequently, just as for the other methods reported above, this approach has not resulted in a useful method for para-nitration of phenol. Indeed, even with zeolite catalysis, ortho-nitrophenol is usually the major product.

\subsection{Selective nitration of substrates of moderate activity}

Regioselective nitration of toluene and other simple aromatics over zeolite catalysts has been the subject of much study, ${ }^{76-106}$ and it has become clear that the selectivity of the reaction depends on the nature of both the catalyst and the nitrating reagent. 
Toluene (4) has been successfully nitrated with $n$-propyl nitrate over HZSM-5 zeolite at $116^{\circ} \mathrm{C}$. When a high silica form $(\mathrm{Si} / \mathrm{Al}=1000)$ was used and the reaction was carried out at high dilution, mononitrated toluenes were produced in 54\% yield with a paralortho ratio of 19 , though a very large quantity of the zeolite was required. ${ }^{76}$ Unfortunately, a more common HZSM-5 $(\mathrm{Si} / \mathrm{Al}=30)$ was less selective. ${ }^{76}$

Our approach was to consider acyl nitrates, which are more reactive than alkyl nitrates, as reagents. Indeed, nitration of toluene by benzoyl nitrate in the presence of zeolites proceeded readily, presumably via production of nitronium ion (Scheme 3). ${ }^{77}$

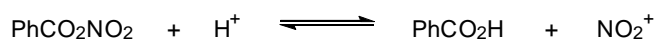

Scheme 3 Generation of $\mathrm{NO}_{2}{ }^{+}$from benzoyl nitrate

Because no water was present, any of a range of solvents could be added to increase the mobility of the mixture and diffusion of the materials through the zeolite pores. Of several zeolites tested, H-mordenite gave the best results. For example, nitration of toluene (4) over H-mordenite in the presence of benzoyl nitrate at room temperature gave 2-nitrotoluene (5) and 4-nitrotoluene (7) in 32 and 67\% yields, respectively, along with $1 \%$ of 3 -nitrotoluene $(\mathbf{6}$; Scheme 4$){ }^{77}$ The reaction was therefore high yielding and much more para-selective than traditional nitration reactions, and the zeolite could also be recovered and re-used. ${ }^{77}$ When a similar reaction was carried out by others over surface-deactivated ZSM-11 in hexane, 7 was obtained in even higher selectivity (98\%), though in lower yield. ${ }^{78,79}$

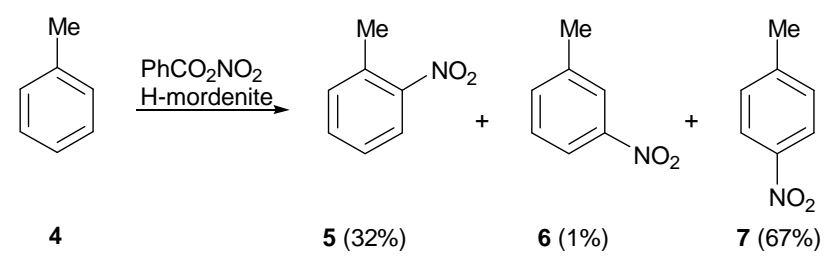

Scheme 4 Nitration of toluene (4) using benzoyl nitrate over H-mordenite

Unfortunately, benzoyl nitrate is expensive to produce. Acetyl nitrate, formed in-situ from acetic anhydride and nitric acid (Scheme 5), is more economical.

$\mathrm{Ac}_{2} \mathrm{O}+\mathrm{HNO}_{3} \rightleftharpoons \mathrm{AcONO}_{2}+\mathrm{AcOH}$

Scheme 5 Generation of acetyl nitrate from nitric acid and acetic anhydride 
Indeed, simple aromatic compounds $\mathbf{8}$ were nitrated (Scheme 6) in excellent yields (Table 4) and with high regioselectivity under mild conditions with acetyl nitrate, generated using stoichiometric quantities of nitric acid and acetic anhydride and in the absence of any additional solvent, when zeolite $\mathrm{H} \beta$ was the catalyst. ${ }^{80}$

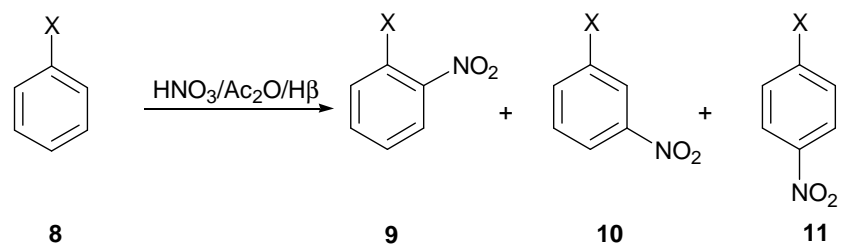

Scheme 6 Nitration of simple aromatics 8 using a $\mathrm{HNO}_{3} / \mathrm{Ac}_{2} \mathrm{O} / \mathrm{H} \beta$ system

The order of addition of the materials had a significant effect on the paraselectivity of the reaction. The best order involved premixing the zeolite with nitric acid, followed by addition of acetic anhydride and lastly the aromatic compound. This is consistent with the formation of acetyl nitrate predominantly within the pores of the zeolite, where reaction with the substrate then takes place.

Table 4 Nitration of simple aromatics 8 using a $\mathrm{HNO}_{3} / \mathrm{Ac}_{2} \mathrm{O} / \mathrm{H} \beta$ system according to Scheme $6^{a}$

\begin{tabular}{|c|c|c|c|c|c|}
\hline \multirow[t]{2}{*}{$X$} & \multirow[t]{2}{*}{$\mathrm{t}(\mathrm{min})$} & \multirow{2}{*}{ Yield (\%) } & \multicolumn{3}{|c|}{ Proportions of the isomers $(\%)$} \\
\hline & & & 9 & $\mathbf{1 0}$ & 11 \\
\hline $\mathrm{Me}$ & 30 & $>99$ & 18 & 3 & 79 \\
\hline Et & 10 & $>99$ & 15 & 3 & 82 \\
\hline${ }^{i} \operatorname{Pr}$ & 30 & $>99$ & 9 & 3 & 88 \\
\hline${ }^{t} \mathrm{Bu}$ & 30 & 92 & 8 & traces & 92 \\
\hline $\mathrm{F}$ & 30 & $>99$ & 6 & 0 & 94 \\
\hline $\mathrm{Cl}$ & 30 & $>99$ & 7 & 0 & 93 \\
\hline $\mathrm{Br}$ & 30 & $>99$ & 13 & 0 & 87 \\
\hline \multicolumn{6}{|c|}{$\begin{array}{l}{ }^{a} \text { A mixture of } \mathrm{H} \beta(1 \mathrm{~g}), \mathrm{HNO}_{3}(35 \mathrm{mmol} \text { of } 90 \%), \mathrm{Ac}_{2} \mathrm{O}(53 \mathrm{mmol}) \text { and } \mathbf{8}(35 \mathrm{mmol}) \\
\text { was stirred at room temperature for the indicated reaction time followed by distillation } \\
\text { under reduced pressure. }\end{array}$} \\
\hline
\end{tabular}

It is clear that it is possible to nitrate toluene in essentially quantitative yield with high para-selectivity (79\%) and without recourse to expensive or relatively inaccessible reagents or to conditions (e.g. temperature and solvent) that would preclude application on a large scale. The procedure can be applied to a range of substrates of moderate activity, which are the ones that often give selectivity problems 
in traditional nitrations. The zeolite can be recycled, and the only by-product is acetic acid, which can be separated easily from the nitration products by distillation. These results represent the highest para-selectivities yet achieved in high yielding nitration reactions for such an extensive range of substrates, and dinitro compounds are not formed in significant amounts. ${ }^{80}$ The mechanism of the reaction has been investigated in detail by the group of Prins. Their studies confirm the intermediacy of acetyl nitrate and support the view that the selectivity arises by constrictions on the transition state within the zeolite pores. ${ }^{81-83}$

Although this method seems to meet most of the criteria of a cleaner, greener, environmentally more acceptable nitration process, commercial organisations appear reluctant to adopt the new technology, possibly because of the hazards of acetyl nitrate. Therefore, alternative methods of achieving selective nitration are still needed.

Aromatic compounds $\mathbf{8}$ can also be readily nitrated more para-selectively with dinitrogen pentoxide over zeolite catalysts. ${ }^{84}$ However, the process suffers several disadvantages such as the production of one mole of nitric acid per mole of product. Moreover, the reagent can only be produced using special facilities. Vapour phase nitration with nitrogen dioxide at elevated temperatures in the presence of zeolites has also been reported, but generally without particular benefits. ${ }^{85-88}$ However, one report of nitration of chlorobenzene with nitrogen dioxide in the presence of oxygen over zeolite $\mathrm{H} \beta$ at $150{ }^{\circ} \mathrm{C}$ gave an ortho/meta/para product distribution of 3/1/96, though the overall yield of chloronitrobenzenes was only $38 \%{ }^{89}$ A reaction utilising $\mathrm{N}_{2} \mathrm{O}_{4}$ and oxygen can be catalysed by tris(pentane-2,4-dionato)iron(III) (Fe(acac) $)_{3}$ ) in an organic solvent, ${ }^{90,91}$ so that it occurs under moderate conditions in a highly atomefficient process, but it is not regioselective. We decided to reinvestigate the zeolitecatalysed reaction and found that it could be carried out under mild conditions for simple aromatics 8. The higher temperatures used earlier were not required. For example, nitration of chlorobenzene with excess liquid $\mathrm{N}_{2} \mathrm{O}_{4}$ in dichloroethane over various zeolites at $0{ }^{\circ} \mathrm{C}$ in the presence of oxygen (assuming the stoichiometry shown in Scheme 7, $\mathrm{X}=\mathrm{Cl}$ ) gave high yields and reasonable para-selectivity (Table 5). ${ }^{92,93}$

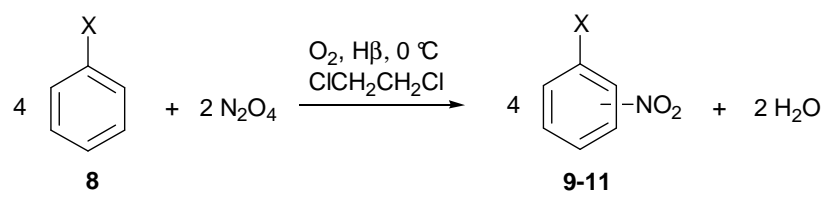

Scheme 7 Assumed stoichiometry for nitration of simple aromatic compounds 8 over a $\mathrm{N}_{2} \mathrm{O}_{4} / \mathrm{O}_{2} / \mathrm{H} \beta$ system with excess $\mathrm{N}_{2} \mathrm{O}_{4}$ 
Table 5 Nitration of chlorobenzene $(8 ; \mathrm{X}=\mathrm{Cl})$ over a $\mathrm{N}_{2} \mathrm{O}_{4} / \mathrm{O}_{2} / \mathrm{H} \beta$ system according to Scheme $7^{a}$

\begin{tabular}{|c|c|c|c|c|c|}
\hline \multirow[t]{2}{*}{ Catalyst (Si/Al) } & \multirow[t]{2}{*}{$\mathrm{t}(\mathrm{h})$} & \multirow[t]{2}{*}{ Yield (\%) } & \multicolumn{3}{|c|}{ Proportions of the isomers $(\%)$} \\
\hline & & & ortho & meta & para \\
\hline - & 50 & 2 & 39 & 0 & 61 \\
\hline $\mathrm{SiO}_{2}$ & 50 & 28 & 29 & $<1$ & 70 \\
\hline $\mathrm{H \beta}(12.5)$ & 50 & 90 & 14 & $<1$ & 85 \\
\hline $\mathrm{Na} \beta(12)$ & 50 & 96 & 15 & 0 & 85 \\
\hline $\mathrm{K} \beta(12)$ & 50 & 92 & 21 & 0 & 79 \\
\hline $\mathrm{NH}_{4} \beta(12.5)$ & 50 & 70 & 30 & 1 & 69 \\
\hline HY (30) & 50 & 91 & 16 & 2 & 82 \\
\hline $\mathrm{NaY}(28)$ & 50 & 91 & 16 & 1 & 83 \\
\hline H-mordenite (10.5) & 50 & 28 & 27 & 0 & 73 \\
\hline HZSM-5 (50) & 72 & 42 & 28 & 2 & 70 \\
\hline HZSM-5 (150) & 72 & 32 & 20 & $<1$ & 79 \\
\hline
\end{tabular}

Zeolites $\mathrm{H} \beta$ and $\mathrm{Na} \beta$ produced the greatest selectivity for parachloronitrobenzene (85\%) and among the highest yields (90 and 96\%). The reaction over $\mathrm{H} \beta$ has been applied to a range of other aromatic substrates 8 (Scheme 7) to give excellent yields of mononitrated products 9-11 (Table 6), with moderate paraselectivities somewhat better than those of traditional reactions. ${ }^{92,93}$

Table 6 Nitration of simple aromatic compounds 8 over a $\mathrm{N}_{2} \mathrm{O}_{4} / \mathrm{O}_{2} / \mathrm{H} \beta$ system according to Scheme $7^{a}$

\begin{tabular}{|c|c|c|c|c|c|}
\hline \multirow[t]{2}{*}{$\mathrm{X}$} & \multirow{2}{*}{$\mathrm{t}(\mathrm{h})$} & \multirow{2}{*}{ Yield (\%) } & \multicolumn{3}{|c|}{ Proportions of the isomers $(\%)$} \\
\hline & & & ortho & meta & para \\
\hline $\mathrm{Me}$ & 24 & 85 & 53 & 2 & 45 \\
\hline $\mathrm{F}$ & 48 & 95 & 7 & 0 & 93 \\
\hline $\mathrm{Cl}$ & 48 & 95 & 14 & $<1$ & 85 \\
\hline $\mathrm{Br}$ & 48 & 94 & 22 & $<1$ & 77 \\
\hline I & 48 & 95 & 37 & 1 & 62 \\
\hline
\end{tabular}

In principle, this method could offer a potentially clean synthesis of halogenonitrobenzenes. However, the reactions are not very selective, and involve a 
large excess of dinitrogen tetroxide, a halogenated solvent, cooling and a reaction time of $48 \mathrm{~h}$, all of which reduce the green credentials of the process.

Suzuki showed that better selectivities for production of para-isomers could be achieved at low conversion using the substrate as its own solvent in the liquid phase, ${ }^{94}$ while we avoided the need for cooling by use of an autoclave to contain the dinitrogen tetroxide. In this way substrates $\mathbf{8}$ could be nitrated in high yields with moderate para-selectivities (Table 7) under mild conditions (ambient temperature and a modest pressure), using only the stoichiometric amount of dinitrogen tetroxide, and using air instead of oxygen. ${ }^{93,95}$ Actually, it transpired that the stoichiometry is not as indicated in Scheme 7, but instead results in production of one mole of nitric acid for each 3 moles of product (Scheme 8). A means of recycling the nitric acid would also therefore need to be developed in order to make the process really attractive.

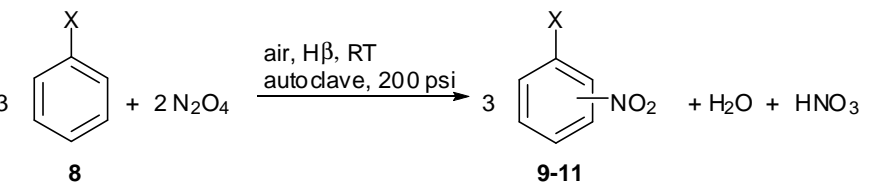

Scheme 8 Nitration of simple aromatic compounds 8 over a $\mathrm{N}_{2} \mathrm{O}_{4} / \mathrm{air} / \mathrm{H} \beta$ system under autoclave conditions

Table 7 Nitration of simple aromatic compounds 8 over a $\mathrm{N}_{2} \mathrm{O}_{4} / \mathrm{air} / \mathrm{H} \beta$ system according to Scheme $8^{a}$

\begin{tabular}{llllll}
\hline \multirow{2}{*}{$\mathrm{X}$} & \multirow{2}{*}{$(\mathrm{h})$} & Yield $(\%)$ & \multicolumn{3}{l}{ Proportions of the isomers $(\%)$} \\
\cline { 4 - 6 } & & & ortho & meta & para \\
\hline $\mathrm{Me}$ & 24 & 76 & 50 & 3 & 47 \\
$\mathrm{~F}$ & 16 & 95 & 9 & $<1$ & 91 \\
$\mathrm{Cl}$ & 14 & 97 & 15 & $<1$ & 84 \\
$\mathrm{Br}$ & 14 & 90 & 19 & $<1$ & 80
\end{tabular}

${ }^{a}$ A mixture of $\mathrm{H} \beta(3 \mathrm{~g}), 8(33 \mathrm{mmol})$ and $\mathrm{N}_{2} \mathrm{O}_{4}(c a .1 .4 \mathrm{ml})$ was stirred under $200 \mathrm{psi}$ air pressure at room temperature for the indicated reaction time. ${ }^{93,95}$

Under the conditions described in Table 7 the reaction is rather slow, but simply raising the temperature to $30-40{ }^{\circ} \mathrm{C}$ in the sealed system used reduces the required reaction period dramatically. Therefore, only three remaining obstacles prevent this reaction from fulfilling all the desired criteria. One is the relatively low para-selectivity (though already significantly better than for traditional methods). Another is the production of a modest amount of nitric acid as by-product, which can 
deactivate the zeolite by adsorption or reaction, limits the efficiency of usage of the dinitrogen tetroxide and could lead to plant corrosion. The third disadvantage is the use of an autoclave, and on some occasions the reactions have unexpectedly shown thermal runaway, which would need to be understood and then prevented.

One other approach involves use of nitric acid as the reagent. ${ }^{96-101}$ In this case, a modest amount of zeolite can be used in a catalytic way. However, higher temperatures and longer reaction times are needed. At higher temperatures, catalyst deactivation takes place rapidly and oxidation products are produced. Also, the yields and selectivities tend to be lower than those obtained with the nitric acid/acetic anhydride system. Nevertheless, progress has been made and the method has the advantages of simplicity and cheap reagents.

\subsection{Selective nitration of deactivated substrates}

Normally, nitrations of deactivated compounds and therefore polynitration of toluene are carried out using aggressive nitric acid-oleum mixtures. Dinitration of toluene with mixed acids produces 2,4- and 2,6-dinitrotoluenes in a ratio of 4:1, from which 2,4-dinitrotoluene is isolated for the manufacture of toluene di-isocyanate (TDI), which is used in the manufacture of polyurethanes and toluenediamine. Zirconium and hafnium derivatives catalyse nitration of 2-nitrotoluene (5), but the ratio of 2,4-:2,6-dinitrotoluene is modest (66:34). ${ }^{107}$ Dinitration of toluene using claycop (copper nitrate on K10 clay), acetic anhydride and nitric acid in the presence of tetrachloromethane has produced dinitrotoluenes in a yield of $85 \%$ with a ratio of 2,4-:2,6-dinitrotoluene of 9:1, ${ }^{108}$ but the method requires a large excess of nitric acid, use of an unacceptable solvent, high dilution, a large quantity of catalyst and a long reaction time. Nitration of a 1:1 mixture of 2-NT and 4-NT (i.e. somewhat richer in 4-NT than is produced by nitration of toluene with mixed acids), using nitric acid over zeolite $\mathrm{H} \beta$ as catalyst, with azeotropic removal of water, gives a 2,4:2,6-dinitrotoluene ratio of $c a .14$, but in modest yield ( $c a .20 \%$ with one equivalent of nitric acid, $30 \%$ with two) and with significant deactivation of the catalyst during the reaction. ${ }^{97,109}$

Nitrobenzene can be successfully nitrated using fuming nitric acid and trifluoroacetic anhydride (TFAA) in equimolar proportions at $45-55{ }^{\circ} \mathrm{C} .{ }^{110}$ However, such conditions are generally not very selective in nitration of substituted nitrobenzenes. ${ }^{111,112}$ Because there is only one actived position, 4-nitrotoluene (7) is 
nitrated by a TFAA/ $\mathrm{HNO}_{3}$ mixture to give exclusively 2,4-dinitrotoluene (12) in high yield at room temperature. ${ }^{111,112}$ By contrast, nitration of 2-nitrotoluene (5) gives two main products, 12 and 2,6-dinitrotoluene (13). We studied the reaction in the presence of zeolite $\mathrm{H} \beta$ in an attempt to improve regioselectivity for the 2,4-isomer. Indeed, on nitration of 5 with $\mathrm{TFAA} / \mathrm{HNO}_{3}$ in the presence of zeolite $\mathrm{H} \beta$ the regioselectivity improved slightly (12:13 ratio of 3:1 compared to 2:1 without zeolite), although there was little effect on the overall reaction rate or product yield. It appeared that the free solution reaction was too fast for the reactants to diffuse fully into the pore system and so reaction occurred primarily in free solution or at the external surface of the zeolite.

In order to slow down the overall reaction, acetic anhydride was added as a diluent, thereby giving the zeolite a better chance to exert influence over the reaction. Indeed, this led to a slower reaction and zeolite $\mathrm{H} \beta$ then exerted a greater influence over both rate and selectivity. In the presence of acetic anhydride but absence of zeolite the combined yield of $\mathbf{1 2}$ and $\mathbf{1 3}$ from 2-nitrotoluene (5) after $2 \mathrm{~h}$ at $-10{ }^{\circ} \mathrm{C}$ was only $16 \%$ and the $\mathbf{1 2 : 1 3}$ ratio was $2: 1$. In the presence of zeolite $\mathrm{H} \beta$ ( $1 \mathrm{~g}$ for 17.5 mmol of 5), the yield increased to $99 \%$ and the 12:13 ratio to $17: 1$ (Scheme 9). ${ }^{111}$

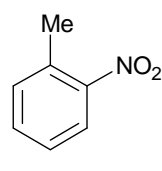

5

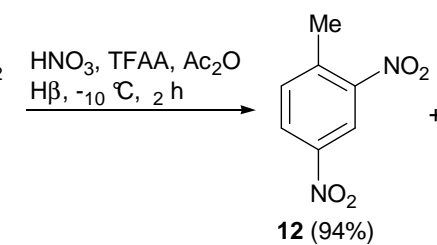

$12(94 \%)$

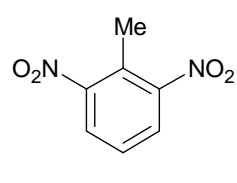

$13(5.4 \%)$

Scheme 9 Nitration of 2-nitrotoluene (5) using a $\mathrm{HNO}_{3} / \mathrm{TFAA} / \mathrm{Ac}_{2} \mathrm{O} / \mathrm{H} \beta$ system

4-Nitrotoluene (7) could also be nitrated with the system optimised for 2-nitrotoluene (5), but the reaction was much slower. Therefore, for direct dinitration of toluene it was necessary to minimise the amount of the diluent used. When this was done, single step nitration of toluene (4) using two equivalents of $\mathrm{HNO}_{3}$ with TFAA and $\mathrm{Ac}_{2} \mathrm{O}$ gave 12 and $\mathbf{1 3}$ in almost quantitative yield with high para-selectivity (12:13 = 24:1 using $1 \mathrm{~g}$ and 14:1 using $0.5 \mathrm{~g}$ of $\mathrm{H} \beta$ for a $17.5 \mathrm{mmol}$ reaction). ${ }^{111}$ Excellent though these results were, the ratio of 12:13 was less than would be predicted if the first step were to give 2- and 4-nitrotoluenes in the published ratio for the $\mathrm{HNO}_{3} / \mathrm{Ac}_{2} \mathrm{O} / \mathrm{H} \beta$ system ( $c$. 4:1) and the second nitration step were to proceed as described above. 4-Nitrotoluene (7) should give only 12, while 2-nitrotoluene (5) 
should give $\mathbf{1 2}$ and $\mathbf{1 3}$ in $c a$. 17:1 ratio, leading to a ratio expected for the overall process of $c a .98: 2$ to $99: 1$. It seemed likely that the problem was a less selective first step using TFAA and therefore a two-step nitration process was investigated.

The two-step nitration process, involving only acetic anhydride and zeolite $\mathrm{H} \beta$ in the first step, with TFAA and extra $\mathrm{H} \beta$ zeolite added in the second step (Scheme 10), improved the para-regioselectivity to a $\mathbf{1 2 : 1 3}$ ratio of $70: 1$, and a quantitative yield was obtained after $2 \mathrm{~h}$ at around $-10{ }^{\circ} \mathrm{C} .{ }^{111}$ Pure 2,4-dinitrotoluene (12) was isolated in $90 \%$ yield from this reaction simply by filtration of the zeolite, concentration of the mother liquor, and recrystallization from acetone or diethyl ether.

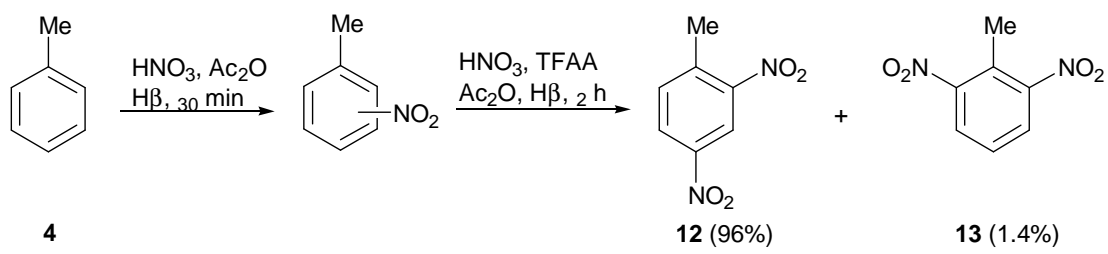

Scheme 10 Two-step nitration of toluene (4) with a $\mathrm{HNO}_{3} / \mathrm{TFAA} / \mathrm{Ac}_{2} \mathrm{O} / \mathrm{H} \beta$ system

The mono-nitrotoluene intermediates in the dinitration of toluene are only moderately deactivated because of the activating influence of the methyl group and 2,4-DNT has the two electron-withdrawing groups meta- to each other, in line with traditional regioselectivity. To test the limits of the methods, it was of interest to see how they would behave with substrates having just a single deactivating substituent. A series of deactivated monosubstituted benzenes $\mathbf{8}$ bearing meta-directing groups was therefore subjected to the $\mathrm{HNO}_{3} / \mathrm{TFAA} / \mathrm{H} \beta$ and $\mathrm{HNO}_{3} / \mathrm{TFAA} / \mathrm{Ac}_{2} \mathrm{O} / \mathrm{H} \beta$ systems (Scheme 6, $\left.\mathrm{X}=\mathrm{NO}_{2}, \mathrm{CO}_{2} \mathrm{H}, \mathrm{CN}\right){ }^{111}$ The results, recorded in Table 8, showed that reasonable yields of mononitrated products were obtained using the $\mathrm{HNO}_{3} / \mathrm{TFAA} / \mathrm{H} \beta$ system, but that yields were lower with the system containing $\mathrm{Ac}_{2} \mathrm{O}$. In comparison to mixed acid, the $\mathrm{HNO}_{3} / \mathrm{TFAA} / \mathrm{Ac}_{2} \mathrm{O} / \mathrm{H} \beta$ system in particular led to higher proportions of para-isomers (to 19\% in the case of benzonitrile), presumably as a result of shapeselectivity imposed on the transition state. With benzoic acid the proportion of orthoisomer also increased (to $11 \%$ ), possibly by rearrangement of benzoyl nitrate formed in-situ. However, in all cases the meta-isomer was still vastly predominant. ${ }^{111}$ 
Table 8 Nitration of deactivated monosubstituted benzenes 8 according to Scheme 6 but using $\mathrm{HNO}_{3} / \mathrm{TFAA} / \mathrm{H} \beta^{a}$ and $\mathrm{HNO}_{3} /$ TFAA/ $/ \mathrm{Ac}_{2} \mathrm{O} / \mathrm{H} \beta$ systems ${ }^{b}$

\begin{tabular}{|c|c|c|c|c|c|}
\hline \multirow[t]{2}{*}{$X$} & \multirow{2}{*}{ Nitration system } & \multirow{2}{*}{ Yield (\%) } & \multicolumn{3}{|c|}{ Proportions of the isomers $(\%)$} \\
\hline & & & ortho & meta & para \\
\hline $\mathrm{NO}_{2}$ & $\mathrm{HNO}_{3} / \mathrm{TFAA} / \mathrm{H} \beta$ & 72 & 5 & 88 & 7 \\
\hline $\mathrm{CO}_{2} \mathrm{H}$ & $\mathrm{HNO}_{3} / \mathrm{TFAA} / \mathrm{H} \beta$ & 86 & 2 & 97 & 1 \\
\hline $\mathrm{CN}$ & $\mathrm{HNO}_{3} / \mathrm{TFAA} / \mathrm{H} \beta$ & 54 & 13 & 74 & 13 \\
\hline $\mathrm{NO}_{2}$ & $\mathrm{HNO}_{3} / \mathrm{TFAA} / \mathrm{Ac}_{2} \mathrm{O} / \mathrm{H} \beta$ & 25 & 2 & 91 & 7 \\
\hline $\mathrm{CO}_{2} \mathrm{H}$ & $\mathrm{HNO}_{3} / \mathrm{TFAA} / \mathrm{Ac}_{2} \mathrm{O} / \mathrm{H} \beta$ & 74 & 11 & 79 & 10 \\
\hline $\mathrm{CN}$ & $\mathrm{HNO}_{3} / \mathrm{TFAA} / \mathrm{Ac}_{2} \mathrm{O} / \mathrm{H} \beta$ & 17 & 10 & 71 & 19 \\
\hline \multicolumn{6}{|c|}{$\begin{array}{l}{ }^{a} \text { A mixture of } \mathrm{H} \beta(1 \mathrm{~g}), 8(17.5 \mathrm{mmol}), \mathrm{HNO}_{3}(17.5 \mathrm{mmol} \text { of } 90 \%) \text { and TFFA }(17.5 \\
\mathrm{mmol}) \text { was stirred at }-10^{\circ} \mathrm{C} \text { for } 2 \mathrm{~h} .{ }^{111}{ }^{b} \mathrm{~A} \text { mixture of } \mathrm{H} \beta(1 \mathrm{~g}), \mathbf{8}(17.5 \mathrm{mmol}), \mathrm{HNO}_{3} \\
(17.5 \mathrm{mmol} \text { of } 90 \%) \text {, TFFA }(17.5 \mathrm{mmol}) \text { and } \mathrm{Ac}_{2} \mathrm{O}(3.5 \mathrm{ml}, 37 \mathrm{mmol}) \text { was stirred at } \\
-10^{\circ} \mathrm{C} \text { for } 2 \mathrm{~h} .111\end{array}$} \\
\hline
\end{tabular}

Recently, we undertook a more detailed study of the nitration of such monosubstituted deactivated benzenes 8 (Scheme 11) using $\mathrm{HNO}_{3} /(\mathrm{RCO})_{2} \mathrm{O} /$ zeolite systems. ${ }^{112}$ Solvents were used because some of the anhydrides were not liquid and to make the mixtures more mobile. Initial nitration of benzonitrile $(\mathbf{8} ; \mathrm{X}=\mathrm{CN})$ with $\mathrm{HNO}_{3}$ and chloroacetic anhydride over zeolite $\mathrm{H} \beta(\mathrm{Si} / \mathrm{Al}=12.5)$ in dichloromethane at room temperature for $2 \mathrm{~h}$ gave only 3-nitrobenzonitrile $(\mathbf{1 0} ; \mathrm{X}=\mathrm{CN})$ and 4-nitrobenzonitrile $(\mathbf{1 1} ; \mathrm{X}=\mathrm{CN})$ in 17 and 4\% yields, respectively, with no orthonitrated product. In the absence of catalyst no reaction occurred. The absence of ortho-isomer was interesting. Since the cyano group is linear and provides little steric hindrance to ortho-nitration, and since traditional nitration produces significantly more ortho-nitrated product than para-, a higher ortho/para ratio had been expected.

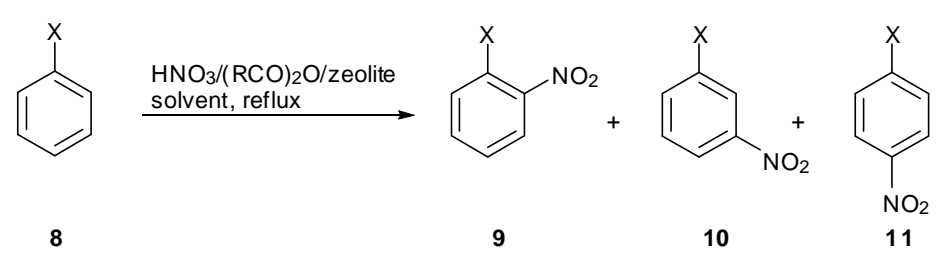

Scheme 11 Nitration of deactivated monosubstituted benzenes 8 using a mixture of $\mathrm{HNO}_{3}$ and $(\mathrm{RCO})_{2} \mathrm{O}$ over zeolite

Higher yields were obtained under reflux conditions and reaction proceeded similarly in various chlorinated hydrocarbon solvents, although reflux temperature seemed to influence the overall yield of nitrobenzonitriles (NBNs), possibly by 
decomposition or loss through evaporation of the active nitrating agent at higher temperatures. The yields of $\mathbf{1 0}$ and $\mathbf{1 1}$ were highest for reaction in dichloromethane, which was therefore used for further investigation. ${ }^{112}$ Other anhydrides and other zeolites were tested and a few of the results are recorded in Table 9. ${ }^{112}$

Table 9 Nitration of benzonitrile $(\mathbf{8} ; \mathrm{X}=\mathrm{CN})$ using $\mathrm{HNO}_{3} /(\mathrm{RCO})_{2} \mathrm{O} /$ zeolite systems under reflux in dichloromethane according to Scheme $11^{a}$

\begin{tabular}{|c|c|c|c|c|}
\hline \multirow{2}{*}{ Catalyst ( $\mathrm{Si} / \mathrm{Al}$ ratio) } & \multirow{2}{*}{ Anhydride $/(\mathrm{RCO})_{2} \mathrm{O}$} & \multicolumn{3}{|c|}{ Yield (\%) } \\
\hline & & 8 & 10 & 11 \\
\hline $\mathrm{H} \beta(12.5)$ & Acetic & 100 & - & - \\
\hline $\mathrm{H} \beta(12.5)$ & Propionic & 100 & - & 一 \\
\hline $\mathrm{H} \beta(12.5)$ & Chloroacetic & 25 & 56 & 18 \\
\hline $\mathrm{H} \beta(12.5)$ & Dichloroacetic $^{b}$ & 34 & 41 & 15 \\
\hline $\mathrm{H} \beta(12.5)$ & Trifluoroacetic & 4 & 75 & 21 \\
\hline $\mathrm{H} \beta(150)$ & Chloroacetic & 42 & 46 & 11 \\
\hline $\mathrm{H} \beta(300)$ & Chloroacetic & 27 & 62 & 12 \\
\hline HY (12.5) & Chloroacetic & 80 & 14 & 4 \\
\hline HY (28) & Chloroacetic & 70 & 27 & 2 \\
\hline
\end{tabular}

In a reaction over zeolite H-ZSM-5 (a medium pore zeolite), no NBNs were formed, presumably because the pores are too small to accommodate the reacting species and the number of acidic sites on the surface is low. The results were similar when ferrierite and mordenite were used as catalysts. These zeolites, although having relatively large entry ports, contain one-dimensional channel systems, which restricts diffusion within the channels and inhibits interaction between species. By contrast, large pore zeolites with three-dimensional channels (zeolites $\beta$ and Y) showed significant conversions of benzonitrile into nitrobenzonitriles (Table 9). ${ }^{112}$

The $\mathrm{Si} / \mathrm{Al}$ ratio of zeolites used also influenced the selectivity of the reactions, with samples having lower $\mathrm{Si} / \mathrm{Al}$ ratios giving higher proportions of 4-substituted product than those with higher ratios. Thus, using chloroacetic anhydride with zeolite $\mathrm{HY}(\mathrm{Si} / \mathrm{Al}=12.5)$ as catalyst the para:meta ratio was 4:14, while over zeolite $\mathrm{HY}$ $(\mathrm{Si} / \mathrm{Al}=28)$ the ratio was $2: 27$. Similarly, with zeolite $\mathrm{H} \beta$ the para:meta ratio varied from $18: 56$ over $\mathrm{H} \beta(\mathrm{Si} / \mathrm{Al}=12.5)$ to $12: 62$ over $\mathrm{H} \beta(\mathrm{Si} / \mathrm{Al}=300) .{ }^{112}$

Clearly, acetyl and propionyl nitrates were not reactive enough for such a deactivated substrate. The results with dichloroacetic anhydride were unusual - the 
para/meta ratio was relatively high (0.37), but there was also a significant quantity of the ortho-isomer. ${ }^{112}$ On the other hand, chloroacetyl and trifluoroacetyl nitrates gave only 10 and 11, with the latter giving a higher yield than the former but with a slightly lower para/meta ratio $\left(0.28 ; c f .0 .32\right.$ for chloroacetyl nitrate). ${ }^{112}$

Trifluoroacetic anhydride is intrinsically more reactive than chloroacetic anhydride, so a higher reaction rate was not unexpected. However, this alone could not explain why a higher yield was obtained, since deactivation of the zeolite appeared to be the limiting factor with chloroacetyl nitrate. Perhaps the greater volatility of trifluoroacetic acid and a lower tendency to complex the zeolite (Scheme 12) might result in a greater amount of free zeolite being available to catalyse the reaction. If so, a smaller quantity of zeolite might be able to generate a high yield of product. Indeed, the results (Table 10) indicated that nitration of benzonitrile could be catalysed with as little as $0.10 \mathrm{~g}$ of $\mathrm{H} \beta$ for a $9.5 \mathrm{mmol}$ reaction. Under such conditions the reaction was nearly complete (96\% after $4 \mathrm{~h}$ ) and the yield of 4-nitrobenzonitrile $(\mathbf{1 1}, \mathrm{X}=\mathrm{CN})$ was around $24 \%$, with a para/meta ratio of $0.33 .^{112}$

Zeolite $+\mathrm{RCO}_{2} \mathrm{H} \rightleftharpoons$ Zeolite. $\mathrm{RCO}_{2} \mathrm{H}$

Scheme 12 Possible deactivation of zeolite by complexation

Table 10 Nitration of benzonitrile $(\mathbf{8} ; \mathrm{X}=\mathrm{CN})$ according to Scheme 11 using TFAA over various quantities of zeolite $\mathrm{H} \beta^{a}$

\begin{tabular}{|c|c|c|c|c|}
\hline \multirow[t]{2}{*}{$\mathrm{H} \beta(\mathrm{Si} / \mathrm{Al}=12.5 ; \mathrm{g})$} & \multirow{2}{*}{ Reaction time (h) } & \multicolumn{3}{|c|}{ Yield $(\%)$} \\
\hline & & 8 & 10 & 11 \\
\hline - & 4 & 100 & - & - \\
\hline 4.0 & 4 & - & 77 & 23 \\
\hline 2.0 & 4 & - & 76 & 24 \\
\hline 0.50 & 4 & - & 77 & 23 \\
\hline 0.25 & 4 & - & 77 & 23 \\
\hline 0.10 & 6 & 1 & 75 & 24 \\
\hline 0.10 & 4 & 4 & 72 & 24 \\
\hline 0.10 & 2 & 5 & 72 & 23 \\
\hline 0.10 & 0.5 & 41 & 46 & 13 \\
\hline \multicolumn{5}{|c|}{$\begin{array}{l}{ }^{a} \mathrm{~A} \text { mixture of } \mathrm{H} \beta(\mathrm{Si} / \mathrm{Al}=12.5) \text {, nitric acid }(19 \mathrm{mmol} \text { of } 100 \%) \text {, TFAA }(3.50 \mathrm{ml}, 25 \\
\text { mmol }) \text { and } 8(\mathrm{X}=\mathrm{CN} ; 1.03 \mathrm{~g}, 9.5 \mathrm{mmol}) \text { in } \mathrm{DCM}(20 \mathrm{ml}) \text { was refluxed for the stated } \\
\text { reaction time. }\end{array}$} \\
\hline
\end{tabular}

A range of cation-exchanged $\beta$ zeolite catalysts was also tested in the nitration of benzonitrile under similar conditions. ${ }^{112}$ The results, reported in Table 11, showed 
some interesting features. For example, the yield of NBNs was only $7 \%$, with no 4-NBN, when $\mathrm{K}^{+} \beta$ was used as catalyst. ${ }^{12} \mathrm{~K}^{+} \beta$ is not very acidic and $\mathrm{K}^{+}$is a large univalent cation that may inhibit entry to the zeolite pores, spoiling its potential as a catalyst. The small amount of NBN produced may have arisen by reaction at the small number of external sites, thereby reducing the tendency to produce para-isomer.

For the divalent cation-exchanged zeolites the yield of NBNs was high in the case of $\mathrm{Zn}^{2+} \beta$ and $\mathrm{Cd}^{2+} \beta$ but only moderate with $\mathrm{Hg}^{2+} \beta .{ }^{112}$ The higher yields with the smaller cations could reflect easier entry to the pore network. The lower yield with $\mathrm{Hg}^{2+} \beta$ would be consistent with the larger cation causing greater constriction to access to the pore network. There was also a slight increase in para-selectivity going from $\mathrm{Zn}^{2+} \beta$ to $\mathrm{Hg}^{2+} \beta$ as the cations get larger, but at the expense of overall yield.

Table 11 Nitration of benzonitrile $(\mathbf{8} ; \mathrm{X}=\mathrm{CN})$ according to Scheme 11 over various cation-exchanged zeolites $\beta^{a}$

\begin{tabular}{|c|c|c|c|}
\hline \multirow{2}{*}{ Zeolite } & \multicolumn{3}{|c|}{ Yields $(\%)$} \\
\hline & 8 & 10 & 11 \\
\hline $\mathrm{H}^{+} \beta$ & - & 76 & 24 \\
\hline $\mathrm{K}^{+} \beta$ & 90 & 7 & - \\
\hline $\mathrm{Zn}^{2+} \beta$ & 2 & 80 & 17 \\
\hline $\mathrm{Cd}^{2+} \beta$ & - & 78 & 22 \\
\hline $\mathrm{Hg}^{2+} \beta$ & 54 & 34 & 11 \\
\hline $\mathrm{Al}^{3+} \beta$ & 2 & 77 & 22 \\
\hline $\mathrm{Fe}^{3+} \beta$ & - & $77(73)^{b}$ & $24(28)^{b}$ \\
\hline $\mathrm{In}^{3+} \beta$ & - & 85 & 15 \\
\hline $\mathrm{La}^{3+} \beta$ & - & 87 & 14 \\
\hline $\mathrm{Ce}^{3+} \beta$ & - & 85 & 15 \\
\hline \multicolumn{4}{|c|}{$\begin{array}{l}{ }^{a} \text { A mixture of zeolite }(2.00 \mathrm{~g}) \text {, nitric acid }(19 \mathrm{mmol} \text { of } 100 \%) \text {, TFAA }(3.50 \mathrm{ml}, 25 \\
\text { mmol }) \text { and } 8(\mathrm{X}=\mathrm{CN} ; 1.03 \mathrm{~g}, 9.5 \mathrm{mmol}) \text { in DCM }(20 \mathrm{ml}) \text { was refluxed for } 4 \mathrm{~h}^{112} \\
{ }^{b} \text { Figures in parentheses are for similar reactions, but with } 4 \mathrm{~g} \text { of zeolite } \mathrm{Fe}^{3+} \beta \text {. }\end{array}$} \\
\hline
\end{tabular}

All trivalent cations produced quantitative yields of NBNs, of which 4-NBN (11) was in the range of $14-24 \%$, the best being with $\mathrm{Fe}^{3+} \beta$ and $\mathrm{Al}^{3+} \beta{ }^{112}$ Furthermore, 11 was obtained in even better yield $(28 \%)$ when $4 \mathrm{~g}$ of $\mathrm{Fe}^{3+} \beta$ zeolite was used instead of $2 \mathrm{~g}$, while use of only $0.1 \mathrm{~g}$ resulted in $22 \%$ of $\mathbf{1 1}, 58 \%$ of $\mathbf{1 0}$ and $21 \%$ unreacted benzonitrile. Therefore, $\mathrm{Fe}^{3+} \beta$ behaved in a manner broadly similar to that of $\mathrm{H} \beta$.

Surface-passivated zeolites offered the possibility of further improvement in para-selectivity, by eliminating reaction catalysed at the external surface of the zeolite 
and by introducing further constraints on access to the pores. Indeed, with $1 \mathrm{~g}$ of zeolite $\mathrm{H} \beta$ passivated by trimethylchlorosilane for a 19 mmol reaction, reaction was complete within $1 \mathrm{~h}$, giving $67 \%$ of $\mathbf{1 0}$ and $33 \%$ of $\mathbf{1 1}$, which is easily the highest proportion of $\mathbf{1 1}$ ever achieved in nitration of benzonitrile (Table 12). ${ }^{112}$

Table 12 Nitration of benzonitrile $(8 ; X=C N)$ according to Scheme 11 over various quantities of passivated zeolite $\mathrm{H} \beta^{a}$

\begin{tabular}{|c|c|c|c|}
\hline \multirow{2}{*}{ Passivated H $\beta$ (g) } & \multicolumn{3}{|c|}{ Yields $(\%)$} \\
\hline & 8 & 10 & 11 \\
\hline 0.10 & 40 & 45 & 15 \\
\hline 0.25 & 4 & 65 & 30 \\
\hline 0.50 & 5 & 64 & 31 \\
\hline 1.00 & - & 67 & 33 \\
\hline 2.00 & - & 67 & 33 \\
\hline \multicolumn{4}{|c|}{$\begin{array}{l}\text { A mixture of passivated zeolite } \mathrm{H} \beta \text {, nitric acid }(19 \mathrm{mmol} \text { of } 100 \%) \text {, trifluoroacetic } \\
\text { anhydride }(25 \mathrm{mmol}, 3.5 \mathrm{ml}) \text { and } \mathbf{8}(\mathrm{X}=\mathrm{CN} ; 1.03 \mathrm{~g}, 9.5 \mathrm{mmol}) \text { in DCM }(20 \mathrm{ml}) \text { was } \\
\text { refluxed for } 2 \mathrm{~h} .{ }^{112}\end{array}$} \\
\hline
\end{tabular}

Similar conditions were applied to a range of other mono-substituted deactivated benzenes using standard zeolite $\mathrm{H} \beta$ (Table 13; results compared with those with mixed acids) and using passivated $\mathrm{H} \beta$ (Table 14). ${ }^{112}$

Table 13 Nitration of deactivated aromatics 8 according to Scheme 11 using nitric acid and TFAA over zeolite $\mathrm{H} \beta$ and comparison with use of 'mixed acids' ${ }^{a}$

\begin{tabular}{|c|c|c|c|}
\hline \multirow[t]{2}{*}{$\mathrm{R}$} & \multicolumn{3}{|c|}{ Yield $(\%)^{b}$} \\
\hline & 9 & 10 & 11 \\
\hline $\mathrm{CN}$ & $-(17)$ & $76(80)$ & $24(2)$ \\
\hline $\mathrm{NO}_{2}$ & $-(6)$ & $92(91)$ & $7(2)$ \\
\hline $\mathrm{CHO}$ & $10(22)$ & $76(72)$ & $14(1)$ \\
\hline $\mathrm{COMe}$ & $-(-)$ & $67(75)$ & $15(-)$ \\
\hline $\mathrm{COBu}$ & $10(18)^{c}$ & $52(27)^{c}$ & $30(-)^{c}$ \\
\hline $\mathrm{COBu}^{t}$ & $38(33)$ & $26(41)$ & $36(26)$ \\
\hline $\mathrm{CO}_{2} \mathrm{H}$ & $-(27)$ & $75(72)$ & $21(1)$ \\
\hline $\mathrm{CO}_{2} \mathrm{Me}$ & $4(20)$ & 85 (69) & $10(3)$ \\
\hline $\mathrm{CO}_{2} \mathrm{Et}$ & $8(20)$ & 77 (78) & $12(3)$ \\
\hline $\mathrm{CO}_{2} \mathrm{Bu}$ & $10(20)$ & $75(74)$ & $13(2)$ \\
\hline \multicolumn{4}{|c|}{$\begin{array}{l}{ }^{a} \text { A mixture of } \mathrm{H} \beta(\mathrm{Si} / \mathrm{Al}=12.5,0.25 \mathrm{~g}) \text {, nitric acid }(19 \mathrm{mmol} \text { of } 100 \%) \text {, TFAA }(3.50 \\
\mathrm{ml}, 25 \mathrm{mmol}) \text { and } \mathbf{8}(9.5 \mathrm{mmol}) \text { in } \mathrm{DCM}(20 \mathrm{ml}) \text { was refluxed for } 4 \mathrm{~h} .{ }^{112}{ }^{b} \text { Figures in } \\
\text { parentheses are for similar reactions using mixed acids. }{ }^{c} \text { Reaction was carried out } \\
\text { using only nitric acid rather than mixed acid; starting material }(\mathrm{ca} .55 \%) \text { remained. }\end{array}$} \\
\hline
\end{tabular}


Table 14 Nitration of deactivated aromatics 8 according to Scheme 11 using nitric acid and TFAA over passivated zeolite $\mathrm{H} \beta^{a}$

\begin{tabular}{|c|c|c|c|}
\hline \multirow[t]{2}{*}{$\mathrm{R}$} & \multicolumn{3}{|c|}{ Yield $(\%)$} \\
\hline & 9 & 10 & 11 \\
\hline $\mathrm{CN}$ & - & 67 & 33 \\
\hline $\mathrm{NO}_{2}$ & - & 90 & 8 \\
\hline $\mathrm{CHO}$ & 12 & 73 & 15 \\
\hline COMe & $\mathcal{L}^{c}$ & $70^{c}$ & $17^{c}$ \\
\hline $\mathrm{COBu}$ & 10 & 50 & 33 \\
\hline $\mathrm{COBu}^{t}$ & 37 & 26 & 37 \\
\hline $\mathrm{CO}_{2} \mathrm{H}$ & - & 78 & 24 \\
\hline $\mathrm{CO}_{2} \mathrm{Me}$ & 4 & 85 & 10 \\
\hline $\mathrm{CO}_{2} \mathrm{Et}$ & 8 & 78 & 13 \\
\hline $\mathrm{CO}_{2} \mathrm{Bu}$ & 11 & 72 & 14 \\
\hline
\end{tabular}

Tables 13 and 14 showed that nitration of deactivated aromatics $\mathbf{8}$ generally gave quantitative yields of nitro products. Both types of zeolite $H \beta$, but especially the passivated one, enhanced the para-selectivity in all such reactions. ${ }^{112}$ Nitration of benzonitrile, butyl phenyl ketone, tert-butyl phenyl ketone and benzoic acid gave the highest proportions of para-isomers, several being over $30 \%$. Furthermore, in all cases except one (tert-butyl phenyl ketone) the ortho-products were obtained in lower proportions than by traditional nitration, in several cases the amount being so low as to be unmeasurable. The proportion of meta-isomer was often not very different than that produced in traditional nitration reactions, increases in the amount of para-isomer having been more or less matched by decreases in the amount of ortho-isomer. ${ }^{112}$

The case of tert-butyl phenyl ketone was an exception to the general trend. As with other substrates, the proportion of para-isomer increased for the zeolite-catalysed process, but uniquely the ortho-isomer had also increased and the meta-isomer had become the minor product. ${ }^{112}$ The proportions with this substrate are unusual even for traditional nitration of an acylbenzene, attributed to the bulky tert-butyl group forcing the carbonyl group out of alignment with the benzene ring. ${ }^{113,114}$ Within the confines of the zeolite pores this twisting may be further enforced.

In summary, these zeolite-catalysed processes for nitration of monosubstituted deactivated aromatic compounds 8 (Scheme 11) are general and give significantly increased proportions of para-substituted isomers compared with the results obtained 
from the traditional mixed acid method. In most cases the proportion of ortho-isomer is substantially reduced. Although the reactions are not sufficiently para-selective to render them suitable for commercial application, they produce substantially higher proportions of para-nitro compounds than has been possible previously from such substrates. They demonstrate how careful choice of catalyst, reagent, solvent and conditions can give powerful improvements in para-selectivity even with substrates that normally give very little para-product, and may point the way to design of methods to overturn completely the normal selectivity with deactivated aromatics.

\section{Regioselective halogenation of aromatic compounds}

The usual methods for halogenation of aromatics lead in many cases to mixtures of regioisomers that may be difficult to separate. Commercial processes might be simplified considerably by the use of solid, heterogeneous catalysts such as zeolites, since separation of the catalyst from the reaction mixture would be easy. ${ }^{48,115}$

\subsection{Selective chlorination of aromatic compounds}

We first became interested in the use of solid acid catalysts when products from reactions of trialkylboranes with dichloramine-T were modified during column chromatography on silica. ${ }^{116}$ It transpired that systems comprising an active chlorinecontaining compound such as dichloramine-T and an acidic solid such as silica were capable of chlorinating benzenoid compounds, with both the nature of the chlorinecontaining compound and the acidity of the solid affecting the activity of the system. Thus, for example, phenols could be chlorinated with very weak systems comprising a chlorodialkylamine and chromatographic silica, and interestingly such reactions were highly ortho-selective. ${ }^{117}$ However, the greatest challenge would be to enhance the para-selectivity for chlorination of compounds of moderate reactivity, such as toluene, which gives predominantly ortho-chlorotoluene by traditional chlorination methods. Zeolites offer an opportunity for providing such para-selectivity. Indeed, regioselective para-chlorination of phenol has been achieved using sulfuryl chloride over partially cation exchanged $\mathrm{L}$ type zeolites in 2,2,4-trimethylpentane at room temperature for 20-42 h. The procedure provided 2-chloro and 4-chlorophenols in a combined yield of $96 \%$, with a paralortho ratio of $8 .{ }^{118}$

Numerous reagents have been used to enhance either the ortho or para selectivity of aromatic chlorination reactions. ${ }^{119-141}$ The rates of chlorination reactions 
with molecular chlorine ${ }^{128-130}$ are generally faster but less para-selective than those with sulfuryl chloride. ${ }^{131-137}$ Consequently, achieving good para-selectivity is not easy when chlorine is the reagent, even by use of zeolites. For example, chlorination of toluene (4) with chlorine in the presence of chloroacetic acid over various zeolite catalysts (Scheme 13) showed para-selectivity only over zeolite KL (Table 15). ${ }^{128}$ In the absence of chloroacetic acid the $\mathbf{1 5 / 1 4}$ ratio was only 1.76 , although the role of the reagent in the reaction is not clear. The best selectivity (15/14 ratio 6.7) was obtained when the reaction was carried out in dilute solution in 1,2-dichloroethane at $80{ }^{\circ} \mathrm{C}$. However, the absolute yield of para-chlorotoluene was never very high. ${ }^{128}$

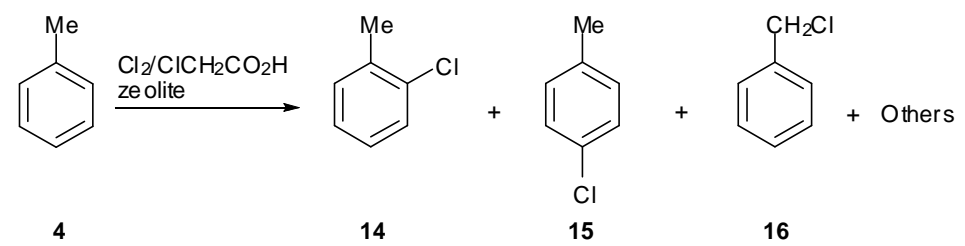

Scheme 13 Chlorination of toluene (4) using chlorine in the presence of chloroacetic acid over a zeolite

Table 15 Chlorination of toluene (4) using a $\mathrm{Cl}_{2} / \mathrm{ClCH}_{2} \mathrm{CO}_{2} \mathrm{H} /$ zeolite system according to Scheme $13^{a}$

\begin{tabular}{|c|c|c|c|c|c|}
\hline \multirow{2}{*}{ Catalyst (Si/Al) } & \multicolumn{5}{|c|}{ Yield $(\%)^{b}$} \\
\hline & 4 & 14 & 15 & 16 & Others $^{c}$ \\
\hline - & 52 & 1 & 0.5 & 45 & 2 \\
\hline $\mathrm{FeCl}_{3}$ & 56 & 24 & 12 & 6 & 3 \\
\hline K-ZSM-5 (82) & 56 & 23 & 16 & 3 & 2 \\
\hline K-Mordenite (44) & 57 & 22 & 15 & 4 & 2 \\
\hline $\mathrm{KX}(4.8)$ & 60 & 16 & 11 & 11 & 2 \\
\hline KY (8.2) & 56 & 23 & 18 & 2 & 1 \\
\hline $\mathrm{K} \beta(65.4)$ & 56 & 24 & 20 & 0.5 & - \\
\hline KL (12.6) & 55 & 10 & 33 & 1 & - \\
\hline \multicolumn{6}{|c|}{$\begin{array}{l}{ }^{a} \text { To a stirred mixture of toluene }(4,0.32 \mathrm{~mol}) \text {, catalyst }(1.6 \mathrm{~g}) \text { and } \mathrm{ClCH}_{2} \mathrm{CO}_{2} \mathrm{H}(0.32 \\
\mathrm{g}) \mathrm{Cl}_{2} \text { was added at a flow rate of } 0.08 \mathrm{~mol} / \mathrm{h} \text { at } 80{ }^{\circ} \mathrm{C} .{ }^{128}{ }^{b} \text { Numbers expressed as } \\
\text { percentages have been rounded to the whole number. }{ }^{c} \text { Polychlorinated toluenes (di-, } \\
\text { tri- and tetrachlorotoluenes). }\end{array}$} \\
\hline
\end{tabular}

Chlorination of toluene ${ }^{134-139}$ and other simple aromatics such as cumene $e^{138}$ using sulfuryl chloride over several types of zeolites is more selective than with conventional Lewis acids but simple substrates like toluene remain problematical and the reaction also suffers from formation of side products from side-chain and multiple chlorinations. Also, deactivation of the zeolite is rapid under the conditions. 
Our own approach was to use a less active reagent that would not give rise to a highly acidic by-product such as $\mathrm{HCl}$. This should give the zeolite greater opportunity to influence the reaction, and avoid its early destruction. Indeed, use of tert-butyl hypochlorite over proton-exchanged zeolite $\mathrm{X}(\mathrm{HX})$ resulted in almost quantitative ring chlorination of toluene, with $74 \%$ of para-chlorotoluene produced within one hour at $25^{\circ} \mathrm{C}$ in tetrachloromethane (Scheme $\left.14, \mathrm{X}=\mathrm{Me}\right) .{ }^{142}$ Other zeolites were less successful, consistent with faujasite's large pore diameter and three-dimensional lattice structure allowing easy diffusion of substrate and reagents while restricting transition state freedom sufficiently to favour para-isomer formation. Zeolite HY also has the faujasite structure, but it is more strongly acidic than HX, resulting in a greater proportion of by-products. The effect of solvent on yield and selectivity for reaction over HNaX was investigated. ${ }^{142}$ Some of the results are recorded in Table 16.

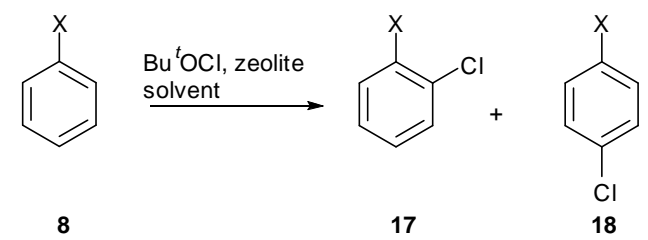

Scheme 14 Chlorination of monosubstituted benzenes 8 using tert-butyl hypochlorite over a zeolite

Table 16 Chlorination of toluene using tert-butyl hypochlorite over zeolite HX according to Scheme $14(\mathrm{X}=\mathrm{Me})^{a}$

\begin{tabular}{lllll}
\hline \multirow{2}{*}{ Solvent } & \multirow{2}{*}{$(\mathrm{h})$} & Yield $(\%)$ & \multicolumn{2}{l}{ Isomer proportions $(\%)$} \\
\cline { 4 - 5 } & & & ortho & para \\
\hline Pentane & 1 & 78 & 37 & 63 \\
Toluene & 28 & - & 29 & 71 \\
$\mathrm{CH}_{2} \mathrm{Cl}_{2}$ & 1 & 95 & 26 & 74 \\
$\mathrm{CCl}_{4}$ & 1 & 95 & 26 & 74 \\
$\mathrm{Et}_{2} \mathrm{O}$ & 0.5 & 63 & 8 & 92 \\
$\mathrm{CH}_{2} \mathrm{Cl}_{2}: \mathrm{Et}_{2} \mathrm{O}(3: 1)$ & 1 & 95 & 9 & 91 \\
$\mathrm{DMF}_{\mathrm{MeCN}}$ & 24 & 5 & 50 & 50 \\
$\mathrm{MeOH}$ & 0.5 & 100 & 18 & 82 \\
${ }^{a} \mathrm{~A}$ mixture of toluene $(2.5$ mmol $), \mathrm{Bu}{ }^{t} \mathrm{OCl}(2.5 \mathrm{mmol}), \mathrm{HNaX}(1.5 \mathrm{~g})$ and solvent $(10$ \\
ml) was stirred at $25^{\circ} \mathrm{C}$ for the reaction time.
\end{tabular}

Good yields of monochlorotoluenes were obtained both in a non-polar solvent such as pentane and in a very polar aprotic solvent like acetonitrile. Solvents having a 
strongly coordinating functionality (e.g. DMF) or strong hydrogen-bonding tendencies (e.g. methanol) inhibited the reaction, possibly by deactivating the acid sites of the zeolite and also inhibiting diffusion of reactants in and out of the lattice. The high regioselectivity ( $92 \%$ para) obtained in diethyl ether may reflect a polarity sufficient to render it capable within the pores of stabilising the likely intermediate oxonium cation but not fully to deactivate the acidic sites. Unfortunately, in the case of less active substrates, for which the rates of reaction were slower, the competing reaction of tert-butyl hypochlorite with ether itself became a problem. In view of this, acetonitrile appeared to be a better solvent for a general procedure. ${ }^{142}$ The $\mathrm{Bu}^{t} \mathrm{OCl} / \mathrm{HX} / \mathrm{MeCN}$ system has been applied successfully to a range of substituted aromatics of moderate activity. ${ }^{142}$ Some of the results are recorded in Table 17.

Table 17 Chlorination of aromatic compounds 8 using tert-butyl hypochlorite over zeolite HX according to Scheme $14^{a}$

\begin{tabular}{lccccc}
\hline $\mathrm{X}$ & $\mathrm{T}\left({ }^{\circ} \mathrm{C}\right)$ & $\mathrm{t}(\mathrm{h})$ & Yield $(\%)$ & \multicolumn{2}{l}{ Isomer proportions $(\%)$} \\
\cline { 5 - 6 } & & & & $\mathbf{1 7}$ & $\mathbf{1 8}$ \\
\hline $\mathrm{Me}$ & 25 & 1 & 100 & 18 & 82 \\
$\mathrm{Et}$ & 40 & 3.5 & 100 & 10 & 90 \\
$\mathrm{Pr}^{i}$ & 40 & 96 & 90 & 20 & 80 \\
$\mathrm{Bu}^{t}$ & 40 & 96 & 99 & 2 & 98 \\
$\mathrm{Ph}$ & 45 & 72 & 86 & 14 & 86 \\
$\mathrm{Cl}$ & 40 & 120 & 95 & 3 & 97 \\
$\mathrm{Br}$ & 40 & 96 & 75 & 3 & 97 \\
$\mathrm{OMe}$ & 25 & 3 & 100 & 18 & 82 \\
${ }^{a} \mathrm{~A}$ mixture of $\mathbf{8}(2.5$ mmol $), \mathrm{Bu}^{t}$ OCl $(2.5$ mmol $)$, MeCN $(10 \mathrm{ml})$ and zeolite HX $(1.5$ \\
g) was stirred at the indicated temperature and reaction time. ${ }^{142}$ \\
\hline
\end{tabular}

Excellent yields (75-100\%) and high para-selectivities (82-97\%) were achieved although reactions of less active substrates were rather slow. Furthermore, the reaction worked for preparation of para-chlorotoluene and para-dichlorobenzene on 0.1 mole scale with no detrimental effects on yield or selectivity. ${ }^{142}$

In view of the relative lack of success in chlorination of toluene over zeolites other than the large pore zeolite HX, we felt that the transition state was taking up most of the space within the zeolite cavity and, therefore, it was by no means certain that disubstituted benzenes would react at all readily with tert-butyl hypochlorite over zeolite HX. Nevertheless, the system was applied to the selective chlorination of a range of disubstituted benzenes and most of the ones tried could eventually be 
chlorinated in high yield with moderate to excellent selectivities. Slightly deactivated ortho- and meta-chlorotoluenes gave predominantly chlorination para to one of the substituents, with a substantial preference for substitution para to chlorine. paraChlorotoluene was very selectively chlorinated ortho to the methyl group but the very low rate of the reaction makes it impractical for synthetic purposes. ${ }^{142}$ More activated ortho and meta-xylenes gave good selectivity for substitution para- to one of the existing methyl groups ( $\mathrm{ca} .90 \%$ at $20{ }^{\circ} \mathrm{C}$ ), but heating the reaction mixture to $40{ }^{\circ} \mathrm{C}$ led to the emergence of unwanted polychlorinated compounds. ${ }^{142}$ para-Xylene afforded $o$-chloro- $p$-xylene together with polychlorinated aromatics at $40{ }^{\circ} \mathrm{C}$. ortho-Chloroanisole was very selectively ( $\mathrm{ca}$. 100\%) chlorinated para to the methoxy moiety. ${ }^{142}$ In summary, therefore, the $\mathrm{Bu}^{t} \mathrm{OCl} /$ zeolite $\mathrm{HX} / \mathrm{MeCN}$ system provides an excellent general method for para-selective chlorination of a range of mono- and disubstituted benzenes of moderate activity. Furthermore, the $\mathrm{Bu}^{t} \mathrm{OH}$ can in principle be reconverted into $\mathrm{Bu}^{t} \mathrm{OCl}$, the zeolite can be recovered and the solvent for the reaction can be chosen to be relatively benign, so that the green credentials are good.

\subsection{Selective bromination of aromatic compounds}

Following our earlier work on chlorination reactions over silica, we investigated several systems involving active bromine-containing compounds in the presence of silica. A system involving $N$-bromosuccinimide (NBS) and silica proved useful for selective bromination of some relatively active substrates, including heterocyclic systems such as indoles, carbazoles, benzimidazoles and iminodibenzyls. ${ }^{143}$ Such systems were not of value for regioselective bromination of most simple benzenoid compounds, however. Therefore, we turned our attention to use of zeolite catalysts.

There have been a number of studies of zeolite catalysts in regioselective bromination of simple aromatic compounds, ${ }^{144-158}$ but in many cases only limited improvement in selectivity was shown. For example, early studies showed that bromination of halobenzenes with bromine could be catalysed over partially exchanged zeolite $\mathrm{Y}^{144}$ Para/ortho ratios were higher than for conventional procedures and the highest ratios were obtained in a solvent-free procedure.

Bromination of phenol with $\mathrm{KBr}$ in the presence of acetic acid and hydrogen peroxide at room temperature over CrZSM-5 for $5 \mathrm{~h}$ gave 58 and $25 \%$ yields, respectively, of 4-bromophenol and 2-bromophenol. ${ }^{148}$ No products were obtained 
when moderately active substrates such as toluene or deactivated substrates such as nitrobenzene and benzoic acid were used, even for a longer reaction time ( $24 \mathrm{~h})$.

Bromination of anisole with NBS in carbon tetrachloride over HZSM-5 under reflux conditions for $5 \mathrm{~h}$ gave bromoanisoles in $70 \%$ yield with a para/ortho ratio of $28,{ }^{149}$ but anisole is naturally substituted highly para-selectively and the reaction has not been tried for other simple substituted benzenes such as alkyl and halobenzenes.

Bromination of chlorobenzene with bromine in the presence of sulfuryl chloride over various zeolites gave 4-bromochlorobenzene in high selectivity when $\mathrm{CaY}$ was used as the catalyst, but the para-selectivity was not high for toluene. ${ }^{150}$ Bromination of toluene using bromine or NBS over $\mathrm{H} \beta$ gave a mixture of brominated toluenes in which the para/ortho ratio was 4-5.5, but under the conditions used the product from side-chain bromination was also significant. ${ }^{151}$ Sasson's group achieved significant improvement in selective bromination of toluene using bromine as the brominating agent, zeolite $\mathrm{NaY}$ as catalyst and an epoxide as a hydrogen bromide scavenger. Although the selectivity and rate of reaction diminished as the reaction proceeded, such procedures gave excellent para-selectivity at low yield. ${ }^{152-155}$

When we began to investigate the bromination of toluene, as one of the most testing and important of substrates, two possibilities seemed to offer significant potential: (i) use of $\mathrm{Bu}^{t} \mathrm{OBr}$ by analogy with our earlier chlorination reaction (see above); and (ii) gaining an understanding of the Sasson method, so that the high selectivity could be retained in a reaction that gave higher yields. We tested bromination of toluene (4) with tert-butyl hypobromite over several zeolites (Scheme 15) at $20{ }^{\circ} \mathrm{C}$ for one hour in a mixture of tetrachloromethane and diethyl ether as solvent. ${ }^{156}$ Some of the results obtained are recorded in Table 18.

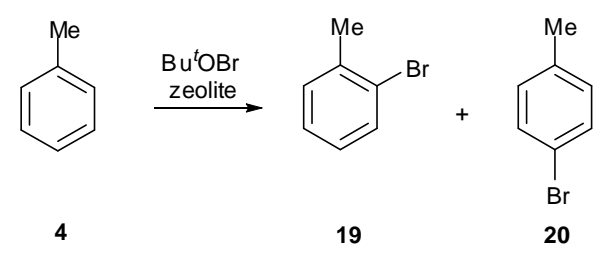

Scheme 15 Bromination of toluene (4) using tert-butyl hypobromite over zeolites 
Table 18 Bromination of toluene over various zeolites according to Scheme $15^{a}$

\begin{tabular}{llll}
\hline \multirow{2}{*}{ Zeolite } & Yield (\%) & \multicolumn{2}{c}{ Isomer proportions $(\%)$} \\
\cline { 3 - 4 } & & $\mathbf{1 9}$ & $\mathbf{2 0}$ \\
\hline $\mathrm{HNaX}$ & 49 & - & 100 \\
$\mathrm{HNaY}$ & 77 & 36 & 64 \\
$\mathrm{H}-$ Mordenite & 62 & 54 & 46 \\
$\mathrm{HZSM}-5$ & 4 & 30 & 70 \\
${ }^{a} \mathrm{~A}$ mixture of zeolite $(1.5 \mathrm{~g}), \mathrm{Bu}^{t} \mathrm{OBr}(2.6 \mathrm{mmol}), \mathbf{4}(2.5 \mathrm{mmol}), \mathrm{Et}_{2} \mathrm{O}(7.5 \mathrm{ml})$ and \\
$\mathrm{CCl}_{4}(2.5 \mathrm{ml})$ was stirred at $20^{\circ} \mathrm{C}$ for $1 \mathrm{~h} .^{.156}$ & \\
\hline
\end{tabular}

For the medium pore zeolite HZSM-5, the reaction was slow and the yield was very low (4\%), while the large pore zeolites H-mordenite and HY gave reasonable yields but in low para-selectivity. However, as in the case of chlorination reactions partially exchanged zeolite $\mathrm{X}(\mathrm{HNaX})$, which has large pores to allow reasonable diffusion but weakly acidic sites, turned out to be highly successful, giving almost exclusively 4-bromotoluene as product. Presumably, the catalyst was sufficiently mild to allow the shape-selective constraints of the zeolite pores to exert maximum effect. ${ }^{156}$ The low yield obtained over HNaX was probably because the rate of the reaction was slow enough to allow effective competition from destruction of the hypobromite in ether. Indeed, the yield could be improved by use of a solvent mixture containing a lower proportion of ether, but at the expense of reduced selectivity. Furthermore, when the reaction over zeolite HX was tried with less active substrates, destruction of the hypobromite seemed to become the principle reaction, so that the yields of products were very low (0-36\%). ${ }^{156}$ Consequently, although somewhat better yields could probably be achieved by use of excess reagent, it seemed unlikely that the reaction would be useful as a general method. Therefore, the para-selective bromination of toluene using bromine over various zeolites and in particular zeolite $\mathrm{NaY}$ (Scheme 16; X = Me), as used by Sasson, was investigated further. ${ }^{156,157}$

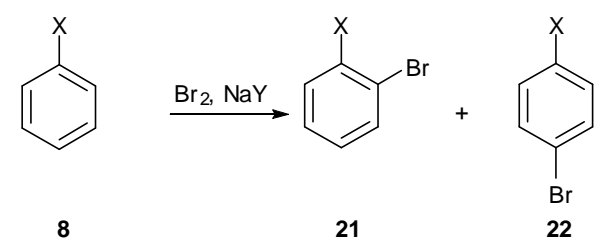

Scheme 16 Bromination of monosubstituted benzenes 8 using bromine over NaY 
It emerged that when $\mathrm{NaY}$ zeolite was used in larger quantity at room temperature para-bromotoluene was obtained in $98 \%$ yield with a paralortho ratio of around $100 .{ }^{156,157}$ This procedure represented the highest para-selectivity yet achieved in high yielding bromination reactions of toluene, and pure para-bromotoluene could be obtained by simple distillation. The scope of the reaction (Scheme 16) with a range of substituted benzenes $\mathbf{8}$ was explored. The results (Table 19) indicated that the reaction gave high yields and para-selectivities for a range of substituted benzenes of moderate activity, including alkyl and halogenobenzenes. ${ }^{156,157}$

Table 19 Bromination of simple aromatic compounds 8 according to Scheme $16^{a}$

\begin{tabular}{llll}
\hline $\mathrm{X}$ & \multicolumn{2}{l}{ Yield (\%) } & $\mathbf{2 2}$ \\
\cline { 2 - 4 } & $\mathbf{8}$ & $\mathbf{2 1}$ & 98 \\
\hline $\mathrm{Me}$ & - & 1 & 97 \\
$\mathrm{Et}$ & - & 1 & 98 \\
$\mathrm{Pr}^{i}$ & - & - & 97 \\
$\mathrm{Bu}^{t}$ & 2 & - & $92(93)^{b}$ \\
$\mathrm{~F}$ & $8(6)^{b}$ & $-(-)^{b}$ & $78(82)^{b}$ \\
$\mathrm{Cl}$ & $22(17)^{b}$ & $-(-)^{b}$ & $56(66)^{b}$ \\
$\mathrm{Br}$ & $44(34)^{b}$ & $-(-)^{b}$ & 93 \\
$\mathrm{OMe}$ & - & - & 9
\end{tabular}

${ }^{a}$ A mixture of zeolite $\mathrm{NaY}(0.55 \mathrm{~g}), 8(0.84 \mathrm{mmol}), \mathrm{Br}_{2}(0.93 \mathrm{mmol})$ and $\mathrm{CH}_{2} \mathrm{Cl}_{2}(8$ $\mathrm{ml})$ at $20^{\circ} \mathrm{C}$ for $5 \mathrm{~h} .{ }^{156,157 \mathrm{~b}}$ Figures in parentheses are for reactions with $\mathrm{NaY}(0.80 \mathrm{~g})$.

The selectivity was remarkable, almost exclusive formation of the para-isomer being achieved in all cases. In many prior studies of zeolite-induced aromatic bromination reactions ${ }^{144,152-155}$ selectivities at total conversion were significantly less, especially for toluene. Also, conventional wisdom suggested that space within the pores of zeolite $\mathrm{Y}$ was so abundant that there was little opportunity for significant shape-selectivity. It appeared that the reaction required the substrate, bromine, NaY and perhaps even solvent molecules all to be involved in the process. In this case, the space within the pores could become much more congested than might be envisaged on cursory consideration, and this might lead to the observed selectivity.

The need for a large amount of zeolite $\mathrm{NaY}$ and reduced selectivity during the later stages of reaction with less $\mathrm{NaY}$ correlate with the zeolite being a stoichiometric rather than catalytic reactant (Fig. 4). Fortunately, by heating the mixture of HY and $\mathrm{NaBr}$ produced, $\mathrm{HBr}$ can be driven off and $\mathrm{NaY}$ recovered for use again. Therefore, 
this is potentially a very useful approach for para-bromination of aromatic substrates. Furthermore, the $\mathrm{HBr}$ by-product is easily oxidised back to bromine using innocuous and cheap reagents, so that this is potentially also quite a green reaction.

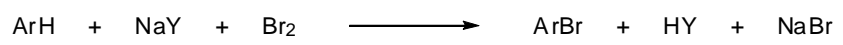

Fig. 4 Conversion of zeolite $\mathrm{NaY}$ to $\mathrm{HY}$ in bromination reaction of aromatics

\section{Regioselective alkylation of aromatic compounds}

Friedel-Crafts alkylation reactions of aromatic compounds suffer two major drawbacks additional to the usual problems of regioselectivity common to all electrophilic aromatic substitution reactions: (i) rearrangement of alkyl groups during reaction renders the incorporation of $n$-alkyl groups longer than ethyl virtually unknown; and (ii) the fact that the initial product is more reactive than the original substrate makes it difficult to control the reaction to get specifically mono- or di-alkyl compounds. Nevertheless, Friedel-crafts alkylation is still important in synthesis of various fine chemicals, pharmaceuticals, agrochemicals, dyes and polymers. ${ }^{159}$ In principle, zeolites could help with all of the problems.

\subsection{Attempts to prevent rearrangement of alkyl groups}

Given that the pores of any zeolite employed in a Friedel-crafts alkylation reaction would need to be large enough to accommodate a benzene ring, it is unlikely that they could be small enough to inhibit isomerization of intermediate cations (e.g. Fig. 5) by shape selectivity. However, the more stable allyl cation might survive long enough to react without rearrangement, and might be constrained by shape-selectivity to react preferentially at the terminal rather than the internal end of the allylic unit.

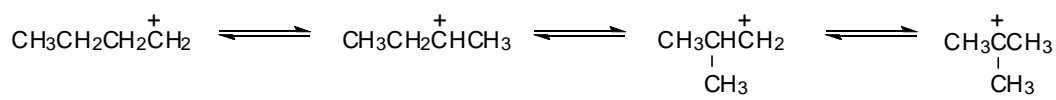

Fig. 5 Isomerization of butyl cations

Therefore, we undertook an investigation of the reaction of monosubstituted benzenes 8 (Scheme 17) with several allylic reagents in the presence of a range of solid catalysts, including zeolites, and observed our best results (very substantially mono-alkylation and almost exclusive attachment at the 1-position) with allylic 
alcohols as reagents and zeolite HY or K10 clay as catalyst. ${ }^{160}$ The reaction produced high yields of 23, of which para-isomers were the major ones. Since 23, obtained as $E$-isomers, are easily converted into $n$-alkylbenzenes by hydrogenation, this offers a possible approach to compounds that are important in the production of detergents.

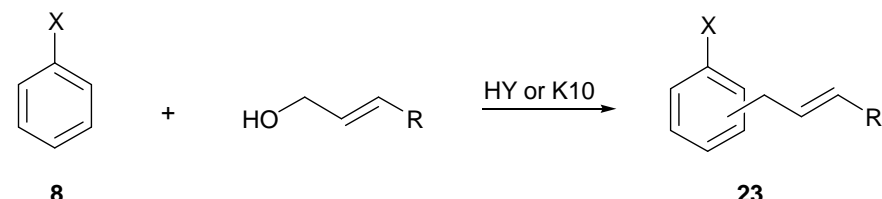

Scheme 17 Allylation of monosubstituted benzenes over HY or K10

\subsection{Attempts to control regioselectivity and polyalkylation for simple substituted benzenes}

The production of para-xylene is of enormous commercial importance since paraxylene is a precursor to terephthalic acid and its polymeric esters. Zeolites of the MFI/ZSM-5 type are used in the commercial production of para-xylene, and the process is often cited as a quintessential demonstration of shape-selectivity in action. The process involves alkylation (e.g. methylation of toluene to give xylenes and poymethylbenzenes), dealkylation (e.g. polymethylbenzenes giving xylenes) and isomerization (e.g. ortho- and meta-xylenes isomerising to para-xylene) and these competing processes, taking place at high temperature at the catalytic sites within the zeolite structure, conspire to produce a product mixture that is significantly richer in para-xylene than can be obtained with any traditional Lewis acid catalysed process. ${ }^{161}$ However, because of the commercial importance of the process, precise details of the underlying science are not easily accessible. Consequently, in this section we concentrate on the published academic studies for which details are known.

Regioselective alkylation of monosubstituted benzenes over solid catalysts has been widely investigated. ${ }^{162-193}$ However, in many cases limited improvement in yield or para-selectivity was achieved. For example, alkylation of phenols with alcohols and alkenes over zeolite catalysts has been reported in both vapour and liquid phases. ${ }^{162-175}$ However, the process produces mixtures of anisole (via $\mathrm{O}$-methylation) and cresols (via both $C$-methylation and isomerization of anisole). ${ }^{162-167}$

Methylation of toluene with methanol at $250^{\circ} \mathrm{C}$ under pressure over CMC-22 zeolite gave a mixture of xylenes in which the proportion of the $o / \mathrm{m} / \mathrm{p}$ isomers was 
$38 / 15 / 44$ after 5 minutes at $37 \%$ conversion. ${ }^{176}$ Some 1,2,3-trimethylbenzene ( $c a$. $3.5 \%$ ) was also obtained. Use of CMC-22 treated with collidine provided a greater proportion of para-xylene (isomer proportions were 6/12/74) with a better conversion $(50 \%) .{ }^{176}$ The authors believed that collidine selectively poisoned the external acid sites, and that the remaining internal acid sites were responsible for the selectivity.

para-Xylene has been produced selectively by methylation of toluene with aqueous methanol in the presence of hydrogen over zeolite ZSM-5 containing boron (ca. 6-9\% by weight), but at very low conversion $(5-8 \%) .{ }^{177}$ Also, under the conditions tried, the boron deposited on the reactor walls as the reaction proceeded. The authors believed that boron restricted pore openings to favour methylation at the para-position, rather than ortho- or meta-positions. Also, boron may have deactivated strong acid sites on the external surface and inhibited isomerization of para-xylene. Vapour-phase methylation of toluene with methanol over ZSM-5 zeolite modified with phosphoric acid (phosphorus content $c a .2 .1 \%$ by weight) produced para-xylene selectively at higher conversion $(43 \%)$, but at very high temperature $\left(425{ }^{\circ} \mathrm{C}\right) .{ }^{178}$

tert-Butylation of toluene (4) with tert-butyl alcohol over zeolite catalysts gives a mixture of mainly 3-tert-butyltoluene (24) and 4-tert-butyltoluene (25) along with other minor products (Scheme 18). ${ }^{179-184}$ 2-tert-Butyltoluene is obtained in only trace amounts as a result of the steric hindrance between the methyl and tert-butyl groups and the restrictions of space within the zeolite pores. Various factors influence the level of conversion and para-selectivity. For example, use of a tert-butyl alcohol:toluene molar ratio of $1: 8$, over $\mathrm{H}$-mordenite at $160^{\circ} \mathrm{C}$, gave a mixture of 24 and 25 in which the selectivity towards the para-isomer increased as the silica content of the catalyst increased $[\mathbf{2 5} / \mathbf{2 4}$ ratio 1.2 for $\mathrm{H}$-mordenite $(\mathrm{Si} / \mathrm{Al}=10)$ but 2.2 for H-mordenite $(\mathrm{Si} / \mathrm{Al}=45)] .{ }^{179}$

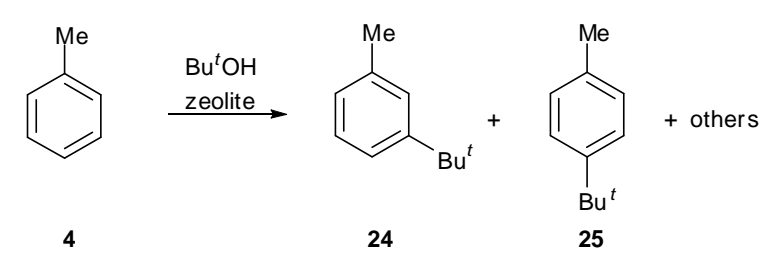

Scheme 18 tert-Butylation of toluene (4) with tert-butyl alcohol over zeolites

Vapour-phase tert-butylation of toluene (4) with a deficiency of tert-butyl alcohol in a flow system over several large-pore zeolites at $120-180{ }^{\circ} \mathrm{C}$ in some cases 
resulted in good selectivity for the para-isomer. ${ }^{180}$ Zeolite $\mathrm{HY}(\mathrm{Si} / \mathrm{Al}=40)$, which has strong acidity but relatively low acid site density, was found to be the most effective catalyst, providing substantial para-selectivity $\mathbf{( 2 5 / 2 4}$ ratio ca. 6 at a toluene conversion of $22 \%){ }^{180}$ The authors believed that higher reaction temperatures and high acid site density (low $\mathrm{Si} / \mathrm{Al}$ ratio) promoted isomerization of the para- to the meta-isomer, reducing the para-selectivity.

On use of excess tert-butyl alcohol under batch conditions at $180{ }^{\circ} \mathrm{C}$ toluene conversion increased with reaction time, but selectivity towards the para-isomer diminished and yields of side products increased. H-Mordenite was the most effective catalyst, giving $59 \%$ conversion after $8 \mathrm{~h}$ and a $\mathbf{2 5 / 2 4}$ ratio of 7:1 (Table 20). ${ }^{181}$ In further studies a somewhat higher conversion (66\%) was achieved after $8 \mathrm{~h}$, but the para-selectivity was similar. ${ }^{182}$ Treatment of H-Mordenite $(\mathrm{Si} / \mathrm{Al}=10.2)$ with sodium hydroxide and sodium aluminate also resulted in only modest conversion (33-52\%) and a relatively poor $\mathbf{2 5 / 2 4}$ ratio in the range of 3.2-4.0. ${ }^{183}$

Table 20 tert-Butylation of toluene (4) with tert-butyl alcohol over zeolites according to Scheme $18^{a}$

\begin{tabular}{|c|c|c|c|c|c|}
\hline \multirow[t]{2}{*}{ Zeolite (Si/Al) } & \multirow[t]{2}{*}{ Time (h) } & \multirow[t]{2}{*}{ Conversion $(\%)^{b}$} & \multicolumn{3}{|c|}{ Yields $(\%)^{b}$} \\
\hline & & & 24 & 25 & Others $^{c}$ \\
\hline H-Mordenite (10) & 1 & 22 & 2 & 19 & 0.4 \\
\hline H-Mordenite (10) & 4 & 44 & 5 & 38 & 1 \\
\hline H-Mordenite (10) & 8 & 54 & 7 & 45 & 2 \\
\hline H-Mordenite (17.5) & 1 & 17 & 2 & 15 & 0.6 \\
\hline H-Mordenite (17.5) & 4 & 42 & 5 & 36 & 1 \\
\hline H-Mordenite (17.5) & 8 & 59 & 7 & 50 & 2 \\
\hline HY (15) & 1 & 11 & 2 & 8 & 0.6 \\
\hline HY (15) & 4 & 20 & 4 & 15 & 1 \\
\hline HY (15) & 8 & 26 & 5 & 19 & 1 \\
\hline $\mathrm{H} \beta(12.5)$ & 1 & 21 & 4 & 17 & 0.4 \\
\hline $\mathrm{H} \beta(12.5)$ & 4 & 41 & 8 & 31 & 1 \\
\hline $\mathrm{H} \beta(12.5)$ & 8 & 51 & 12 & 37 & 2 \\
\hline \multicolumn{6}{|c|}{$\begin{array}{l}{ }^{a} \text { Reaction conditions: } \mathrm{Bu}^{t} \mathrm{OH}(40 \mathrm{mmol}) \text {; toluene }(20 \mathrm{mmol}) \text {; catalyst }(0.35 \mathrm{~g}) \text {; } \\
n \text {-decane solvent }(70 \mathrm{ml}) ; 180{ }^{\circ} \mathrm{C} \cdot{ }^{181}{ }^{b} \text { Numbers expressed as percentages have been } \\
\text { rounded to the whole number except for figure } \leq 1 .{ }^{c} \text { Mainly polyalkylated toluenes. }\end{array}$} \\
\hline
\end{tabular}

Alkylation of biphenyl over zeolites has received some attention, ${ }^{194-199}$ but in most cases selectivity for production of 4,4'-dialkylbiphenyl was not high and high 
temperatures were needed. However, high selectivity was observed in iso-propylation of biphenyl.when dealuminated H-mordenite ( $\mathrm{Si} / \mathrm{Al}$ ca. 1300) was used as catalyst. ${ }^{199}$

In conclusion, zeolites have undoubtedly improved both the regioselectivity and tendency to polyalkylation during alkylation of monosubstituted aromatics, but the reactions still suffer from low yields and/or relatively low selectivity for paraisomer production. In many cases meta-isomers are formed in high proportion. In some cases high para-selectivity can be achieved, but usually at low conversion.

\subsection{Regioselective dialkylation of naphthalene}

There is considerable interest in the use of zeolites to control alkylation of naphthalene, ${ }^{200-220}$ primarily as a result of the commercial importance of 2,6-dimethylnaphthalene, a precursor of naphthalene-2,6-dicarboxylic acid (NDA), which is needed for production of poly(ethylenenaphthalate; PEN). A convenient process for preparation of 2,6-dimethylnaphthalene would be selective dimethylation of naphthalene. Unfortunately, in addition to the usual problems of polyalkyaltion, the $\beta$-positions of naphthalene are less reactive than the $\alpha$-positions and there are 10 possible isomeric dimethylnaphthalenes, so simple double methylation of naphthalene is not easy to control to give the specific compound required. Mixtures are produced and require separation. ${ }^{221}$ Since the 2,6-disubstituted compounds are the most "linear" isomers, zeolites offer a possible way to favour such products.

Indeed, a degree of $\beta$-selectivity in dimethylation could be achieved over zeolite HZSM-5, whereas non-selective alkylation was seen over the larger pore H-mordenite and HY zeolites. ${ }^{22}$ However, even using HZSM-5 a poor yield of the 2,6-isomer was obtained and the ratio of 2,6/2,7 isomers was approximately 1 .

Since other 2,6-dialkylnaphthalenes can in principle also be oxidised to NDC, attempts to gain greater control have been extended to use of alternative alkylating agents. iso-Propylation of naphthalene with propene, ${ }^{223}$ isopropyl alcohol ${ }^{224-227}$ and isopropyl bromide ${ }^{228}$ has been studied using a variety of zeolites and $\beta, \beta$-selectivities of over $75 \%$, with a 2,6/2,7 ratio of approximately 2 , have been reported using $\mathrm{H}$ mordenite. ${ }^{229}$ The best iso-propylation procedure gave 2,6-di-isopropylnaphthalene in $54 \%$ yield with a 2,6/2,7 ratio of $4 .{ }^{229}$ The best reported cyclohexylation makes use of HY zeolite, and results in the corresponding 2,6-dicyclohexylnaphthalene in 19\% yield, with a 2,6/2,7 ratio of $1.2 .{ }^{230}$ The same authors also reported tert-butylation to 
give a 23\% yield of 2,6-di-tert-butylnaphthalene, with a 2,6/2,7 ratio of 5.9, with the added advantage of easy separation of the 2,6-isomer by crystallisation. ${ }^{231}$

In view of this tert-butylation result we decided to study the tert-butylation process in greater detail. Initially, we repeated the tert-butylation of naphthalene (26) in cyclohexane over zeolites under autoclave conditions similar to those reported by Moreau and co-workers. ${ }^{231}$ 2-tert-Butylnaphthalene (27), 2,6-di-tert-butynaphthalene (28) and 2,7-di-tert-butylnaphthalene (29) (Scheme 19) were produced as the major products (Table 21). ${ }^{232,233}$ The trends in results were consistent with those reported, ${ }^{231}$ where direct comparison was possible. The minor variations in absolute results could reflect use of a different autoclave with different dimensions, leading to different selfgenerated pressures, and differences in zeolite samples.

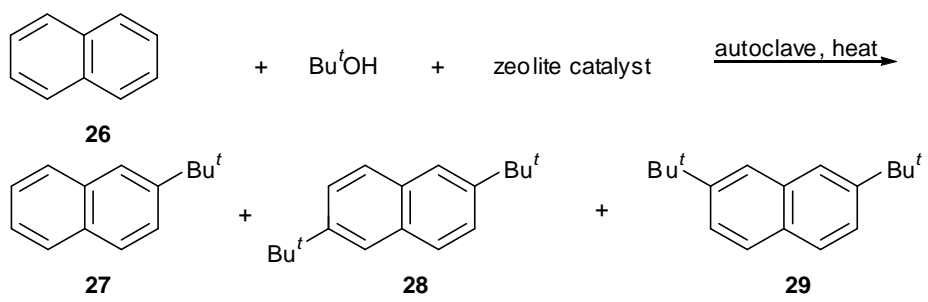

Scheme 19 tert-Butylation of naphthalene (26) over zeolites

Table 21 tert-Butylation of naphthalene (26) according to Scheme $19^{a}$

\begin{tabular}{|c|c|c|c|c|c|}
\hline \multirow[t]{2}{*}{ Zeolite (Si/Al) } & \multirow[t]{2}{*}{ Conversion $(\%)^{b}$} & \multicolumn{3}{|c|}{ Yields $(\%)^{b}$} & \multirow[t]{2}{*}{ 28/29 ratio $^{c}$} \\
\hline & & 27 & 28 & 29 & \\
\hline HY (15) & 89 & 39 & 33 & 12 & 2.7 \\
\hline HY (30) & 89 & 41 & 30 & 11 & 2.8 \\
\hline HY (40) & 87 & 41 & 28 & 10 & 2.9 \\
\hline $\mathrm{H} \beta(12.5)$ & 49 & 46 & 2 & 2 & 1.1 \\
\hline H-Mordenite (10) & 24 & 22 & 2 & - & - \\
\hline H-Mordenite (17.5) & 31 & 22 & 6 & 0.4 & 14.0 \\
\hline HZSM-5(25) & 0 & - & - & - & - \\
\hline
\end{tabular}

$\beta$-Substituted products were formed virtually exclusively, except over HZSM5 , where no reaction took place, presumably because the pores were too small to allow reaction to occur. Zeolite $\mathrm{HY}$ was the most active solid, while zeolite $\mathrm{H} \beta$ was less active and non-selective for production of $\mathbf{2 8}$ over $\mathbf{2 9}(\mathbf{2 8 / 2 9}$ ratio 1.1$) .{ }^{232,233}$ With $\mathrm{H}$-mordenite $(\mathrm{Si} / \mathrm{Al}=17.5)$, naphthalene conversion was $31 \%$ and a $6.4 \%$ yield of dialkyl products with a $\mathbf{2 8 / 2 9}$ ratio of 14 was observed. Interestingly, with 
$\mathrm{H}$-mordenite $(\mathrm{Si} / \mathrm{Al}=10)$ the only dialkyl isomer detected was $\mathbf{2 8}$, albeit that the yield was very low. ${ }^{232,233}$ Therefore, this zeolite was selected for further study.

Conversion into desirable product increased under more forcing conditions (increased reaction time and temperature) and by adding more zeolite and/or tert-butyl alcohol. Doubling the amount of $\mathrm{H}$-mordenite $(\mathrm{Si} / \mathrm{Al}=10)$ increased the conversion by $12 \%$ and the yield of di-tert-butylnaphthalenes by $4 \%$. Also, it was then possible to identify the 2,7-isomer 29 in the mixture and to calculate a $\mathbf{2 8 / 2 9}$ ratio of 17.3. ${ }^{232,233}$ Increasing the temperature to $200{ }^{\circ} \mathrm{C}$ increased both conversion and yield of $\mathbf{2 8}$, (Table 22), but selectivity for $\mathbf{2 8}$ over $\mathbf{2 9}$ reduced at the higher temperature. ${ }^{232,233}$

Table 22 tert-Butylation of naphthalene (26) according to Scheme 19 over $\mathrm{H}$-mordenite $(\mathrm{Si} / \mathrm{Al}=10)$ at various temperatures ${ }^{a}$

\begin{tabular}{|c|c|c|c|c|c|}
\hline \multirow[t]{2}{*}{$\mathrm{T}^{\circ} \mathrm{C}$} & \multirow[t]{2}{*}{ Conversion $(\%)^{b}$} & \multicolumn{3}{|c|}{ Yields $(\%)^{b}$} & \multirow[t]{2}{*}{$28 / 29$ ratio $^{c}$} \\
\hline & & 27 & 28 & 29 & \\
\hline 140 & 40 & 33 & 5 & 0.2 & 22.8 \\
\hline 160 & 43 & 34 & 8 & 0.5 & 16.4 \\
\hline 180 & 47 & 38 & 9 & 0.6 & 13.4 \\
\hline 200 & 52 & 41 & 10 & 1 & 9.5 \\
\hline 220 & 42 & 31 & 8 & 1 & 6.4 \\
\hline
\end{tabular}

Increasing the amount of tert-butyl alcohol to $80 \mathrm{mmol}$ increased conversion and the yield of $\mathbf{2 8}$, although yet more caused both to fall. Inerestingly, the $\mathbf{2 8 / 2 9}$ ratio increased with increasing tert-butyl alcohol without peaking (Table 23). ${ }^{232,233}$

Table 23 tert-Butylation of naphthalene (26) according to Scheme 19 over $\mathrm{H}$-mordenite $(\mathrm{Si} / \mathrm{Al}=10)$ using various quantities of tert-butyl alcohol $^{a}$

\begin{tabular}{|c|c|c|c|c|c|}
\hline \multirow{2}{*}{$\begin{array}{l}\mathrm{Bu}^{t} \mathrm{OH} \\
(\mathrm{mmol})\end{array}$} & \multirow[t]{2}{*}{ Conversion $(\%)^{b}$} & \multicolumn{3}{|c|}{ Yields $(\%)^{b}$} & \multirow[t]{2}{*}{ 28/29 ratio $^{c}$} \\
\hline & & 27 & 28 & 29 & \\
\hline 20 & 54 & 40 & 12 & 1 & 10.9 \\
\hline 40 & 56 & 40 & 16 & 0.5 & 33.9 \\
\hline 80 & 57 & 38 & 19 & 0.4 & 44.2 \\
\hline 160 & 50 & 37 & 12 & 0.2 & 75.6 \\
\hline 530 & 21 & 19 & 3 & - & - \\
\hline
\end{tabular}


The general trend on increasing the reaction time was an increase in the conversion and yield of $\mathbf{2 8}$, with little variation in the $\mathbf{2 8} / \mathbf{2 9}$ ratio. However, even after $24 \mathrm{~h}$ increases in yield and conversion were only modest. Therefore, in an attempt to push the reaction further the initial product was treated with fresh zeolite and reagent. After two successive $1 \mathrm{~h}$ autoclave reactions at $180{ }^{\circ} \mathrm{C}$ a high yield of 28 with high selectivity was achieved. After 2 stages over H-mordenite (17.5), a 60\% yield with a $\mathbf{2 8} / \mathbf{2 9}$ ratio of 50.6 was achieved. Approximately $85 \%$ of the $\mathbf{2 8}$ present in this mixture could be isolated in pure form simply by concentrating the reaction mixture, allowing the product to crystallise and then recrystallisation from ethanol. Separation of the remaining $15 \%$ could be achieved by reduced pressure kugelrohr distillation, providing almost $60 \%$ of pure 2,6-di-tert-butylnaphathalene in total. ${ }^{232,233}$

Although this method is easily the most selective yet discovered for production of a 2,6-dialkylnaphthalene, it may be difficult to oxidise the tert-butyl groups to carboxyl groups. Also, six carbon atoms would be lost during the process, which is wasteful. Therefore, there is still room for considerable improvement in the clean and selective synthesis of naphthalene-2,6-dicarboxylic acid. Consequently, we have looked briefly at other alkylation agents (Scheme 20). Cyclohexylation of naphthalene (26) with various cyclohexylating agents over zeolite catalysts was not particularly selective over $\mathrm{HY}$ and even less so over $\mathrm{H} \beta$, while $\mathrm{H}$-mordenite $(\mathrm{Si} / \mathrm{Al}=$ 10) and HZSM-5 did not give any reaction under the conditions tried. ${ }^{232}$ The results for several other alkylations over H-mordenite are shown in Table $24{ }^{232}$

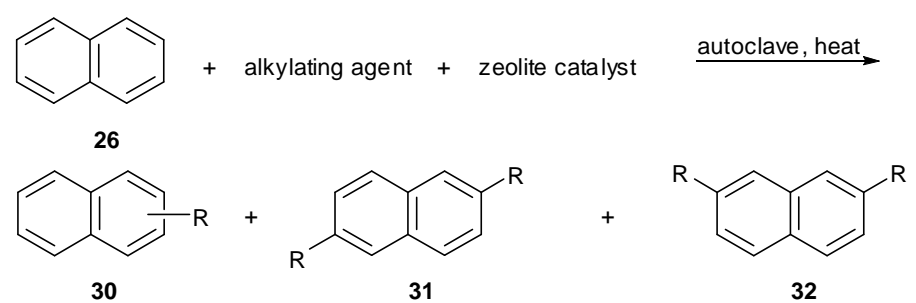

Scheme 20 Various alkylations of naphthalene over zeolites

With iso-propyl alcohol as reagent, modest naphthalene conversion and modest 31/32 ratio (2.2) was achieved, which is consistent with results obtained by others. ${ }^{223}$ Somewhat better results were obtained with 2-butanol (31\% conversion; 31/32 ratio of 3.3), but primary alcohols gave poor conversions and selectivities. ${ }^{232}$ 
Table 24 Alkylation of naphthalene (26) using various alkylating agents according to Scheme 20 over $\mathrm{H}$-mordenite $(\mathrm{Si} / \mathrm{Al}=10)^{a}$

\begin{tabular}{|c|c|c|c|c|c|c|}
\hline \multirow[t]{2}{*}{ Alkylating agent } & \multirow[t]{2}{*}{$\mathrm{R}$} & \multirow[t]{2}{*}{ Conversion $(\%)^{b}$} & \multicolumn{3}{|c|}{ Yields $(\%)^{b}$} & \multirow[t]{2}{*}{$31 / 32$ ratio $^{c}$} \\
\hline & & & 30 & 31 & 32 & \\
\hline iso-Propyl alcohol & $\operatorname{Pr}^{i}$ & 13 & 12 & 0.5 & 0.2 & 2.2 \\
\hline 1-Butanol & $\mathrm{Bu}^{n}$ & 3 & 2 & 0.1 & 0.1 & 1 \\
\hline iso-Butyl alcohol & $\mathrm{Bu}^{i}$ & 5 & 3 & 0.3 & 0.2 & 1.5 \\
\hline 2-Butanol & $\mathrm{Bu}^{s e c}$ & 31 & 24 & 4 & 1 & 3.3 \\
\hline \multicolumn{7}{|c|}{$\begin{array}{l}{ }^{a} 1 \mathrm{~h} \text { stirred autoclave reaction at } 180{ }^{\circ} \mathrm{C} ; \mathrm{H} \text {-mordenite }(\mathrm{Si} / \mathrm{Al}=10 ; 4 \mathrm{~g}) \text {, cyclohexane } \\
(10 \mathrm{ml}), \mathbf{2 6}(10 \mathrm{mmol}) \text {, alkylating agent }(10 \mathrm{mmol}){ }^{232}{ }^{b} \text { Figures rounded to the nearest } \\
\text { whole number, except for those } \leq 1 .{ }^{c} \text { Ratio calculated from pre-rounded yield figures. }\end{array}$} \\
\hline
\end{tabular}

\subsection{Regioselective alkylation of heteroaromatics}

The regioselective alkylation of nitrogen heterocycles such as pyrrole, indole and quinoline is of great interest since the alkylated derivatives are used as intermediates in the synthesis of antibiotics. ${ }^{234}$ Alkylation of various heterocycles with aldehydes, ${ }^{235}$ alcohols $^{236,237}$ and epoxides ${ }^{238}$ over zeolites have been reported. For example, alkylation of indole with methanol and 2-propanol over various types of zeolites at high temperature $\left(300{ }^{\circ} \mathrm{C}\right)$ gave the corresponding 3 -alkylindoles. ${ }^{236}$ However, the maximum yields obtained were $34-40 \%$, with 1-alkyl, dialkyl and polyalkyl indoles being the major by-products. Similarly, alkylation of quinoline with methanol and 2-propanol under similar reaction conditions gave the corresponding 2-alkylated quinolines in yields up to $40-55 \% .^{237} 4$-Alkyl, dialkyl and polyalkyl quinolines were the major by-products.

It has recently been reported that alkylation of various indoles $\mathbf{3 3}$ with styrene oxides over 3D mesoporous aluminosilicates in water at room temperature for a short time (1-2.5 h) gave the corresponding 3-substituted derivatives 34 in high yields (Scheme 21). ${ }^{238}$ However, under similar reaction conditions reactions of 5-nitro and 5-cyanoindoles with 4-chlorostyrene oxide gave low yields (10 and 18\%, respectively) even after a longer reaction time $(24 \mathrm{~h}) .{ }^{238}$ Reactions of pyrrole and $\mathrm{N}$-methylpyrrole with styrene oxide under similar reaction conditions gave mixtures of 2- and 3-substituted pyrroles in 80 and $73 \%$ yields, respectively, of which the 2-substituted derivatives were the major products (65 and 60\%, respectively, after 2.5 h). ${ }^{238}$ 


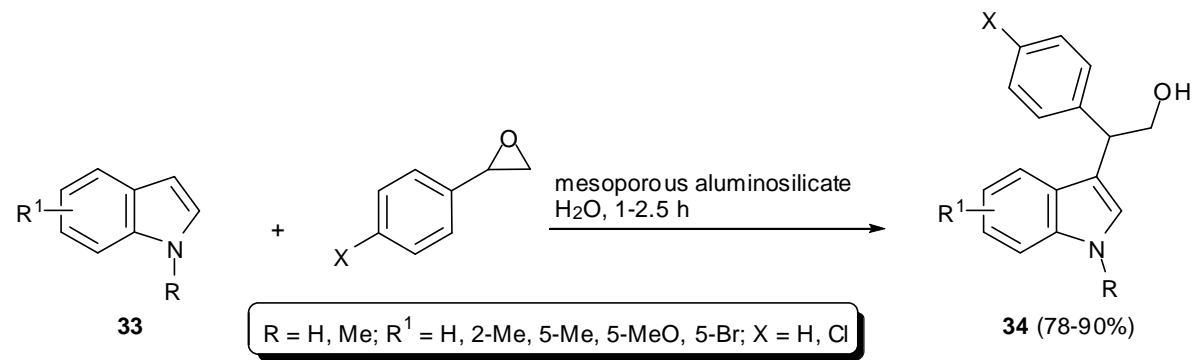

Scheme 21 Alkylation of indoles 33 with styrene oxides over 3D mesoporous aluminosilicates

\section{Regioselective acylation of aromatic compounds}

Acylation of aromatic compounds over zeolite catalysts to produce the corresponding para-acylated aromatics selectively has been extensively investigated. ${ }^{43,239-286}$ The early reports provided modest yields or mixtures of products and some involved use of solvents. ${ }^{239,240}$ However, substantial progress has been made and zeolite-catalysed acylation of aromatic ethers has been applied on a commercial scale. ${ }^{262-265}$

\subsection{Regioselective acylation of simple aromatics}

Zeolites have not yet provided a good solution for para-selective acylation of phenol. Indeed, acetylation of phenol (1) with various acetylating reagents over zeolites gives a mixture of products (Scheme 22) including phenyl acetate (35) by $O$-acetylation along with 2-hydroxyacetophenone (36) and 4-hydroxyacetophenone (37), which can be formed either by direct $C$-acetylation of the aromatic ring or via Fries rearrangement of 35. $C$-Acetylation is slower than $O$-acetylation and $\mathbf{3 6}$ generally predominates over 37. ${ }^{266-273}$ For example, acetylation of $\mathbf{1}$ with acetic anhydride (Scheme 22) over HZSM-5 zeolite gave a mixture of 35, $\mathbf{3 6}$ and $\mathbf{3 7}$ in yields of $c a .20$, 48 and $>1 \%$, respectively, at a phenol conversion of $72 \%{ }^{267}$

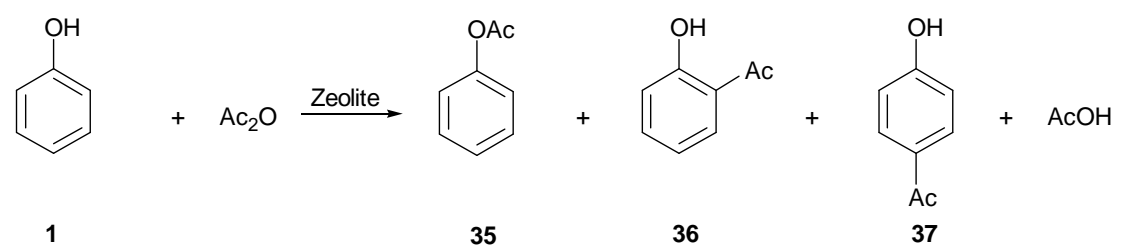

Scheme 22 Acetylation of phenol (1) with acetic anhydride over a zeolite

Reaction of phenol (1) with propanoyl chloride (1:propanoyl chloride ratio = 3) over various large pore zeolites gave mixtures in which phenyl propionate was the 
major product. $^{268}$ The most active zeolite for $C$-acylation was $\mathrm{H} \beta$, which also favoured 4-hydroxypropiophenone production ( $p / o=1.9$, compared to 0.9 for $\mathrm{AlCl}_{3}$ ).

Acylation of anisole (38, R = Me; Scheme 23) over zeolite catalysts has been reported by several groups. ${ }^{43,263-265,274-279}$ We found that acid anhydrides are much better reagents than the corresponding acids or acyl chlorides for such acylations, and that zeolite $\mathrm{H} \beta$ was the most active zeolite catalyst of those tried, followed by HY. ${ }^{43}$ For example, acetylation of anisole using acetic anhydride over $\mathrm{H} \beta(\mathrm{Si} / \mathrm{Al}=12.5)$ in the absence of solvent at $120{ }^{\circ} \mathrm{C}$ for $2 \mathrm{~h}$ gave exclusively para-methoxyacetophenone (38, $\mathrm{R}=\mathrm{R}^{\prime}=\mathrm{Me}$; Scheme 23) in $98 \%$ yield. ${ }^{43}$ The catalyst was recovered, regenerated and reused to give almost the same yield as that given by the fresh zeolite. ${ }^{43}$ The same process was investigated concurrently in industry and production of 4-acetylanisole using zeolite $\mathrm{H} \beta$ was introduced as a commercial process. ${ }^{263-265}$

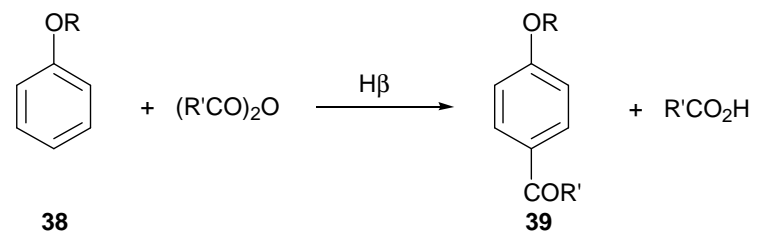

Scheme 23 Acylation of aromatic ethers $\mathbf{3 8}$ using anhydrides over zeolite $\mathrm{H} \beta$

We explored the reaction scope by varying the substrate (anisole, phenetole and diphenyl ether) and acid anhydride over zeolite $\mathrm{H} \beta(\mathrm{Si} / \mathrm{Al}=12.5) .{ }^{43}$ The yields of the para-acylated products $\mathbf{3 9}$ obtained are recorded in Table 25.

Table 25 Acylation of aromatic ethers 38 according to Scheme $23^{a}$

\begin{tabular}{llll}
\hline Acylating agent & $\mathrm{R}$ & $\mathrm{R}^{\prime}$ & Yield of 39 $(\%)$ \\
\hline $\mathrm{Ac}_{2} \mathrm{O}$ & $\mathrm{Me}$ & $\mathrm{Me}$ & 76 \\
$(\mathrm{EtCO})_{2} \mathrm{O}$ & $\mathrm{Me}$ & $\mathrm{Et}$ & 73 \\
$\left(\mathrm{Pr}^{i} \mathrm{CO}\right)_{2} \mathrm{O}$ & $\mathrm{Me}$ & $\mathrm{Pr}^{i}$ & 73 \\
$\left(\mathrm{Bu}{ }^{t} \mathrm{CO}\right)_{2} \mathrm{O}$ & $\mathrm{Me}$ & $\mathrm{Bu}^{t}$ & 10 \\
$\mathrm{Ac}_{2} \mathrm{O}$ & $\mathrm{Et}$ & $\mathrm{Me}$ & 77 \\
$(\mathrm{EtCO})_{2} \mathrm{O}$ & $\mathrm{Et}$ & $\mathrm{Et}$ & 74 \\
$\left(\mathrm{Pr}^{i} \mathrm{CO}\right)_{2} \mathrm{O}$ & $\mathrm{Et}$ & $\mathrm{Pr}^{i}$ & 75 \\
$\left(\mathrm{Bu}{ }^{t} \mathrm{CO}\right)_{2} \mathrm{O}$ & $\mathrm{Et}$ & $\mathrm{Bu}^{t}$ & 14 \\
$\mathrm{Ac}_{2} \mathrm{O}$ & $\mathrm{Ph}$ & $\mathrm{Me}^{2}$ & 52 \\
$(\mathrm{EtCO})_{2} \mathrm{O}$ & $\mathrm{Ph}$ & $\mathrm{Et}^{i}$ & 43 \\
$\left(\mathrm{Pr}^{i} \mathrm{CO}\right)_{2} \mathrm{O}$ & $\mathrm{Ph}$ & $\mathrm{Pr}^{i}$ & 27 \\
$\left(\mathrm{Bu}{ }^{t} \mathrm{CO}\right)_{2} \mathrm{O}$ & $\mathrm{Ph}$ & $\mathrm{Bu}^{t}$ & - \\
${ }^{a} \mathrm{~A} \mathrm{mixture}$ of $\mathrm{H} \beta$ & $(1.5-2.5 \mathrm{~g})$, acylating agent $(30-50$ mmol $)$ & and 38 (30-50 mmol) \\
\multicolumn{2}{l}{ was heated at $100{ }^{\circ} \mathrm{C}$ for $3 \mathrm{~h}^{43}$} & & \\
\hline
\end{tabular}


There was a general reduction in yield on going from acetic to successively more hindered anhydrides, and with increasing complexity of the ether. Consequently, the acylation of diphenyl ether with pivalic anhydride did not take place at all under the standard reaction conditions due to a combination of steric and electronic effects. ${ }^{43}$

2-Phenylbutanoylation of anisole [Scheme 23; R = Me; R' = EtCH(Ph)] over zeolite $\mathrm{H} \beta(\mathrm{Si} / \mathrm{Al}=12.5)$ or $\mathrm{HY}(\mathrm{Si} / \mathrm{Al}=40)$ was conducted with various acylating agents and some of the results are recorded in Table $26 .^{280}$

Table 26 Yield of $39\left[\mathrm{R}=\mathrm{Me} ; \mathrm{R}^{\prime}=\mathrm{EtCH}(\mathrm{Ph})\right]$ from acylation of anisole (38; $\mathrm{R}$ $=\mathrm{Me}$ ) according to Scheme 23 using various acylating reagents over zeolites ${ }^{a}$

\begin{tabular}{lllll}
\hline Acylating reagent & Zeolite $(\mathrm{Si} / \mathrm{Al})$ & Time $(\mathrm{h})$ & $\mathrm{T}\left({ }^{\circ} \mathrm{C}\right)$ & Yield of $39(\%)$ \\
\hline $\mathrm{PhCH}(\mathrm{Et}) \mathrm{COCl}$ & $\mathrm{H} \beta(12.5)$ & 5 & 85 & 43 \\
$\mathrm{PhCH}(\mathrm{Et}) \mathrm{COCl}$ & $\mathrm{HY}(40)$ & 5 & 85 & 40 \\
$\mathrm{PhCH}(\mathrm{Et}) \mathrm{CO}_{2} \mathrm{COCF}_{3}$ & $\mathrm{H} \beta(12.5)$ & 4 & Reflux & 96 \\
$\mathrm{PhCH}(\mathrm{Et}) \mathrm{CO}_{2} \mathrm{H}$ & $\mathrm{H} \beta(12.5)$ & 24 & 85 & - \\
$\mathrm{PhCH}(\mathrm{Et}) \mathrm{CO}_{2} \mathrm{COCH}(\mathrm{Et}) \mathrm{Ph}^{b}$ & $\mathrm{H} \beta(12.5)$ & 4 & 120 & 48 \\
${ }^{a} \mathrm{~A} \mathrm{mixture} \mathrm{of} \mathrm{zeolite}(0.5 \mathrm{~g})$, acylating reagent & $(12.0 \mathrm{mmol})$ and anisole $(1.01 \mathrm{~g}, 10.0$ \\
mmol) was heated for the stated time. ${ }^{280} b$ & Excess reagent $(20$ mmol) was used. \\
\hline
\end{tabular}

2-Phenylbutanoyl trifluoroacetate, formed in situ from 2-phenylbutanoic acid and trifluoroacetic anhydride, was more effective than the simple anhydride or acid chloride, giving $39\left[\mathrm{R}=\mathrm{Me}, \mathrm{R}^{\prime}=\mathrm{EtCH}(\mathrm{Ph})\right]$ in $96 \%$ yield after $4 \mathrm{~h}$ reflux over $\mathrm{H} \beta{ }^{280}$

Acetylation of substituted aryl ethers resulted in substitution almost exclusively para- to a substituent. ${ }^{281}$ For example, reaction of 3-methylanisole (40) with acetic anhydride at $120{ }^{\circ} \mathrm{C}$ over $\mathrm{H} \beta(\mathrm{Si} / \mathrm{Al}=12.5)$ or $\mathrm{HY}(\mathrm{Si} / \mathrm{Al}=40)$ led to mixtures of regioisomers 41 and 42 (Scheme 24), with 41 being obtained in a typical yield of $60-70 \%$ while $\mathbf{4 2}$ was never formed in greater than $25 \%$ yield. ${ }^{281}$

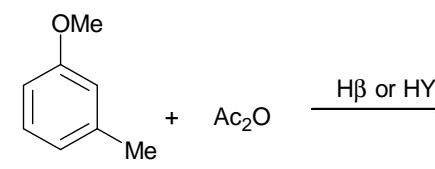

40

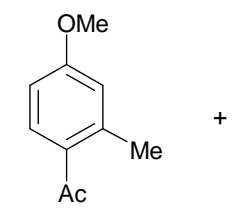

41

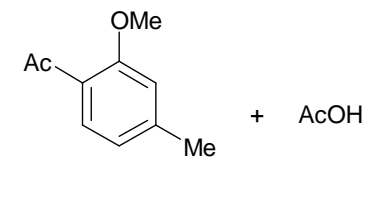

42

Scheme 24 Acetylation of 3-methylanisole (40) with acetic anhydride over zeolites

By contrast, acetylation of 2-substituted aryl ethers $\mathbf{4 3}$ gave almost exclusively products of substitution para- to the alkoxy group (44; Scheme 25) in high yields. ${ }^{281}$ 


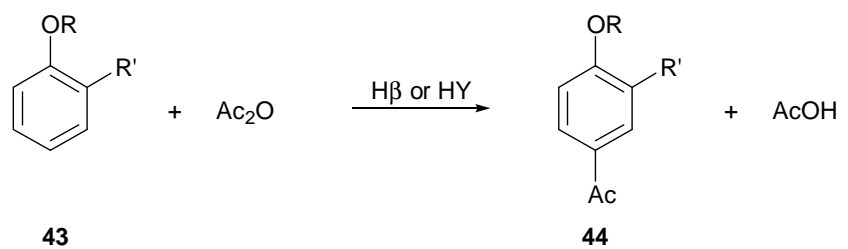

Scheme 25 Acetylation of 2-substituted aryl ethers 43 over zeolites

Regioselective acylation of 2,3-dihydrobenzofuran (45) with various acid anhydrides over H $\beta$ or HY gave the corresponding 5-acylated products 46 (Scheme 26) uncontaminated by their isomeric products (Table 27). ${ }^{280,281}$ Zeolite $\mathrm{H} \beta$ was not as effective as a catalyst for reactions involving more hindered anhydrides, but HY was somewhat more effective (40 and 57\%, respectively for $\mathrm{R}=\mathrm{Ph}$ and $\mathrm{Bu}^{t}$ after $4.5 \mathrm{~h}$ ). ${ }^{280}$

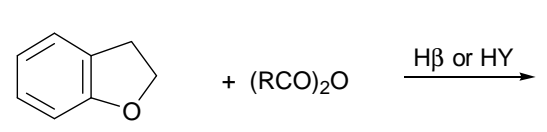

45

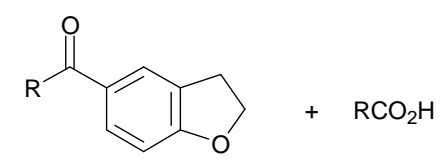

46

Scheme 26 Acylation of 2,3-dihydrobenzofuran (45) over zeolites

Table 27 Acylation of 2,3-dihydrobenzofuran (45) according to Scheme $26^{a}$

\begin{tabular}{llll}
\hline Zeolite $(\mathrm{Si} / \mathrm{Al})$ & $\mathrm{R}$ & $\mathrm{t}(\mathrm{h})$ & Yield of $\mathbf{4 6}(\%)$ \\
\hline $\mathrm{H} \beta(12.5)$ & $\mathrm{Me}$ & 1.5 & 95 \\
$\mathrm{H} \beta(12.5)$ & $\mathrm{Et}$ & 1.5 & 90 \\
$\mathrm{H} \beta(12.5)$ & $\mathrm{Pr}^{i}$ & 1.5 & 70 \\
$\mathrm{H} \beta(12.5)$ & $\mathrm{Bu}^{t}$ & 4.5 & 29 \\
$\mathrm{HY}(40)$ & $\mathrm{Bu}^{t}$ & 4.5 & 57 \\
$\mathrm{H} \beta(12.5)$ & $\mathrm{Ph}$ & 1.5 & 26 \\
$\mathrm{H} \beta(12.5)$ & $\mathrm{Ph}$ & 4.5 & 29 \\
$\mathrm{HY}(40)$ & $\mathrm{Ph}$ & 4.5 & 40 \\
$\mathrm{H} \beta(12.5)$ & $\mathrm{ClCH}$ & 8 \\
${ }^{a} \mathrm{~A}$ mixture of zeolite $(0.5 \mathrm{~g}),(\mathrm{RCO})_{2} \mathrm{O}(12 \mathrm{mmol})$ and $\mathbf{4 5}(10 \mathrm{mmol})$ at $120{ }^{\circ} \mathrm{C}$ for \\
\multicolumn{2}{l}{ the indicated reaction time. }
\end{tabular}

Ethyl (2,3-dihydrobenzofuran-5-yl)glyoxylate (47; Scheme 27) is a useful pharmaceutical intermediate that can be produced in $88 \%$ yield by Friedel-Crafts acylation of 45 with ethyl oxalyl chloride in the presence of $\mathrm{AlCl}_{3}$. We investigated the possibility of catalysing the reaction with large pore zeolites (Scheme 27), but a reasonable yield $(73 \%)$ could be obtained only by conducting the reaction in ethyl oxalyl chloride as solvent at high temperature for $168 \mathrm{~h}$ in the presence of a large 
quantity of $H \beta{ }^{280}$ Such conditions are not attractive for commercial application. A major problem was formation of by-products from further reactions of $47 .^{280}$

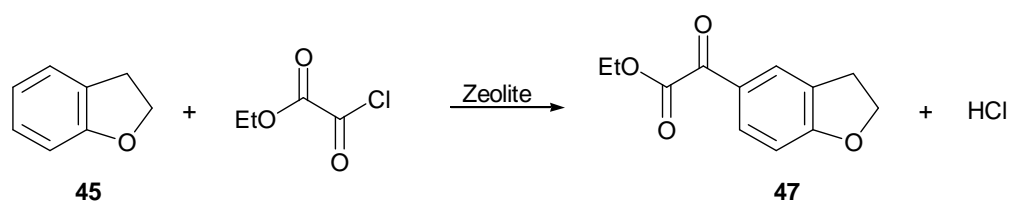

Scheme 27 Reaction of 2,3-dihydrobenzofuran (45) with ethyl oxalyl chloride

Several reports have documented acylation of toluene (4) with acid anhydrides and acid chlorides over zeolite catalysts. ${ }^{282-286}$ For example, vapour phase acylation of 4 with various acylating reagents over zeolite HZSM-5 gave a mixture of 2-methylacetophenone (48, Scheme 28) and 4-methylacetophenone (49) (Table 28). ${ }^{284}$

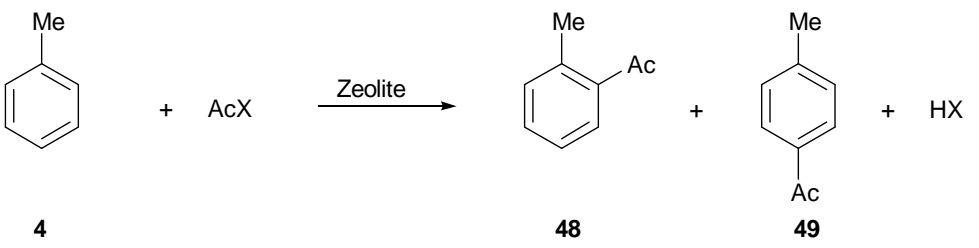

Scheme 28 Acetylation of toluene (4) with various acylating reagents over zeolites

Table 28 Acetylation of toluene (4) over zeolites according to Scheme $28^{a}$

\begin{tabular}{|c|c|c|c|c|c|c|}
\hline \multirow[t]{2}{*}{ AcX } & \multirow{2}{*}{$\begin{array}{l}\text { Zeolite } \\
(\mathrm{Si} / \mathrm{Al}=20.5)\end{array}$} & \multirow[t]{2}{*}{ Conversion $^{b}$} & \multicolumn{3}{|c|}{ Isomers proportions $(\%)$} & \multirow[t]{2}{*}{$49 / 48$ ratio } \\
\hline & & & 48 & 49 & Others $^{c}$ & \\
\hline $\mathrm{AcCl}$ & HZSM-5 & 60 & 9.0 & 88.3 & 2.7 & 9.8 \\
\hline $\mathrm{Ac}_{2} \mathrm{O}$ & HZSM-5 & 19 & 10.3 & 86.5 & 3.2 & 8.4 \\
\hline $\mathrm{AcOH}$ & HZSM-5 & 11 & 13.2 & 78.5 & 8.5 & 5.9 \\
\hline $\mathrm{AcCl}$ & $\mathrm{HNa}(28.9) Z \mathrm{ZM}-5^{d}$ & 42 & 6.0 & 92.0 & 2.0 & 15.3 \\
\hline $\mathrm{AcCl}$ & $\mathrm{HNa}(26.5) \mathrm{ZSM}-5^{d}$ & 27 & 5.8 & 93.4 & 0.8 & 16.1 \\
\hline $\mathrm{AcCl}$ & $\mathrm{HNa}(37.3) \mathrm{ZSM}-5^{d}$ & 18 & 6.0 & 91.9 & 2.1 & 15.3 \\
\hline \multicolumn{7}{|c|}{$\begin{array}{l}{ }^{a} \text { Catalyst }(2 \mathrm{~g}) ; 4 / \mathrm{AcX} \text { molar ratio }=2 \text {; feed rate }=2 \mathrm{ml} / \mathrm{h} ; 180{ }^{\circ} \mathrm{C} \cdot{ }^{284 b} \text { Conversion of } \\
\text { acetylating reagent, rounded to the nearest whole number. }{ }^{c} \text { Diacetylated products. } \\
{ }^{d} \text { Values in parenthesis represent the degree of Na-exchange }(\%) \text { in H-ZSM- } 5 \text {. }\end{array}$} \\
\hline
\end{tabular}

Acetyl chloride was better in terms of its conversion $(60 \%)$ than acetic anhydride $(19 \%)$ or acetic acid $(11 \%)$ and also in terms of para-selectivity. ${ }^{284}$ Zeolite HZSM-5 that had been partially exchanged with sodium cations gave even better para-selectivity, but in lower conversion. Conversion of acetyl chloride increased 
with reaction temperature and toluene to acetyl chloride molar ratio, while it decreased with increasing time on stream as the zeolite was deactivated.

Highly selective production of $\mathbf{4 9}$, with less than $2 \%$ of the ortho- and metaisomers, can be achieved over zeolite $\mathrm{H} \beta$ at a $4 / \mathrm{Ac}_{2} \mathrm{O}$ ratio of $20,{ }^{285}$ but although yield increased with increasing time on stream, catalyst deactivation became a problem.

Acetylation of toluene with linear, branched and aromatic anhydrides and chlorides of different chain lengths over zeolite $\mathrm{H} \beta$ gave higher conversion of the acylating reagent with increasing chain length of the reagent up to hexanoic derivatives and then became almost constant. ${ }^{286}$ The selectivity towards para-isomer also increased with increasing chain length of the anhydride.

\subsection{Regioselective acylation of naphthalene and 2-methoxynaphthalene}

Acylation of naphthalene with acetic anhydride and benzoyl chloride has been investigated in the presence of several zeolites. ${ }^{287,288}$ Zeolite $\mathrm{H} \beta$ was found to be an effective catalyst and 2-substituted naphthalenes were formed in greater proportions than with use of $\mathrm{AlCl}_{3}$, which afforded the 1-susbstituted derivatives preferentially.

Acylation of 2-methoxynapthalene (50) with acid anhydrides over different zeolites has been extensively studied since 2-acetyl-6-methoxynapthalene (52, Scheme 29) is a precursor for the anti-inflammatory drug Naproxen. ${ }^{289}$ Acetylation of 50 traditionally takes place at the kinetically controlled 1-position to produce 1-acetyl2-methoxynaphthalene (51). However, in the presence of zeolites different product distributions were obtained, depending on the zeolite and reaction conditions. ${ }^{290-299}$

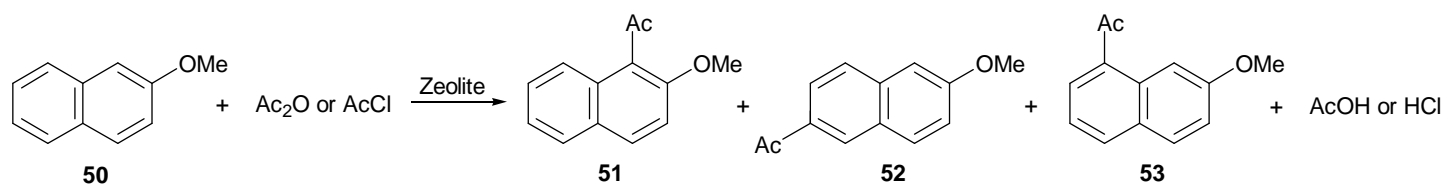

Scheme 29 Acetylation of 2-methoxynapthalene (50) over zeolites

For example, acetylation of $\mathbf{5 0}$ with acetic anhydride over zeolite $\mathrm{H} \beta$ initially gave predominantly 51. ${ }^{293-296}$ However, as reaction proceeded $\mathbf{5 1}$ was isomerised to mainly 52, with some 53. Disappearance of $\mathbf{5 1}$ was fast at high temperature and $\mathbf{5 2}$ was obtained in $80 \%$ yield at $\geq 170{ }^{\circ} \mathrm{C}$ in nitrobenzene. ${ }^{296}$ Acylation of $\mathbf{5 0}$ with various anhydrides over zeolite in polar solvents has been applied industrially. ${ }^{297}$ 
Acetylation of $\mathbf{5 0}$ with acetyl chloride (Scheme 29) at a $\mathbf{5 0 / A c C l}$ ratio of 1 , over zeolites H $\beta$, HY and H-mordenite in sulfolane, gave conversions around 30-40\% and selectivity for formation of $\mathbf{5 2}$ around $70-80 \%$ at $100-150{ }^{\circ} \mathrm{C}$ for all zeolites. ${ }^{298}$

\subsection{Regioselective acylation of heteroaromatics}

The regioselective Friedel-Crafts acylation of heterocycles is of great importance since the corresponding ketones represent useful intermediates for the production of a number of biologically active compounds and fine chemicals. ${ }^{299}$ Acylation of various heterocycles with acid anhydrides or chlorides over zeolites has been reported. ${ }^{300-306}$ For example, acetylation of furan and pyrrole (54, X=O, NH; Scheme 30) with acetic anhydride over various HZSM-5 zeolites produced the corresponding 2-acetyl derivatives 55. ${ }^{302}$ The maximum yield of 2 -acetylfuran was $63 \%$ at $150{ }^{\circ} \mathrm{C}$ over HZSM-5 $(\mathrm{Si} / \mathrm{Al}=30)$, whereas the maximum yield of 2 -acetylpyrrole was $59 \%$ at $250{ }^{\circ} \mathrm{C}$ over HZSM-5 $(\mathrm{Si} / \mathrm{Al}=280) .{ }^{302}$ No 3 -acetyl or diacetyl derivatives were identified under the conditions tried.

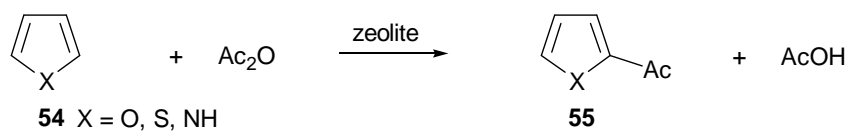

Scheme 30 Acetylation of heteroaromatics 54 over zeolites

Acetylation of heteroaromatics $\mathbf{5 4}(\mathrm{X}=\mathrm{O}, \mathrm{S}, \mathrm{NH})$ over over various forms of zeolite $\beta$ with acetic anhydride ( 2 equivalents in 1,2 -dichloroethane at $25-80^{\circ} \mathrm{C}$ ) was reported to give the corresponding 2-acetyl derivatives $\mathbf{5 5}$ as the major products, along with 3-acetyl and 2,5-diacetyl derivatives as the main by-products. ${ }^{303}$ Conversions were in the range of $26-91 \%$, while selectivity towards the 2-acetyl derivative was 58-100\%. A more recent report suggests that furan and thiophene are acetylated highly selectively over zeolite $\mathrm{H} \beta$ with acetic anhydride (4-5 equivalents without added solvent at $60{ }^{\circ} \mathrm{C}$ for 1-2 h), giving the 2-acetylated derivatives in 91 and $97 \%$ yields, respectively, while acetylation of pyrrole was less regioselective to give a mixture of 2-acetyl and 3-acetylpyrroles in 72 and $17 \%$ yields, respectively, after $7 \mathrm{~h}^{304}$

Acetylation of indole (56; Scheme 31) was slower and gave 3-acetylindole (57) in $35 \%$ yield after $7 \mathrm{~h}^{304}$ By contrast, acetylation of benzofuran and 
benzothiophene $(\mathbf{5 8}, \mathrm{X}=\mathrm{O}, \mathrm{S})$ with acetic anhydride over zeolite $\beta$ at $130{ }^{\circ} \mathrm{C}$ for $6 \mathrm{~h}$ gave the corresponding 2-acetyl derivatives 59 selectively (Scheme 32) but with low conversions (20 and $30 \%$, respectively). ${ }^{303}$

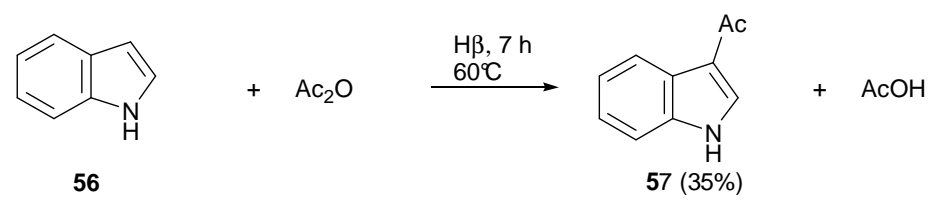

Scheme 31 Acetylation of indole over zeolite $\beta$

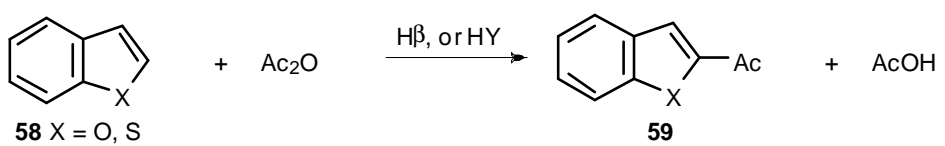

Scheme 32 Acetylation of benzofuran and benzothiophene over zeolite $\beta$ or Y

Use of zeolite $\mathrm{Y}(\mathrm{Si} / \mathrm{Al}=15)$ at $60^{\circ} \mathrm{C}$ as catalyst for acetylation of benzofuran gave 2-acetylbenzofuran in better yield $(43 \%) .{ }^{305,306}$ Diacetylated and triacetylated benzofurans were produced as by-products. Acetylation of 2-methylbenzofuran (60) under similar conditions gave 3-acetyl-2-methylbenzofuran (61) in 95\% yield (Scheme 33). ${ }^{305,306}$

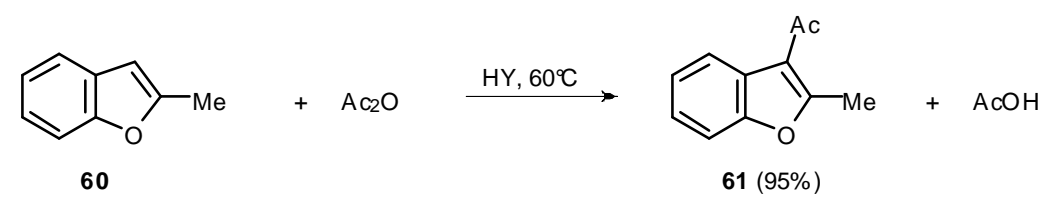

Scheme 33 Acetylation of 2-methylbenzofuran over zeolite Y

\section{Regioselective methanesulfonylation and related aromatic substitutions}

Direct sulfonylation of aromatic compounds is one of the most important methods for the synthesis of sulfones. ${ }^{307,308}$ However, relatively little detailed attention has been paid to this reaction. ${ }^{309-312}$ In order to allow the reaction to proceed at a satisfactory rate, an activator such as $\mathrm{AlCl}_{3}$ is usually needed, but $\mathrm{AlCl}_{3}$ forms a 1:1 complex with the product and therefore has to be used in more than stoichiometric amount. ${ }^{307}$ Use of methanesulfonyl chloride as reagent affords methyl tolyl sulfones in only 52\% yield with an ortho/metalpara isomer distribution of 53/14/33. ${ }^{310}$ Furthermore, the $\mathrm{AlCl}_{3}$ cannot be recovered, creating an effluent problem. Several non-zeolitic systems have 
been developed for catalysing such sulfonylation reactions, including use of $\mathrm{Fe}(\mathrm{III})-$ exchanged montmorillonite clay, ${ }^{313,314} \mathrm{Bi}(\mathrm{III})$ triflate, ${ }^{315}$ triflic acid (TfOH)-Bi(III) halide $^{316}$ and certain metal salts under microwave irradiation. ${ }^{317-319}$

Methanesulfonylation of toluene with methanesulfonyl chloride over zeolite $\mathrm{H} \beta$ was reported in a patent to give a mixture of methyl tolyl sulfones in which the proportion of the para-isomer was $81 \% .{ }^{320}$ However, in the most favourable case the yield was only $14 \%$. We therefore undertook a detailed study of methanesulfonylation of toluene (4) with methanesulfonic anhydride over zeolite catalysts, which gave methyl $o$-tolyl sulfone (62), methyl $m$-tolyl sulfone (63) and methyl $p$-tolyl sulfone (64; Scheme 34). Some of the results obtained are recorded in Table 29. ${ }^{321,322}$

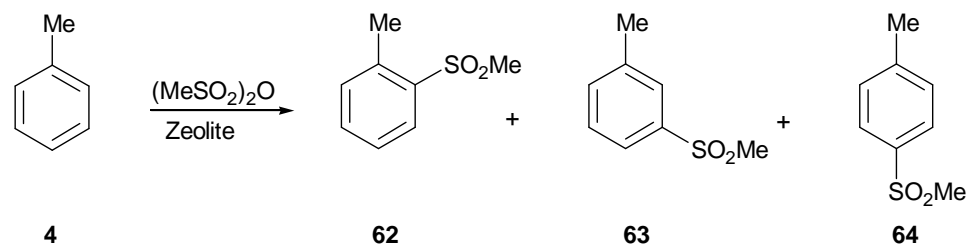

Scheme 34 Methansulfonylation of toluene (4) over zeolites

Table 29 Methanesulfonylation of toluene (4) with methanesulfonic anhydride over various zeolites according to Scheme $34^{a}$

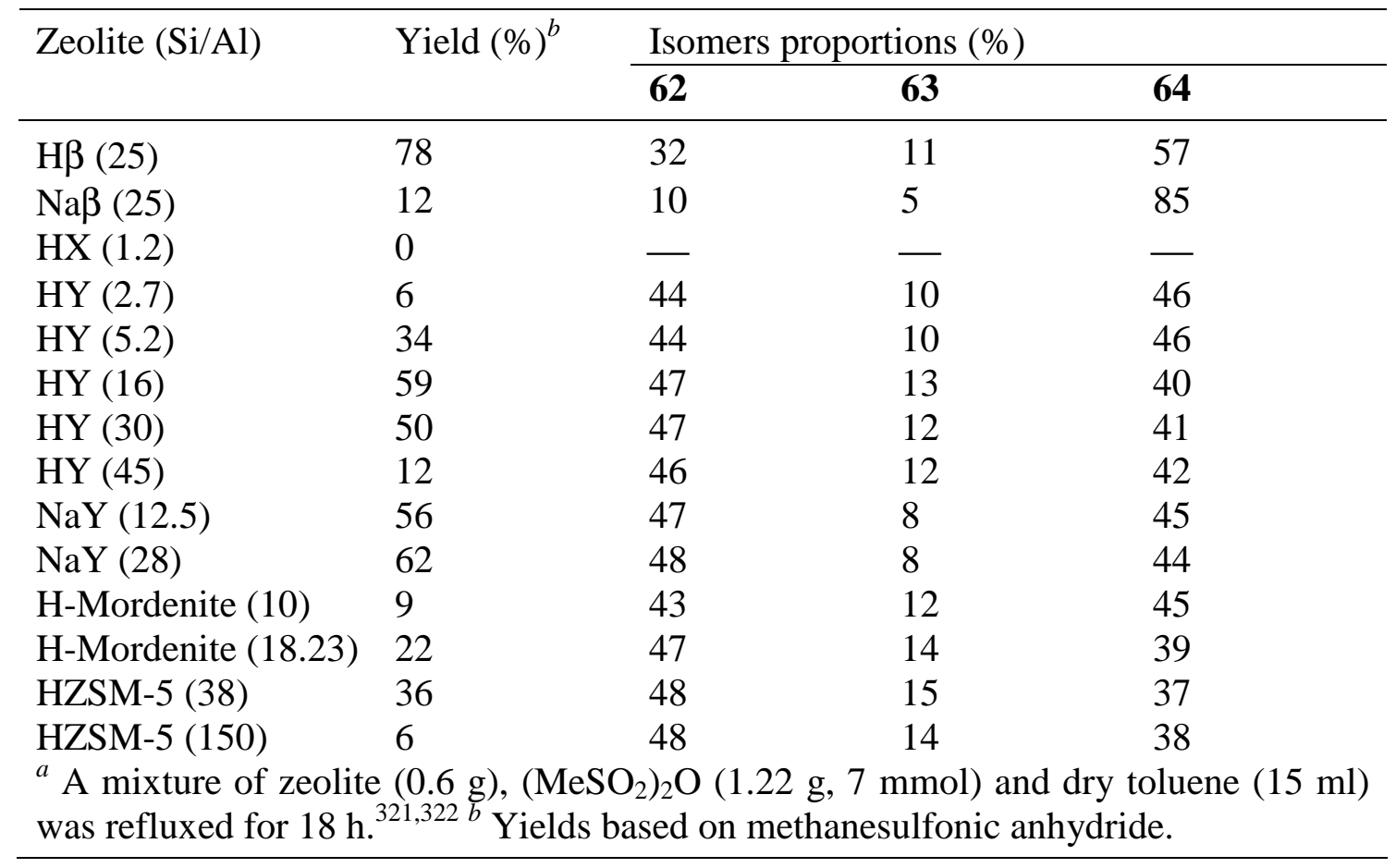

The results indicated that H-mordenite and HZSM-5 are not good catalysts for para-selective methanesulfonylation of toluene (4). The poor yields (9-22\%) obtained 
on use of H-mordenite may be due to the limited one-dimensional entry to the pores of this solid, which causes statistical disadvantage in comparison to a catalyst with three-dimensional entry. The poor yields and low para-selectivity with HZSM-5 may be because reaction does not take place within the restricted pores of the catalyst, but takes place primarily at external sites. ${ }^{322}$ Zeolite HX gave no reaction, presumably because its acidic sites are not strong enough to catalyse the reaction. By contrast, significant yields (34-59\%) of sulfones 62-64 could be achieved with more acidic HY samples having $\mathrm{Si} / \mathrm{Al}$ ratios in the range 5-30, but for samples having higher ratios, and therefore fewer acid sites, the yields decreased again. Samples of NaY gave results similar to those of the corresponding HY samples. Zeolite H $\beta$ was the most active zeolite tried, giving a 78\% yield of sulfones 62-64 with an isomer distribution of 32/11/57..$^{321,322}$ Zeolite Naß produced methanesulfonylated products 62-64 in only a low yield (12\%), but with high para-selectivity $(62 / 63 / 64=10 / 5 / 85)$.

In view of the interesting results with $\mathrm{H} \beta$ and $\mathrm{Na} \beta$, reactions over various cation-exchanged forms of zeolite $\beta$ (obtained by refluxing the corresponding metal salts with $\mathrm{H} \beta$ ) were studied (Table 30). ${ }^{321,322}$

Table $30 \quad$ Methanesulfonylation of toluene (4) over various cation-exchanged zeolites of type $\beta$ according to Scheme $34^{a}$

\begin{tabular}{lll}
\hline Zeolite $(\mathrm{Si} / \mathrm{Al}=25)$ & Overall Yield $(\%)^{b}$ of $\mathbf{6 2 - 6 4}$ & Proportion $(\%)$ of $\mathbf{6 4}$ \\
\hline $\mathrm{H} \beta$ & 78 & 57 \\
$\mathrm{Li}^{+} \beta$ & 51 & 55 \\
$\mathrm{Na}^{+} \beta$ & 18 & 95 \\
$\mathrm{~K}^{+} \beta$ & 12 & 53 \\
$\mathrm{Rb}^{+} \beta$ & 3 & 79 \\
$\mathrm{Cs}^{+} \beta$ & 1 & 67 \\
$\mathrm{Be}^{2+} \beta$ & 52 & 67 \\
$\mathrm{Mg}^{2+} \beta$ & 69 & 43 \\
$\mathrm{Ca}^{2+} \beta$ & 62 & 61 \\
$\mathrm{Sr}^{2+} \beta$ & 33 & 62 \\
$\mathrm{Ba}^{2+} \beta$ & 50 & 71 \\
$\mathrm{Ce}^{3+} \beta$ & 68 & 50 \\
$\mathrm{Cr}^{3+} \beta$ & 73 & 50 \\
$\mathrm{Fe}^{3+} \beta$ & 46 & 54 \\
$\mathrm{Co}^{2+} \beta$ & 77 & 55 \\
$\mathrm{Cu}^{2+} \beta$ & 65 & 55 \\
$\mathrm{Hg}^{2+} \beta$ & 28 & 77 \\
$\mathrm{~A}$ mixture of zeolite $(1 \mathrm{~g}),\left(\text { MeSO }_{2}\right)_{2} \mathrm{O}(1.22$ g, 7 mmol) and dry toluene $(15 \mathrm{ml})$ \\
${\text { was refluxed } 18 \mathrm{~h}^{321,322} b}^{\text {Yields based on methanesulfonic anhydride. }}$ \\
\hline
\end{tabular}


It was found that within Group 1 the yields decreased down the group as the cations became larger. The larger cations presumably block entry to the pore system of the zeolite, spoiling its potential as a catalyst. However, the restriction of the pore size might also be expected to lead to an increase in para-selectivity, which is apparent with sodium but tails off thereafter. With the larger cations it may be that a substantial proportion of the product arises from reaction at the external surface, thereby reducing the regioselectivity and also limiting the yield because of the relatively small number of available sites. ${ }^{321,322}$

For Group 2 the yields were generally higher than their Group 1 counterparts. Presumably the smaller divalent cations allow easier entry into the pore network, which would be consistent with the increased yields. There was also a general increase in para-selectivity going down the group as the cations became larger, but again at the expense of overall yield. $\mathrm{Be}^{2+} \beta$ appears to be an exception, giving a lower yield and higher selectivity than its $\mathrm{Mg}^{2+} \beta$ analogue. ${ }^{321,322}$

Most trivalent cations, as well as divalent cations of the first transition series, produced reasonable yields (typically 60-70\%) and para-product proportions in the range of $40-50 \%$. This is consistent with the idea that small cations allow more space for reaction and it is clear that overall there is a broad correlation between cation size and both yield and selectivity. ${ }^{321,322}$ Unfortunately, there is a trade-off between the two, with those cases providing highest para-selectivity also giving rather poor yields.

The process was also applied to several mono-substituted benzenes $\mathbf{8}$ over H $\beta$ or Naß zeolite (Scheme 35). Yields of $\mathbf{6 5 - 6 7}$ and selectivity are given in Table $31 .^{322}$

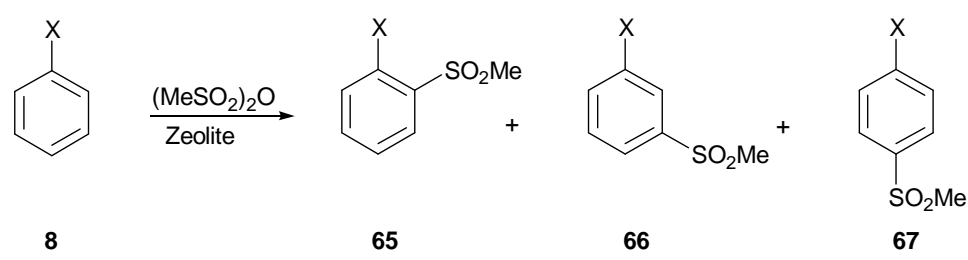

Scheme 35 Methanesulfonylation of compounds 8 over zeolites $\mathrm{H} \beta$ and $\mathrm{Na} \beta$

The results indicated that in all cases the proton-exchanged zeolite $\beta$ was considerably more active than $\mathrm{Na} \beta$. Anisole was the only substrate that afforded a reasonable yield $(43 \%)$ of the corresponding sulfones when $\mathrm{Na} \beta$ was used as a catalyst. $^{322}$ The high reactivity of anisole to electrophilic substitution may be the reason for the relatively high yield over $\mathrm{Na \beta}$. Also, substitution of anisole generally 
favours higher para-selectivity. Although most of the results are not likely to stimulate commercial processes, in many cases they do represent significant improvements in para-selectivity compared with traditional reactions. The procedure using $\mathrm{H} \beta$ has also been applied successfully to methanesulfonylation reactions of some disubstituted benzene derivatives. ${ }^{322}$

Table 31 Methanesulfonylation of compounds 8 according to Scheme $35^{a}$

\begin{tabular}{llllll}
\hline $\mathrm{X}$ & Zeolite $(\mathrm{Si} / \mathrm{Al}=25)$ & Yield $(\%)^{b}$ & \multicolumn{3}{l}{ Isomers proportions $(\%)$} \\
\cline { 3 - 5 } & & & $\mathbf{6 5}$ & $\mathbf{6 6}$ & $\mathbf{6 7}$ \\
\hline $\mathrm{Me}$ & $\mathrm{H} \beta$ & 78 & 32 & 11 & 57 \\
$\mathrm{Me}$ & $\mathrm{Na} \beta$ & 18 & 3 & 2 & 95 \\
$\mathrm{Et}$ & $\mathrm{H} \beta$ & 53 & 15 & 11 & 74 \\
$\mathrm{Et}$ & $\mathrm{Na} \beta$ & 13 & 14 & 10 & 76 \\
$\mathrm{Pr}^{i}$ & $\mathrm{H} \beta$ & 74 & 13 & 20 & 67 \\
$\mathrm{Pr}^{i}$ & $\mathrm{Na} \beta$ & 5 & 2 & 8 & 90 \\
$\mathrm{Ph}$ & $\mathrm{H} \beta$ & 66 & - & - & 100 \\
$\mathrm{Ph}$ & $\mathrm{Na} \beta$ & 2 & - & - & 100 \\
$\mathrm{OMe}$ & $\mathrm{H} \beta$ & 54 & 26 & - & 74 \\
$\mathrm{OMe}$ & $\mathrm{Na} \beta$ & 43 & 17 & - & 83 \\
$\mathrm{~F}$ & $\mathrm{H} \beta$ & 12 & 4 & 11 & 85 \\
$\mathrm{~F}$ & $\mathrm{Na} \beta$ & 2 & - & - & 100 \\
$\mathrm{Cl}$ & $\mathrm{H} \beta$ & 23 & - & 12 & 88 \\
$\mathrm{Br}$ & $\mathrm{H} \beta$ & 33 & - & - & 100 \\
$a$ & $\mathrm{~A}$ mixture of $\mathrm{H} \beta(0.6 \mathrm{~g})$ or $\mathrm{Na} \beta(1 \mathrm{~g}),\left(\mathrm{MeSO}_{2}\right)_{2} \mathrm{O}(7$ mmol $)$ and $\mathbf{8}(15$ ml) was \\
refluxed for $18 \mathrm{~h}{ }^{322}{ }^{b}$ Yields based on methanesulfonic anhydride. & \\
\hline
\end{tabular}

Sulfonylation of substituted benzenes has also been investigated over cationexchanged zeolites (ZSM-5, Y, $\beta$ ), using methanesulfonyl chloride and benzenesulfonyl chloride as reagents. ${ }^{323}$ Partially zinc-exchanged zeolites were found to be significantly more active than their corresponding proton forms with these sulfonyl chlorides. However, the conversion achieved for toluene was low (1-43\%). For example, methanesulfonylation of toluene over HZnY gave methyl $o$-tolyl sulfone (62), methyl $m$-tolyl sulfone (63) and methyl $p$-tolyl sulfone (64) in the proportions of 36,8 and $56 \%$, respectively, with $12 \%$ conversion. This is virtually the same selectivity as we found with the anhydride over $\mathrm{H} \beta$, but the yield is much lower. The highest toluene conversion in benzenesulfonylation of toluene over $\mathrm{HZn} \beta$ using 
benzenesulfonyl chloride was $43 \%$, and the corresponding $o^{-}, m$ - and $p$-sulfones were obtained in the ratio $22,4,74 \%$, respectively. ${ }^{323}$

\section{Conclusion}

Zeolite catalysts offer possibilities for both catalysis and selectivity enhancement in a range of electrophilic aromatic substitution reactions, with the advantage of easy separation of the catalyst from the reaction mixture by filtration. Furthermore, the zeolites can often be recovered and reused several times to give almost the same yields and selectivities as with fresh zeolite, with the avoidance of toxic waste generated by traditional Lewis acids. Therefore, there is substantial potential for the development of greener chemical processes.

Phenol has been nitrated using nitric acid over various types of zeolites, but in this case ortho-nitrophenol generally predominates to a much greater extent than with a mixture of sulfuric and nitric acids, regardless of the structure of the zeolite. However, $\mathrm{HNO}_{3} / \mathrm{Ac}_{2} \mathrm{O} / \mathrm{H} \beta$ is an effective system for para-selective nitration of monosubstituted aromatic substrates of moderate activity. Alkylbenzenes and halogenobenzenes are nitrated in quantitative yields with excellent para selectivities using a stoichiometric quantity of nitric acid and enough acetic anhydride to convert all the nitric acid into acetyl nitrate and all the water into acetic acid. Dinitro compounds are not formed in any significant amounts. The intermediacy of hazardous acetyl nitrate is an issue, but could possibly be handled by ensuring the intermediate was only ever present in small amount. When the nitration system is adapted to include TFAA, which enhances the reactivity considerably, the nitration of deactivated aromatics occurs readily. Optimisation of the process has enabled the most selective double nitration of toluene yet attained, giving 2,4-dinitrotoluene in high yield. It is recognised that trifluoroacetic anhydride's volatility, toxicity and cost may render it unattractive for larger scale commercial processes, but recovery of TFAA should be easy. Alternative anhydrides have also been employed. Interestingly, such processes provide improved para-regioselectivity even in nitration of metadirecting substrates such as benzonitrile. The zeolite catalysed reaction produces only 3- and 4-nitrobenzonitriles in quantitative yield, with no 2-nitrobenzonitrile produced. Zeolite $\mathrm{H} \beta$ with a Si/Al ratio of 12.5 , that has had its surface passivated, renders the reaction capable of producing the para-isomer in $32 \%$ yield. 
In an alternative approach to mononitration of simple aromatics, dinitrogen tetroxide in the presence of air has been used over $\mathrm{H} \beta$. This provides selectivity for para-substitution that is higher than in the traditional approach, though the reactions are less selective than with the acyl nitrate systems.

A system comprising $\mathrm{HNaX} / \mathrm{Bu}^{t} \mathrm{OCl} / \mathrm{MeCN}$ is effective for para-selective monochlorination of aromatic compounds of moderate activity. The procedure has been applied successfully to a wide range of aromatic substrates under mild conditions to give excellent yields of monochlorinated aromatics with good to excellent regioselectivity.

High para-selectivity has been achieved in bromination of toluene by use of tert-butyl hypobromite as reagent, $\mathrm{HNaX}$ zeolite as catalyst, and a solvent mixture comprising diethyl ether and tetrachloromethane. The use of tetrachloromethane as solvent is, however, a substantial drawback. The reaction of bromine with substituted benzenes of moderate activity in the presence of sufficient $\mathrm{NaY}$ zeolite at room temperature provides a convenient, high yielding and highly regioselective method for synthesis of para-brominated products. Consequently, this approach has the potential to become a commercially realistic possibility for the synthesis of para-bromo substituted benzenes. The use of a large quantity of zeolite is a disadvantage, but heating of the spent zeolite liberates $\mathrm{HBr}$, which is easily reconverted to bromine, and regenerates the active zeolite, so the overall process could still be quite green.

$n$-Allylbenzenes can be obtained with reasonable selectivity by allylation using an allylic alcohol over zeolite HY or K10 clay and could easily be hydrogenated to give $n$-alkylbenzenes. Direct alkylation of simple aromatic compounds over zeolites is more difficult to control, but provides mixtures of meta- and para-isomers with bulky reagents such as tert-butyl alcohol. High para-selectivity can sometimes be achieved, but only at low conversion.

Highly regioselective dialkylation of naphthalene has been achieved over zeolite H-mordenite using tert-butyl alcohol as alkylating agent under autoclave conditions. The process provides a particularly convenient, high yielding and highly regioselective method for the synthesis of 2,6-di-tert-butylnaphthalene, which has been isolated in $60 \%$ yield with a 2,6/2,7 ratio of over 50 . Although this method is easily the most selective yet discovered for production of a 2,6-dialkylnaphthalene, it may be difficult to oxidise the tert-butyl groups to carboxyl groups. Therefore, there is 
still room for considerable improvement in the clean synthesis of naphthalene-2,6dicarboxylic acid, for which 2,6-dialkylnaphthalenes are potential precursors.

Acetylation of aromatic ethers over zeolite $\mathrm{H} \beta$ or $\mathrm{HY}$ gives high selectivity for substitution para to the alkoxy group and the process using $\mathrm{H} \beta$ has been commercialised. Deactivating groups cause considerable slowing of the reaction and in this case the more open and more active HY is a better catalyst.

Acylation of 2,3-dihydrobenzofuran (DHBF) with simple anhydrides over zeolite $\mathrm{H} \beta$ occurs readily, giving the corresponding 5-acyl derivatives regioselectively in good yields, even from bulkier acylating agents such as trimethylacetic and benzoic anhydrides if longer reaction times are used. A related procedure with ethyl oxalyl chloride has been applied to the synthesis of commercially important ethyl (2,3-dihydrobenzofuran-5-yl)glyoxylate, but a high yield of the desired product could be obtained only by conducting the reaction in ethyl oxalyl chloride as solvent at a high temperature for a prolonged period in the presence of a large quantity of catalyst.

High para-selectivity has been achieved in methanesulfonylation of toluene ovr zeolite $\mathrm{Na}$, but in low yield. Alternatively, reasonable para-selectivity can be achieved in quite good yield by use of proton or various other cation-exchanged forms of zeolite $\beta$. All of these cases provide much better para-selectivity than the published reaction with aluminium chloride and methanesulfonyl chloride and in most cases the yield is substantially improved too.

In short, as a result of the application of zeolites remarkable progress has been made in controlling artomatic substitution reactions to provide good yields of parasubstituted or related products. While there is still need for more research, several of the reactions developed offer the possibility of greener chemical processes. For example, traditional Friedel-Crafts acylations generally require more than one equivalent of Lewis acid due to strong complexation of the Lewis acid by the carbonyl group of the acylation product. Consequently, when applied to production of 4-acetylanisole, the traditional process produces, per $\mathrm{kg}$ of product, $4.5 \mathrm{~kg}$ of aqueous waste containing $\mathrm{HCl}, \mathrm{AlCl}_{3}$ hydrolysis products, solvent residues and acetic acid. Zeolite $\mathrm{H} \beta$ has been introduced as a catalyst for the acetylation of anisole, using acetic anhydride as the reagent. ${ }^{42,43}$ This process generates just $0.035 \mathrm{~kg}$ of aqueous waste (more than 100 times less than in the traditional process), along with around $0.75 \mathrm{~kg}$ of recyclable acetic acid. Table 32 compares the traditional and catalytic processes. 
Table 32 Traditional and catalytic Friedel-Crafts acylations of anisole

\begin{tabular}{ll}
\hline Traditional process (homogeneous) \\
\hline $85-95 \%$ yield & $95-98 \%$ yield, higher purity \\
Non-recyclable $\mathrm{AlCl}_{3}(1.1$ equiv) & Regenerable $\mathrm{H} \beta$ (catalytic) \\
Chlorinated hydrocarbon solvent & No solvent \\
Aqueous hydrolysis work-up & No liquid-liquid phase separation \\
Liquid-liquid phase separation & 0.035 kg of aq. waste per kg of product \\
4.5 kg of aq. waste per kg of product & Generation of recyclable HOAc \\
Generation of $\mathrm{HCl}$ in the aqueous phase &
\end{tabular}

It is of interest to compare theoretical E-factors for some traditional processes with those calculated for alternative zeolite catalysed processes described in this review. Assuming recycling of the zeolite and any other easily recyclable materials, the zeolite-catalysed processes offer much lower E-factors (Table 33).

Table 33 E-factors for some zeolite-catalysed and traditional processes

\begin{tabular}{lll}
\hline Zeolite-catalysed process & Calculated E-factor & Traditional process E-factor \\
\hline $\begin{array}{l}\text { 4-Nitrotoluene from toluene, } \\
\mathrm{HNO}_{3}, \mathrm{Ac}_{2} \mathrm{O} \text { and } \mathrm{H} \beta\end{array}$ & $1.94^{a}$ & $>5.4^{b}$ \\
$\begin{array}{l}\text { 4-Bromotoluene from toluene, } \\
\mathrm{Br}_{2} \text { and NaY }\end{array}$ & $0.50^{a}$ & $>5.6^{c}$ \\
4-Acetylanilsole from anisole, & $0.35^{a, d}$ & $4.5^{d}$ \\
$\mathrm{Ac}_{2} \mathrm{O}$ and $\mathrm{H} \beta$ & \\
${ }^{a}$ Assumes complete recycling of zeolite. ${ }^{b}$ Assumes use of 2 equiv. $\mathrm{H}_{2} \mathrm{SO}_{4}$ and $40 \%$ \\
yield of desired isomer. ${ }^{c}$ Assumes 1 equiv of $\mathrm{AlBr}_{3}$ and $50 \%$ yield of desired isomer. \\
${ }^{d}$ See Table 32. \\
\hline
\end{tabular}

We and others continue to explore the possibilities for exploitation of zeolites in selective aromatic susbstitution reactions.

\section{References}

1 Green Chemistry: Theory and Practice, ed. P. T. Anastas and J. C. Warner, Oxford University Press, Oxford, 1998.

2 Green Chemical Syntheses and Processes, ed. P. T. Anastas, L. G. Heine and T. C. Williamson, American Chemical Society, Washington DC, 2000. 
3 Green Chemistry: Frontiers in Chemical Synthesis and Processes, ed. P. T. Anastas and T. C. Williamson, Oxford University Press, Oxford, 1998.

4 P. T. Anastas and M. M. Kirchhoff, Acc. Chem. Res., 2002, 35, 686.

5 Benign by Design: Alternative Synthetic Design for Pollution Prevention, ed. P.T. Anastas and C. A. Farris, ACS Symp. Ser. 577, American Chemical Society, Washington DC, 1994.

6 J. H. Clark and D. J. Macquarrie, Handbook of Green Chemistry and Technology, Blackwell, Abingdon, 2002.

7 A. S. Matlack, Introduction to Green Chemistry, Marcel Dekker, New York, 2001.

8 M. Lancaster, Green Chemistry: An Introductory Text, Royal Society of Chemistry, Cambridge, 2002.

9 The Chemistry of Waste Minimization, ed. J. H. Clark, Blackie, London, 1995.

10 Green Chemistry and Solid Catalysis, ed. R. A. Sheldon, I. Arends and U. Hanefeld, Wiley-VCH, Weinheim, Germany, 2007.

11 K. Smith, D. A. Evans and G. A. El-Hiti, Role of Modern Chemistry in Sustainable Arable Agricultural Products “Sustainable Agriculture I', ed. C. Pollock, J. Pretty, I. Crute, C. Leaver and H. Dalton, Phil. Trans. R. Soc. B, 2008, 363, 623.

12 R. A. Sheldon, C. R. Acad. Sci. Paris, IIc, Chimie/Chemistry, 2000, 3, 541.

13 R. A. Sheldon, Industrial Environmental Chemistry, ed. D. T. Sawyer and A. E. Martell, Plenum, New York, 1992, pp. 99-119.

14 R. A. Sheldon, Precision Process Technology, ed. M. P. C. Weijnen and A. A. H. Drinkenburg, Kluwer, Dordrecht, 1993, pp. 125-138.

15 R. A. Sheldon, J. Mol. Catal. A: Chem., 1996, 107, 75.

16 R. A. Sheldon, J. Chem. Technol. Biotechnol., 1997, 68, 381.

17 R. A. Sheldon, Pure Appl. Chem., 2000, 72, 1233.

18 B. M. Trost, Science, 1991, 254, 1471.

19 B. M. Trost, Angew. Chem. Int. Ed., 1995, 34, 259.

20 RSC Clean Technology Monographs, ed. J. H. Clark, Cambridge, 2000.

21 J. H. Clark, Green Chem., 1999, 1, 1.

22 Green Chemistry: Challenging Perspectives, ed. P. Tundo and P. T. Anastas, Oxford Science, Oxford, 2000. 
23 M. Spagnol, L. Gilbert and D. Allby, The Roots of Organic Development, ed. J.-R. Desmurs and S. Rattoy, Elsevier, Amsterdam, 1996, Vol. 8, pp. 29-38.

24 K. Suzuki, H. Kitagawa and T. Mukaiyama, Bull. Chem. Soc. Jpn., 1993, 66, 3729.

25 T. Mukaiyama, T. Ohno, T. Nishimura, S. Suda and S. Kobayashi, Chem. Lett., 1991, 1059.

26 R. M. Roberts and A. A. Khalaf, Friedel-Crafts Alkylation, Marcel Dekker, New York, 1984.

27 G. A. Olah, Friedel-Crafts Chemistry, Wiley-Interscience, New York, 1973.

28 G. A. Olah, R. Malhotra and S. C. Narang, Nitration Methods and Mechanisms, VCH, New York, 1989.

29 Electrophilic Aromatic Substitution, ed. R. Taylor, John Wiley and Sons, Chichester, 1990.

30 K. Smith and G. A. El-Hiti, Curr. Org. Chem., 2006, 10, 1603.

31 K. Smith and G. A. El-Hiti, Curr. Org. Synth., 2004, 1, 253.

32 J. H. Clark, Acc. Chem. Res., 2002, 35, 791.

33 Principles and Practice of Heterogeneous Catalysis, ed. J. M. Thomas and W. J. Thomas, VCH, Weinheim, 1997.

34 Catalysis of Organic Reactions using Supported Inorganic Reagents, ed. J. H. Clark, VCH, New York, 1994.

35 J. H. Clark, S. R. Cullen, S. J. Barlow and T. W. Bastock, J. Chem. Soc., Perkin Trans. 2, 1994, 1117.

36 L. Delaude, P. Laszlo and K. Smith, Acc. Chem. Res., 1993, 26, 607.

37 K. Smith, New Aspects of Organic Synthesis II, ed. Z. Yoshida and Y. Ohshiro, Kadonsha, Tokyo and VCH, Weinheim, 1992, pp. 43.

38 M. Butters, Solid Supports and Catalysts in Organic Synthesis, ed. K. Smith, Ellis Horwood, Chichester, 1992, pp. 130-170.

39 K. Smith, Catalysis of Organic Reactions, ed. M. G. Scaros and M. L. Prunier, Marcel Dekker, New York, 1991, pp. 91.

40 H. Heaney, The Bimolecular Aromatic Friedel-Crafts Reactions In Comprehensive Organic Synthesis, ed. B. M. Trost, Pergamon Press, Oxford, 1991, Vol. 2, Chapter 3.2, pp. 733-752.

41 Introduction to Zeolite Science and Practice, ed. H. van Bekkum, E. M. Flanigan and J. C. Jansen, Stud. Surf. Sci. Catal., 1991, vol. 58. 
42 J. H. Clark, A. J. Butterworth, S. J. Tavener and A. J. Teasdale, J. Chem. Tech. Biotechnol., 1997, 68, 367.

43 K. Smith, Z. Zhenhua and P. K. G. Hodgson, J. Mol. Catal. A, 1998, 134, 121.

44 A. Corma, J. Catal., 2003, 216, 298.

45 A. Vaccari, Catal. Today, 1998, 41, 53.

46 M. M. Sharma, React. Funct. Polym., 1995, 26, 3.

47 A. Chakrabarti and M. M. Sharma, React. Funct. Polym., 1993, $20,1$.

48 Fine Chemicals through Heterogeneous Catalysis, ed. R. A. Sheldon and H. van Bekkum Wiley-VCH, Weinheim, 2001.

49 M. H. Valkenberg and W. F. Hölderich, Catal. Rev., 2002, 44, 321.

50 Chemistry of the Elements, ed. N. N. Greenwood and A. Earnshaw, Pergamon Press, Hong Kong, 1984.

51 C. Baerlocher, W. M. Meier and D. H. Olson, Atlas of Zeolite Framework types, 5th Ed., Elsevier, Amsterdam, 2001.

52 A. Corma, M. Moliner, Á. Cantín, M. J. Díaz-Cabañas, J. L. Jordá, D. Zhang, J. Sun, K. Jansson, S. Hovmöller, and X. Zou, Chem. Mater., 2008, 20, 3218.

53 C. T. O’Connor, K. P. Möller and H. Manstein, Kona, 2007, 25, 230.

54 K. Schofield, Aromatic Nitration; Cambridge University Press, Camridge, 1980.

55 G. A. Olah, S. J. Kuhn, S. H. Flood and J. C. Evans, J. Am. Chem. Soc., 1962, 84, 3687.

56 R. G. Coombes, R. B. Moodie and K. Schofield, J. Chem. Soc. B, 1968, 800.

57 R. G. Coombes, D. H. G. Crout, J. G. Hoggett, R. B. Moodie and K. Schofield, J. Chem. Soc. B, 1970, 347.

58 M. E. Kurz, L. T. A. Yang, E. P. Zahora and R. C. Adams, J. Org. Chem., 1973, 38, 2271.

59 R. G. Coombes, J. G. Golding and P. Hadjigeorgiou, J. Chem. Soc., Perkin Trans. 2, 1979, 1451.

60 J. A. R. Rodrigues, A. P. de Oliveira Filho, P. J. S. Moran and R. Custódio, Tetrahedron, 1999, 55, 6733.

61 W.-P. Yin and M. Shi, Tetrahedron, 2005, 61, 10861.

62 B. Gigante, A. O. Prazeres, M. J. Marcelo-Curto, A. Cornélis and P. Laszlo, J. Org. Chem., 1995, 60, 3445. 
63 T. Milczak, J. Jacniacki, J. Zawadzki, M. Malesa and W. Skupiński, Synth. Commun., 2001, 31, 173.

64 M. M. Heravi, T. Benmorad, K. Bakhtiari, F. F. Bamoharram and H. H. Oskooie, J. Mol. Catal. A: Chem., 2007, 264, 318.

65 S. Mallick and K. M. Parida, Catal. Commun, 2007, 8, 1487.

66 K. M. Parida and D. Rath, J. Mol. Catal. A: Chem., 2006, 258, 381.

67 J. M. Riego, Z. Sedin, J.-M. Zaldlvar, N. C. Marzianot and C. Tortato, Tetrahedron Lett., 1996, 37, 513.

68 M. A. Zolfigol, E. Ghaemi and E. Madrakian, Molecules, 2001, 6, 614.

69 K. R. Sunajadevi and S. Sugunan, Catal. Commun., 2005, 6, 611.

$70 \quad$ K. R. Sunajadevi and S. Sugunan Mater. Lett., 2006, 60, 3813.

71 A. S. Khder and A. I. Ahmed, Appl. Catal., A, 2009, 354, 153.

72 D. Vione, S. Belmondo and L. Carnino, Environ. Chem. Lett., 2004, 2, 135.

73 S. P. Dagade, V. S. Kadam and M. K. Dongare, Catal. Commun., 2002, 3, 67.

74 T. Esakkidurai and K. Pitchumani, J. Mol. Catal. A: Chem., 2002, 185, 305.

75 K. Smith, M. D. Ajarim and G. A. El-Hiti, Top. Catal., 2009, 52, 1696.

76 T. J. Kwok, K. Jayasuriya, R. Damavarapu and B. W. Brodman, J. Org. Chem., 1994, 59, 4939.

77 K. Smith, Bull Soc. Chim. Fr., 1989, 272; K. Smith, K. Fry, M. Butters and B. Nay, Tetrahedron Lett., 1989, 30, 5333.

78 S. M. Nagy, E. A. Zubkov and V. G. Shubin, Bull. Acad. Sci. USSR, Chem. Ser., 1989, 1780 (pp. 1933 in the Russian original); S. M. Nagy, K. A. Yarovoy, M. M. Shakirov, V. G. Shubin, L. A. Vostrikova and K. G. Ione, J. Mol. Catal., 1991, 64, L31.

79 S. M. Nagy, K. A. Yarovoy, V. G. Shubin and L. A. Vostrikova, J. Phys. Org. Chem., 1994, 7, 385.

80 K. Smith, A. Musson and G. A. DeBoos, J. Chem. Soc., Chem. Commun., 1996, 469; J. Org. Chem., 1998, 63, 8448.

81 D. Vassena, A. Kogelbauer and R. Prins, Stud. Surf. Sci. Catal., 1999, 125, 501 .

82 M. Haouas, A. Kogelbauer and R. Prins, Catal. Lett., 2000, 70, 61.

83 M. Haouas, S. Bernascani, A. Kogelbauer and R. Prins, Phys. Chem. Chem. Phys., 2001, 3, 5067. 
84 R. P. Claridge, N. Llewellyn Lancater, R. W. Miller, R. B. Moodie and J. P. B. Sandall, J. Chem. Soc., Perkin Trans. 2, 1999, 1815.

85 I. Schumacher, Eur. Pat., 0053 031, 1981.

86 A. Germain, T. Akouz and F. Figueras, J. Catal., 1994, 147, 163.

87 A. Germain, T. Akouz and F. Figueras, Appl. Catal. A: Gen., 1996, 136, 57.

88 X. Peng and H. Suzuki, Org. Lett., 2001, 3, 3431.

89 N. F. Salakhutdinov, K. G. Ione, E. A. Kobzar and L. V. Malysheva, Zh. Org. Khim., 1993, 29, 546.

90 H. Suzuki, S. Yonezawa, N. Nonoyama and T. Mori, J. Chem. Soc., Perkin Trans. 1, 1996, 2385.

91 R. R. Bak and A. J. Smallridge, Tetrahedron Lett., 2001, 42, 6767.

92 K. Smith, S. Almeer and S. J. Black, Chem. Commun., 2000, 1571.

93 K. Smith, S. Almeer, S. J. Black and C. Peters, J. Mater. Chem., 2002, 12, 3285.

94 X. Peng, H. Suzuki and C. Lu, Tetrahedron Lett., 2001, 42, 4357.

95 K. Smith, S. Almeer and C. Peters, Chem. Commun., 2001, 2748.

96 A. Kogelbauer, D. Vassena, R. Prins and J. N. Armor, Catal. Today, 2000, 55, 151.

97 D. Vassena, A. Kogelbauer and R. Prins, Catal. Today, 2000, 60, 275.

98 Peng, X.; Fukui, N.; Mizuta, M.; Suzuki, H. Org. Biomol. Chem., 2003, 1, 2326.

99 M. G. Kuba, R. Prins and G. D. Pirngruber, Appl. Catal. A: Gen., 2007, 333, 24.

100 M. G. Kuba, R. Prins and G. D. Pirngruber, Appl. Catal. A: Gen., 2007, 333, 78.

101 S.-S. Kim, T. J. Pinnavaia and R. Damavarapu, J. Calal., 2008, 253, 289.

102 B. M. Choudary, M. Sateesh, M. Lakshmi Kantam, K. Koteswara Rao, K. V. Ramprasad, K. V. Raghavan and J. A. R. P. Sarma, Chem. Commun., 2000, 25.

103 A. Gal, M. Kurahashi and M. Kuzumoto, J. Phys. Chem. A., 2000, 104, 10821.

104 Patil, P.T.; Malshe, K.M.; Dagade, S.P.; Dongare, M.K. Catal. Commun., 2003, 4, 429.

105 M. L. Kantam, B. M. Choudary, N. S. Kumar and K. V. Ramprasad, J. Mol. Catal. A: Chem., 2005, 229, 67. 
106 V. N. Sheemol, B. Tyagi and R. V. Jasra, J. Mol. Catal. A: Chem., 2006, 252, 194.

107 F. J. Waller, A. G. M. Barrett, D. C. Braddock and Ramprasad, Tetrahedron Lett., 1998, 39, 1641.

108 B. Gigante, A. O. Prazeres, M. J. Marcelo-Cuto, A. Cornélis and P. Laszlo, J. Org. Chem., 1995, 60, 3445.

109 D. Vassena, A. Kogelbauer, R. Prins and J. Armor, Abstracts from EuropaCatIV, Rimini, 1999, p. 222.

110 E. J. Bourne, M. Stacey, J. C. Tatlow and J. M. Tedder, J. Chem. Soc., 1952, 1695.

111 K. Smith, T. Gibbins, R. W. Millar and R. P. Claridge, J. Chem. Soc. Perkin Trans. 1, 2000, 2753.

112 K. Smith, M. D. Ajarim and G. A. El-Hiti, Catal. Lett., 2010, 134, 270.

113 S. D. Barker, R. K. Norris and D. Randles, Aust. J. Chem., 1981, 34, 1875.

114 R. B. Moodie, Organic Reaction Mechanism, 1982, 231.

115 P. Ratnasamy, A. P. Singh and S. Sharma, Appl. Catal. A: Gen., 1996, 135, 25 .

116 V. B. Jigajinni, W. E. Paget and K. Smith, J. Chem. Res. (S), 1981, 376.

117 K. Smith, M. Butters, W. E. Paget and B. Nay, Synthesis, 1985, 1155.

118 J. M. Gnaim and R. A. Sheldon, Tetrahedron Lett., 2004, 45, 9397.

119 P. B. D. de la Mare, Electrophilic halogenation, Cambridge University Press, Cambridge, 1976.

120 J. R. Lindsay-Smith and L. C. McKeer, Tetrahedron Lett., 1983, 24, 3117.

121 G. A. Olah, L. Ohannesian and M. Arvanaghi, Synthesis, 1986, 868.

122 K. Smith, M. Butters and B. Nay, Tetrahedron Lett., 1988, 29, 1319.

123 J. R. Lindsay-Smith, L. C. McKeer and J. M. Taylor, J. Chem. Soc., Perkin Trans. 2, 1989, 1529 and 1537.

124 R. C. Larock, Comprehensive Organic Transformations; VCH: New York, 1989, pp. 316.

125 L. Delaude and P. Laszlo, Catal. Lett., 1990, 5, 35.

126 J. March, Advanced Organic Chemistry, Wiley, New York, 1992, pp. 531.

127 Y. Goldberg and H. Alper, J. Org. Chem., 1993, 58, 3072.

128 A. P. Singh, S. B. Kumar, A. Paul and A. Raj, J. Catal., 1994, 147, 360; A. P. Singh and S. B. Kumar, Appl. Catal. A: Gen., 1995, 126, 27. 
129 A. P. Singh and S. B. Kumar, Catal. Today, 1999, 49, 245.

130 S. M. Kale and A. P. Singh, J. Mol. Catal. A: Chem., 1999, 138, 263.

131 L. Delaude and P. Laszlo, J. Org. Chem., 1990, 55, 5260.

132 D. Antenucci, L. Delaude, A.-M. Fransolet and P. Laszlo, J. Catal., 1992, 135, 92.

133 A. P. Singh, S. Sharma and S. M. Kale, J. Mol. Catal. A: Chem., 1997, 127, 101.

134 M. C. Hausladen, B. W. Satterley, M. J. Burger and C. R. F. Lund, Appl. Catal. A: Gen., 1998, 166, 55.

135 M. C. Hausladen and C. R. F. Lund, Appl. Catal. A: Gen., 2000, 190, 269.

136 C.-C. Chang, M. J. Burger, G. M. Faitar and C. R. F. Lund, J. Catal., 2001, 202, 59 .

137 M. C. Hausladen, R. C. Cyganovich, H. Y. Huang and C. R. F.Lund, Appl. Catal. A: Gen., 2001, 219, 1 and references cited therein.

138 S. M. Kale and A. P. Singh, Appl. Catal. A: Gen., 2002, 228, 1.

139 B. W. Satterley, M. C. Hausladen and C. R. F. Lund, Zeolites, 1997, 19, 434.

140 S. Deb and K. R. Das, J. Sci. Ind. Res., 1998, 57, 539.

141 S. M. Kale and A. P. Singh, J. Mol. Catal. A: Chem., 2002, 184, 399.

142 K. Smith, M. Butters and B. Nay, Synthesis, 1985, 1157; K. Smith, M. Butters, W. E. Paget, D. Goubet, E. Formentin and B. Nay, Green Chem., 1999, 1, 83.

143 A. G. Mistry, K. Smith and M. R. Bye, Tetrahedron Lett., 1986, 27, 1051; .K. Smith, D. M. James, A. G. Mistry, M. R. Bye and D. J. Faulkner, Tetrahedron, 1992, 48, 7479.

144 Th. M. Wortel, D. Oudijn, C. J. Vleugel, D. P. Roelofsen and H. van Bekkum, J. Catal. 1979, 60, 110.

145 J. van Dijk, J. J. van Daalen and G. B. Paerels, Recl. Trav. Chim. Pays-Bas, $1974,93,72$.

146 T. Miyake, K. Sekizawa, T. Hironaka and Y. Tsutsumi, US Pat., 4861 929, 1989.

147 T. Suzuki and Y. Higuchi, US Pat., 4822 933, 1989.

148 N. Narender, K. V. V. Krishna Mohan, R. Vinod Reddy, P. Srinivasu, S. J. Kulkarni and K. V. Reghavan, J. Mol. Catal. A.: Chem., 2003, 192, 73.

149 V. Paul, A. Sudalai, T. Daniel and K. V. Srinivasan, Tetrahedron Lett., 1994, 35, 7055 . 
150 J. M. Gnaim and R. A. Sheldon, Tetrahedron Lett., 2005, 46, 4465.

151 A. P. Singh, S. P. Mirajkar and S. Sharma, J. Mol. Catal. A.: Chem., 1999, 150, 241.

152 F. de la Vega and Y. Sasson, Zeolites, 1989, 9, 418.

153 F. de la Vega and Y. Sasson, J. Chem. Soc., Chem. Commun., 1989, 653.

154 F. de la Vega, Y. Sasson and K. Huddersman, Zeolites, 1991, 11, 617.

155 F. de la Vega, Y. Sasson and K. Huddersman, Zeolites, 1993, 13, 341.

156 K. Smith, G. A. El-Hiti, M. E. W. Hammond, D. Bahzad, Z. Li and C. Siquet, J. Chem. Soc., Perkin Trans. 1, 2000, 2745.

157 K. Smith and D. Bahzad, Chem. Commun., 1996, 467.

158 K. Smith, P. He and A. Taylor, Green Chem., 1999, 1, 35.

159 E. D. Ozokwelu, Kirk-Othmer Encyclopedia of Chemical Technology, Wiley: New York, 1997; Vol. 24, p 350.

160 K. Smith, G. M. Pollaud and I. Matthews, Green Chem., 1999, 1, 75.

161 Zeolites in Industrial Separation and Catalysis, ed. S. Kulprathipanja, WileyVCH, Weinheim, 2010.

162 M. E. Sad, C. L. Padró and C. R. Apesteguía, Catal. Today, 2008, 133-135, 720.

163 M. E. Sad, C. L. Padró and C. R. Apesteguía, Appl. Catal. A: Gen., 2008, 342, 40 .

164 B. Jansang, T. Nanok and J. Limtrakul, J. Phys. Chem. C, 2008, 112, 540.

165 M. Bregolato, V. Bolis, C. Busco, P. Ugliengo, S. Bordiga, F. Cavani, N. Ballarini, L. Maselli, S. Passeri, I. Rossetti and L. Forni, J. Catal., 2007, 245, 285.

166 G. Moon, W. Böhringer and C. T. ÖConnor, Catal. Today, 2004, 97, 291

167 E. Dumitriu, D. Meloni, R. Monaci and V. Solinas, C. R. Chim., 2005, 8, 441.

168 A. De Klerk and R. J. J. Nel, Ind. Eng. Chem. Res., 2007, 46, 7066.

169 S. Wagholikar, S. Mayadevi and S. Sivasanker, Appl. Catal. A: Gen., 2006, 309, 106.

170 A.V. Krishnan, K. Ojha and N. C. Pradhan, Org. Proc. Res. Dev., 2002, 6, 132.

171 A. Sakthivel, S. K. Badamali and P. Selvam, Microporous Mesoporous Mater., 2000, 39, 457.

172 S. K. Badamali, A. Sakthivel and P. Selvam, Catal. Lett., 2000, 65, 153. 
173 K. Zhang, C. Huang, H. Zhang, S. Xiang, S. Lui, D. Xu and H. Li, Appl. Catal. A: Gen., 1998, 166, 89.

174 S. Subramaniam, A. Mitra, C. V. V. Satyanarayana and D. K. Chakrabarty, Appl. Catal. A: Gen., 1997, 159, 229.

175 R. F. Parton, J. M. Jacobs, D. R. Huybrechts and P. A. Jacobs, Stud. Surf. Sci. Catal., 1988, 46, 163.

176 S. Inagaki, K. Kamino, E. Kikuchi and M. Matsukata, Appl. Catal. A: Gen., 2007, 318, 22.

177 J. P. Breen, R. Burch, M. Kulkarni, D. McLaughlin, P. J. Collier and S. E. Golunski, Appl. Catal. A: Gen., 2007, 316, 53.

178 M. Ghiaci, A. Abbaspur, M. Arshadi and B. Aghabarari, Appl. Catal. A: Gen., 2007, 316, 32.

179 C. P. Sebastian, P. Shivanand, N. Sharanappa and C. V. V. Satyanarayana, J. Mol. Catal. A: Chem., 2004, 223, 305.

180 S. Pai, U. Gupta and S. Chilukuri, J. Mol. Catal. A: Chem., 2007, 265, 109.

181 D. Mravec, P. Zavadan, A. Kaszonyi, J. Joffre and P. Moreau, Appl. Catal. A: Gen., 2004, 257, 49.

182 G. Kostrab, D. Mravec, M. Bajus, I. Janotka, Y. Sugi, S. J. Cho and J. H. Kim, Appl. Catal. A: Gen., 2006, 299, 122.

183 Z. Zhiwei, W. Wenliang, W. Jun and Z. Chongyu, Chin. J. Chem. Eng., 2009, 17, 195.

184 H.-J. Dong and L. Shi, Ind. Eng. Chem. Res., 2010, 49, 2091.

185 S. Sealy and Y. Traa, Appl. Catal. A: Gen., 2005, 294, 273.

186 Y. Sugi, Y. Kubota, K. Komura, N. Sugiyama, M. Hayashi, J.-H. Kim and G. Seo, Appl. Catal. A: Gen., 2006, 299, 157.

187 K. Mantri, E. Dejaegere, G. V. Baron and J. F. M. Denayer, Appl. Catal. A: Gen., 2007, 318, 95.

188 G. Kostrab, M. Lovič, I. Janotka, M. Bajus and D. Mravec, Appl. Catal. A: Gen., 2007, 323, 210.

189 S. Barman, S. K. Maity and N. C. Pradhan, Chem. Eng. J., 2005, 114, 39.

190 M. Cowley, A. de Klerk and R. J. J. Nel, Ind. Eng. Chem. Res., 2005, 44, 5535

191 F. J. Llopis, G. Sastre and A. Corma, J. Catal., 2004, 227, 227.

192 S. Van der Beken, E. Dejaegere, K. A. Tehrani, J. S. Paul, P. A. Jacobs, G. V. Barona and J. F. M. Denayer, J. Catal., 2005, 235, 128. 
193 J. Rigoreau, S. Laforge, N. S. Gnep and M. Guisnet, J. Catal., 2005, 236, 45.

194 Y. Sugi, I. Toyama, H. Tamada, S. Tawada, K. Komura and Y. Kubota, J. Mol. Catal. A: Chem., 2009, 304, 22.

195 T. Shibata, S. Suzuki, H. Kawagoe, K. Komura, Y. Kubota, Y. Sugi, J.-H. Kim and G. Seo, Microporous Mesoporous Mater., 2008, 116, 216.

196 Y. Sugi, H. Maekawa, Y. Hasegawa, A. Ito, R. Asai, D. Yamamoto, K. Komura, Y. Kubota, J.-H. Kim and G. Seo, Catal. Today, 2008, 131, 413.

197 J. Aguilar, S. B. C. Pergher, C. Detoni, A. Corma, F. V. Melo and E. Sastre, Catal. Today, 2008, 133-135, 667.

198 H. Maekawa, C. Naitoh, K. Nakagawa, A. Iida, K. Komura, Y. Kubota, Y. Sugi, J.-H. Kim and G. Seo, J. Mol. Catal. A: Chem., 2007, 274, 24.

199 G. S. Lee, J. J. Maj, S. C. Rocke and J. M. Garces, Catal. Lett., 1989, 2, 243.

200 A. S. Loktev and P. S. Chekriy, Stud. Surf. Sci. Catal., 1994, 84, 1845.

201 S.-B. Pu and T. Inui, Appl. Catal. A: Gen., 1996, 146, 305.

202 S.-B. Pu and T. Inui, Zeolites, 1996, 17, 334.

203 S. Kitabayashi, T. Shindo, K. Ono and H. Ohnuma, Nippon Kagaku Kaishi, 1996, 624; Chem. Abstr., 1996, 125, 89575m.

204 E. Armengol, A. Corma, H. García and J. Primo, Appl. Catal. A: Gen., 1997, 149, 411.

205 O. A. Anunziata and L. B. Pierella, Catal. Lett., 1997, 44, 259.

206 R. Gläser, R. Li, M. Hunger, S. Ernst and J. Weitkamp, Catal. Lett., 1998, 50, 141.

207 M. Motoyuki, K. Yamamoto, J. P. McWilliams and R. G. Bundens, US Pat., 5 $744670,1998$.

208 R. P. Marathe, S. Mayadevi, S. A. Pardhy, S. M. Sabne and S. Sivasanker, J. Mol. Catal. A: Chem., 2002, 181, 201.

209 C. He, Z. Liu, F. Fajula and P. Moreau, Chem. Commun., 1998, 1999.

210 G. Colón, I. Ferino, E. Rombi, E. Selli, L. Forni, P. Magnoux and M. Guisnet, Appl. Catal. A: Gen., 1998, 168, 81.

211 I. Ferino, R. Monaci, E. Rombi, V. Solinas, P. Magnoux and M. Guisnet, Appl. Catal. A: Gen., 1999, 183, 303.

212 G. Pazzuconi, C. Perego, R. Millini, F. Frigerio, R. Mansani and D. Rancati, US Pat., 6147 270, 2000. 
213 P. Moreau, C. He, Z. Liu and F. Fajula, J. Mol. Catal. A: Chem., 2001, 168, 105.

214 R. Millini, F. Frigerio, G. Bellussi, G. Pazzuconi, C. Perego, P. Pallesel and U. Romano, J. Catal., 2003, 217, 298.

215 Ch. Subrahmanyam, B. Viswanathan and T. K. Varadaraj, J. Mol. Catal. A: Chem., 2005, 226, 155.

216 Y. Sugi, H. Maekawa, H. Naiki, K. Komura and Y. Kubota, Bull. Chem. Soc. Jpn., 2008, 81, 1166.

217 Y. Wang, L. Xu, Z. Yu, X. Zhang and Z. Liu, Catal. Commun., 2008, 9, 1982.

218 Y. Sugi, H. Maekawa, Y. Hasegawa, H. Naiki, K. Komura and Y. Kubota, Catal. Today, 2008, 132, 27.

219 T. Shibata, H. Kawagoe, H. Naiki, K. Komura, Y. Kubota and Y. Sugi, J. Mol. Catal. A: Chem., 2009, 297, 80.

220 C. Bouvier, W. Buijs, J. Gascon, F. Kapteijn, B. C. Gagea, P. A. Jacobs and J. A. Martens, J. Catal., 2010, 270, 60.

221 G. A. Olah and J. A. Olah, J. Am. Chem. Soc., 1976, 98, 1839.

222 D. Fraenkel, M. Cherniavsky, B. Ittah and M. Levy, J. Catal., 1986, 101, 273.

223 M. G. Cutrufello, I. Ferino, R. Monaci, E. Rombi, V. Solinas, P. Magnoux and M. Guisnet, Appl. Catal. A: Gen., 2003, 241, 91.

224 R. Brzozowski and W. Tęcza, Appl. Catal. A: Gen., 1998, 166, 21.

225 A. Katayama, M. Toba, G. Takeuchi, F. Mizukami, S.-I. Niwa and S. Mitamura, J. Chem. Soc. Chem. Commun., 1991, 39.

226 A. D. Schmitz and C. S. Song, Catal. Today, 1996, 31, 195; Catal. Lett., 1996, 40, 59 .

227 J.-H. Kim, Y. Sugi, T. Matsuzaki, T. Hanaoka, Y. Kubota, X. Tu, M. Matsumoto, S. Nakata, A. Kato, G. Seo and C. Pak, Appl. Catal. A: Gen., 1995, 131, 15.

228 P. Moreau, A. Finiels, P. Geneste and J. Solofo, J. Catal., 1992, 136, 487.

229 P. P. B. Notte, G. M. J. L. Poncelet, M. J. H. Remy, P. E. M. G. Lardinois and M. J. M. van Hoecke, Eur. Pat., 0528 096, 1993.

230 P. Moreau, A. Finiels, P. Geneste, F. Moreau and J. Solofo, J. Org. Chem. 1992, 57, 5040.

231 Z. Liu, P. Moreau and F. Fajula, Chem. Comm., 1996, 2653; Appl. Catal. A: Gen,. 1997, 159, 305. 
232 K. Smith, S. D. Roberts and G. A. El-Hiti, Org. Biomol. Chem., 2003, 1, 1552.

233 K. Smith and S. D. Roberts, Catal. Today, 2000, 60, 227.

234 B. H. Lipshutz, Chem. Rev., 1986, 86, 795; M. G. N. Russell, R. J. Baker, L. Barden, M. S. Beer, L. Bristow, H. B. Howard, B. Broughton, M. Knowles, G. McAllister, S. Patel and J. L. Castro, J. Med. Chem., 2001, 44, 3881; H.-C. Zhang, H. Ye, A. F. Moretto, K. K. Brumfield and B. E. Maryanoff, Org. Lett., 2000, 2, 89.

235 M. Karthik, A. K. Tripathi, N. M. Gupta, M. Palanichamy and V. Murugesan, Catal. Commun., 2004, 5, 371.

236 D. Venu Gopal and M. Subrahmanyam, Catal. Commun., 2001, 2, 305; D. Venu Gopal, B. Srinivas, D. Durgakumari and M. Subrahmanyam, Appl. Catal. A: Gen., 2002, 224, 121.

237 P. Ram Reddy, K. V. Subba Rao and M. Subrahmanyam, Catal. Lett., 1998, 56, 155; P. Ram Reddy, M. Subrahmanyam and V. Durga Kumari, Catal. Lett., 1999, 60, 161.

238 R. Chakravarti, P. Kalita, S. Tamil Selvan, H. Oveisi, V. V. Balasubramanian, M. Lakshmi Kantam and A. Vinu, Green Chem., 2010, 12, 49.

239 D. E. Akporiaye, K. Daasvatn, J. Solberg and M.Stöcker, Stud. Surf. Sci. Catal., 1993, 78, 521.

240 A. Corma, M. J. Climent, H. Garcia and J. Primo, Appl. Catal., 1989, 49, 109.

241 B. Chiche, A. Finiels, C. Gauthier, P. Geneste, J. Graille and D. Pioch, J. Org. Chem., 1986, 51, 2128; J. Mol. Catal., 1987, 42, 229; C. Gauthier, B. Chiche, A. Finiels and P. Geneste, J. Mol. Catal., 1989, 50, 219.

242 Q. L. Wang, Y. Ma, X. Ji, H. Yan and Q. Qiu, J. Chem. Soc., Chem. Commun., 1995, 2307.

243 A. P. Singh, D. Bhattacharya and S. Sharma, J. Mol. Catal. A: Chem., 1995, $102,139$.

244 K. Gaare and D. Akporiaye, J. Mol. Catal. A: Chem., 1996, 109, 177.

245 B. C. Ranu, K. Ghosh and U. Jana, J. Org. Chem., 1996, 61, 9546.

246 R. Sreekumar and R. Padmakumar, Synth. Commun., 1997, 27, 777.

247 C. De Castro, J. Primo and A. Corma, J. Mol. Catal. A: Chem., 1998, 134, 215 .

248 E. G. Derouane, C. J. Dillon, D. Bethell and S. B. Derouane-Abd Hamid, J. Catal. 1999, 187, 209. 
249 U. Freese, F. Heinrich and F. Roessner, Catal. Today, 1999, 49, 237.

250 H. K. Heinichen and W. F. Hölderich, J. Catal., 1999, 185, 408.

251 P. Moreau, A. Finiels and P. Meric, J. Mol. Catal. A: Chem., 2000, 154, 185.

252 J. M. Escola and M. E. Davis, Appl. Catal. A: Gen., 2001, 214, 111.

253 A. E. W. Beers, T. A. Nijhuis, F. Kapteijn and J. A. Moulijn, Microporous Mesoporous Mater., 2001, 48, 279.

254 F. Bigi, S. Carloni, C. Flego, R. Maggi, A. Mazzacani, M. Rastelli and G. Sartori, J. Mol. Catal. A: Chem., 2002, 178, 139.

255 P. Botella, A. Corma, M. T. Navarro, F. Rey and G. Sastre, J. Catal., 2003, 217, 406.

256 J. Klisáková, L. Červený and J. Čejka, Appl. Catal. A: Gen., 2004, 272, 79.

257 M. E. Davis, Microporous Mesoporous Mater., 1998, 21, 173.

258 C. P. Bezouhanova, Appl. Catal. A: Gen., 2002, 229, 127.

259 G. Sartori and R. Maggi, Chem. Rev., 2006, 106, 1077.

260 A. Wolfson, A. M. Shapira-Tchelet, O. Shokin, P. M. Rao, D. Tavor, M. V. Landau and M. Herskowitz, in Progress in Catalysis Research, ed. L. P. Bevy, Nova Science, New York, 2005, ch. 5, pp. 97-113.

261 R. V. Jasra in Progress in Catalysis Research, ed. L. P. Bevy, Nova Science, New York, 2005, ch. 6, pp. 115-146.

262 P. R. Kurek, US Pat., 5126 489, 1992.

263 M. Spagnol, L. Gilbert, E. Benazzi and C. Marcilly, US Pat., 5 817 878, 1998.

264 M. Spagnol, L. Gilbert, H. Guillot and P. J. Tirel, US Pat., 6194 616, 2001.

265 M. Spagnol, L. Gilbert, A.-M. Le Govic, US Pat., 0120 169, 2002; US Pat., 0 $102654,2004$.

266 I. Neves, F. Jayat, P. Magnoux, G. Pérot, F. R. Ribeiro, M. Gubelmann and M. Guisnet, J. Mol. Catal., 1994, 93, 169.

267 Y. V. Subba Rao, S. J. Kulkarni, M. Subrahmanyam and A. V. Rama Rao, Appl. Catal. A: Gen., 1995, 133, L1.

268 V. D. Chaube, P. Moreau, A. Finiels, A. V. Ramaswamy and A. P. Singh, J. Mol. Catal. A: Chem., 2001, 174, 255.

269 I. Neves, F. Jayat, P. Magnoux, G. Pérot, F. R. Ribeiro, M. Gubelmann and M. Guisnet, Stud. Surf. Sci. Catal., 1997, 105, 1149. 
270 C. L. Padró and C. R. Apesteguía, Catal. Today, 2005, 107-108, 258.

271 Q. L. Wang, M. Torrealba, G. Giannetto, M. Guisnet, G. Pérot, M. Cahoreau and J. Casso, Zeolites, 1990, 10, 703.

272 I. Neves, F. Jayat, P. Magnoux, G. Pérot, F. R. Ribeiro, M. Gubelmann and M. Guisnet, J. Chem. Soc., Chem. Commun., 1994, 717.

273 C. L. Padró and C. R. Apesteguía, J. Catal., 2004, 226, 308.

274 D. P. Serrano, R. A. García and D. Otero, Appl. Catal. A: Gen., 2009, 359, 69.

275 X. Ji, Z. Qin, M. Dong, G. Wang, T. Dou, and J. Wang, Catal. Lett., 2007, 117, 171.

276 S. G. Wagholikar, P. S. Niphadkar, S. Mayadevi and S. Sivasanker, Appl. Catal. A: Gen., 2007, 317, 250.

277 G. Winé, C. Pham-Huu and M.-J. Ledoux, Catal. Commun., 2006, 7, 768.

278 M. L. Kantam, K. V. S. Ranganath, M. Sateesh, K. B. S. Kumar and B. M. Choudary, J. Mol. Catal. A: Chem., 2005, 225, 15.

279 M. A. Harmer and Q. Sun, Appl. Catal. A: Gen., 2001, 221, 45.

280 K. Smith, G. A. El-Hiti, A. J. Jayne and M. Butters, Org. Biomol. Chem., 2003, 1, 2321.

281 K. Smith, G. A. El-Hiti, A. J. Jayne and M. Butters, Org. Biomol. Chem., 2003, 1, 1560.

282 M. Guidotti, C. Canaff, J.-M. Coustard, P. Magnoux and M. Guisnet, J. Catal., 2005, 214, 375.

283 M. Guidotti, J.-M. Coustard, P. Magnoux and M. Guisnet, Pure Appl. Chem., 2007, 79, 1833.

284 T. Jaimol, A. K. Pandey and A. P. Singh, J. Mol. Catal. A: Chem., 2001, 170, 117.

285 P. Botella, A. Corma, J. M. López-Nieto, S. Valencia and R. Jacquot, J. Catal., 2000, 195, 161.

286 M. Bejblová, D. Procházková and J. Vlk, Top. Catal., 2009, 52, 178.

287 D. Bhattacharya, S. Sharma and A. P. Singh, Appl. Catal. A: Gen., 1997, 150, 53.

288 L. Červený, K. Mikulcová, K. and J. Čejka, Appl. Catal. A: Gen., 2002, 223, 65. 
289 K. T. Wan and M. E. Davis, J. Catal., 1994, 152, 25.

290 P. Meric, A. Finiels and P. Moreau, J. Mol. Catal. A: Chem., 2002, 189, 251.

291 M. Casagrande, L. Storaro, M. Lenarda and R. Ganzerla, Appl. Catal. A: Gen., 2000, 201, 263.

292 H. Schuster and W. F. Hölderich, Appl. Catal. A: Gen., 2008, 350, 1.

293 E. Fromentin, J.-M. Coustard and M. Guisnet, J. Catal., 2000, 190, 433.

294 A. Berreghis, P. Ayrault, E. Fromentin and M. Guisnet, Catal. Lett., 2000, 68, 121.

295 M. Casagrande, L. Storaro, M. Lenarda and R. Ganzerla, Appl. Catal., A: Gen. 2000, 201, 263.

296 E. Fromentin, J.-M. Coustard and M. Guisnet, J. Mol. Catal. A: Chem., 2000, 159, 377.

297 M. L. Kantam, M. Satees, B. M. Choudary, K. V. S. Ranganath and K. V. Raghavan, JP pat., 278 832, 2001; Chem. Abstr., 2001, 135, 288592.

298 D. Das and S. Cheng, Appl. Catal. A: Gen., 2000, 201, 159.

299 T. Tomiyama, I. Tomiyama, T. Shirai, S. Wakabayashi, M. Futamura and S. Ichikawa, JP pat., 03261 778, 1991; Chem. Abstr., 1992, 116, 151553.

300 Y. Isaev and J. J. Fripiat, J. Catal., 1999, 182, 257.

301 F. Richard, J. Drouillard, H. Carreyre, J. L. Lemberton and G. Pérot, Stud. Surf. Sci. Catal., 1993, 78, 601.

302 P. Ram Reddy, M. Subrahmanyam and S. J. Kulkarni, Catal. Lett., 1998, 54, 95.

303 M. L. Kantam, K. V. S. Ranganath, M. Sateesh, K. B. S. Kumar, B. M. Choudary, J. Mol. Catal. A: Chem., 2005, 225, 15.

304 V. F. D. Álvaro, A. F. Brigas, E. G. Derouane, J. P. Lourenço and B. S. Santos, J. Mol. Catal. A: Chem., 2009, 305, 100.

305 F. Richard, H. Carreyre and G. Pérot, J. Mol. Catal. A: Chem., 1995, 101, L167; F. Richard, H. Carreyre and G. Pérot, J. Mol. Catal. A: Chem., 1995, 103,51 .

306 F. Richard, H. Carreyre and G. Pérot, J. Catal., 1996, 159, 427.

307 R. Taylor, In Comprehensive Chemical Kinetics; ed. C. H. Banford and C. F. H. Tipper, Elsevier, New York, 1972, p. 77-83. 
308 F. R. Jensen and G. Goldman, In Friedel-Crafts and Related Reactions; ed. G. A. Olah, Wiley-Interscience, New York, 1964, vol. III, p. 1319-1367.

309 F. R. Jensen and H. C. Brown, J. Am. Chem. Soc., 1958, 80, 4046.

310 G. A. Olah, S. Kobayashi and J. Nishimura, J. Am. Chem. Soc., 1973, 95, 564.

311 H. J. Sipe Jr, D. W. Clary, S. B. White and B. Samuel, Synthesis, 1984, 283.

312 M. Ueda, K. Uchiyama and T. Kano, Synthesis, 1984, 323.

313 B. M. Choudary, N. S. Chowdari, M. L. Kantam and R. Kannan, Tetrahedron Lett., 1999, 40, 2859.

314 B. M. Choudary, N. S. Chowdari and M. L. Kantam, J. Chem. Soc., Perkin Trans. 1, 2000, 2689.

315 S. Répichet, C. Le Roux, P. Hernandez, J. Dubac and J.-R. Desmurs, J. Org. Chem., 1999, 64, 6479.

316 S. Répichet, C. Le Roux, J. Dubac, Tetrahedron Lett., 1999, 40, 9233.

317 J. Marquié, A. Laporterie, J. Dubac, N. Roques and J.-R. Desmurs, J. Org. Chem., 2001, 66, 421.

318 J.-R. Desmurs, J. Dubac, A. Laporterie, C. Laporte and J. Marquié, PCT Int. Appl., WO98/40339, 1998; Chem. Abstr., 1998, 129, 244928.

319 C. Laporte, J. Marquié, A. Laporterie, J.-R. Desmurs and J. Dubac, C. R. Acad. Sci. IIC, 1999, 2, 455.

320 S. Daley, K. A. Trevor, K. R. Randles and B. D. Gott, PCT Int. Appl., WO93/18000, 1993; Chem. Abstr., 1994, 120, 54320.

321 K. Smith, G. M. Ewart and K. R. Randles, J. Chem. Soc. Perkin Trans. 1, $1997,1085$.

322 K. Smith, G. M. Ewart, G. A. El-Hiti and K. R. Randles, Org. Biomol. Chem., 2004, 2, 3150 .

323 P. Laidlaw, D. Bethell, S. M. Brown, G. Watson, D. J. Willock, G. J. Huchings, J. Mol. Catal. A: Chem., 2002, 178, 205. 